Universidade de Brasília

Instituto de Ciências Exatas

Departamento de Matemática

\title{
Uma abordagem dinâmica e atual para o ensino das Cônicas na Educação Básica
}

por

Ana Carolina Rabello Nascimento

Brasília

2015 
Ana Carolina Rabello Nascimento

\section{Uma abordagem dinâmica e atual para a ensino das Cônicas na Educação Básica}

Trabalho de Conclusão de Curso apresentado ao Departamento de Matemática da Universidade de Brasília, como parte dos requisitos para obtenção do grau de Mestre.

Orientador: Dr. Rui Seimetz.

Julho de 2015 
Ficha catalográfica elaborada automaticamente, com os dados fornecidos pelo(a) autor(a)

$\mathrm{Ra}$

Rabello Nascimento, Ana Carolina

Uma abordagem dinâmica e atual para o ensino das Cônicas na educação Básica / Ana Carolina Rabello Nascimento; orientador Rui Seimetz. -- Brasília, 2015 .

$185 \mathrm{p}$.

Dissertação (Mestrado - Mestrado em Matemática) -Universidade de Brasilia, 2015.

1. Cônicas. 2. Elipse. 3. Hipérbole. 4. Parábola. I. Seimetz, Rui, orient. II. Título. 
"Mesmo quando tudo parece desabar, cabe a mim decidir entre rir ou chorar, ir ou ficar, desistir ou lutar; porque descobri, no caminho incerto da vida, que o mais importante é o decidir." Cora Coralina (1889 -1985). 


\section{AGRADECIMENTOS}

Em primeiro lugar a Deus, por me por ter me dado forças, saúde, sabedoria e tudo aquilo que precisei nesta caminhada.

À minha amada mãe, minha primeira orientadora nessa vida. Por se dedicar tanto e por todo carinho e amor. Além de seu grande esforço para desempenhar, por muito tempo, a tarefa de mãe e pai.

À minha vovó Esmeralda, a grande matriarca da família. Por ter incentivado e patrocinado os meus estudos. E por suas rezas milagrosas que sempre me acalmaram nos desfios que enfrentei durante a vida.

Ao meu esposo Flávio, presente nos maiores e melhores momentos que eu já vivi, me presenteando com seu amor, paciência, apoio incondicional, companheirismo e cumplicidade.

Ao meu filho Rodrigo, que com sua vinda tornou a minha vida mais bela, alegre e significativa, ele, realmente, foi um presente de Deus.

Ao brilhante Nelson Vidal Gomes, que nessa vida não foi meu pai biológico, mas desempenhou magistralmente essa função. 
Aos professores e colegas com quem tive o prazer de conviver durante este período, em especial ao meu orientador Rui Seimetz, que tão carinhosamente me acolheu, ao Mestre Lineu Neto, que com suas aulas maravilhosas sempre reafirmava em mim o quanto a Matemática é bela, e ao Professor Adail Cavalheiros idealizador desse projeto.

A todos que de forma direta ou indireta contribuíram para a realização deste trabalho que marcou uma nova etapa de minha vida, meu muito obrigada. 


\section{Resumo}

Apesar da grande importância histórica e do seu relevante papel no desenvolvimento tecnológico, o estudo das Cônicas, no Brasil, não acontece para a maioria dos alunos. Em geral, este conteúdo, quando desenvolvido, é tratado de forma superficial e mecânica. Em um panorama de esquecimento, temos por um lado os livros didáticos que tratam este conteúdo de forma meramente algébrica e, por outro lado, esbarramos em docentes que, muitas vezes, desconhecem um maior aprofundamento, domínio e aplicações do assunto. Ou seja, há uma série de dificuldades para transmitir aos alunos a relevância histórica e a importância destes conceitos em aplicações reais. Sendo assim, esta dissertação tem como finalidade promover uma quebra de paradigma neste processo ensino-aprendizagem, propondo uma reflexão sobre o estudo das Cônicas, mostrando a sua relação com os diversos campos da Matemática, trazendo as aplicações reais como consequência de suas propriedades e, ao final, sugerindo uma oficina que abordará o encanto deste conteúdo de forma lúdica e construtivista, estimulando os estudantes a agirem reflexivamente e construindo os seus próprios conceitos significativos.

Palavras-chave: Cônicas, elipse, hipérbole, parábola, Apolônio, Dandelin, Fermat, aplicações das cônicas, oficina sobre cônicas. 


\section{Abstract}

Despite the great historical importance and its role in technological development, the study of Conics in Brazil does not happen to most students. In general, this content, when developed, has been treated superficially and mechanically. In a forgetful context, we have on one hand the textbooks that treat this content in a merely algebraic form and, on the other hand, we run into teachers who are often unaware of further deepening, domain and subject applications. That is, there is a number of difficulties to convey to students the historical relevance and the importance of these concepts in real applications. Thus, this work aims to promote a paradigm shift in the teaching-learning process, proposing a reflection on the study of Conics, showing its relationship with the various fields of mathematics, bringing real applications as a result of its properties, and at the end, suggesting a workshop that will address the charm of this content in a fun and constructive way, encouraging students to act reflexively and build their own meaningful concepts.

Keywords: Conics, ellipse, hyperbole, parabola, Apollonius, Dandelin, Fermat, conical applications, workshop on conics. 


\section{Objetivos}

\section{OBJETIVO GERAL:}

A proposta deste trabalho é trazer uma nova abordagem para o ensino das curvas cônicas na Educação Básica. Com uma forte fundamentação teórica, que auxiliará os docentes a compreenderem melhor a caracterização dessas curvas, as propriedades e as diferentes visões do conteúdo, além de uma oficina que estimulará os estudantes a agirem reflexivamente, construindo os seus próprios conceitos significativos, tornando os, assim, verdadeiros protagonistas no processo ensino-aprendizagem.

\section{OBJETIVOS ESPECÍFICOS:}

Para a concretização desta proposta é necessário:

- Criar um compêndio com um bom embasamento teórico;

- Mostrar diferentes tipos de abordagens para um estudo mais profundo e rico dessas curvas;

- Mostrar como os métodos matemáticos são aplicados em situações reais, em especial, em outras áreas do conhecimento, trabalhando, assim, a interdisciplinaridade; 
- Mostrar estratégias de ensino que fujam do método meramente algébrico adotado, atualmente, pelos principais livros didáticos ;

- Conduzir a visualização de conceitos geométricos através de material concreto e dos recursos computacionais;

- Garantir o uso de programas computacionais de geometria dinâmica como recurso educacional na Matemática;

- Implementar e avaliar o protótipo do sistema proposto. 


\section{ESTRUTURA DO TRABALHO}

Esta dissertação está organizada em 21 capítulos, o primeiro pontua a motivação para a escolha do tema proposto, além de situar o leitor quanto a relevância científica e tecnológica, contextualização e relação com outras áreas do conhecimento.

A teoria das cônicas vem se desenvolvendo desde o início do século I.V. a.C. até os tempos atuais, por isso seguimos com um breve histórico sobre o estudo do conteúdo no decorrer dos séculos. Desta forma, neste capítulo é relatado sobre qual prisma essas curvas foram vistas e a forte relação que possuem com a realidade.

Já os capítulos 3, 6 e 9 trazem o estudo das cônicas em coordenadas cartesianas. Além da obtenção dessas curvas por meio de cortes em um cone resultando, assim, a sua definição como lugar geométrico.

Como é sabido, o sistema cartesiano não é a única forma de se colocar coordenadas em um plano. Então, nos capítulos 4, 7 e 10, são demonstradas as equações dessas curvas em coordenadas polares. Vale ressaltar que a equação polar da elipse teve uma grande importância para a formulação e dedução das Leis de Kepler.

Já os capítulos 5, 8 e 11 ilustram algumas possibilidades de parametrização dessas curvas, uma vez que dependendo do processo de decisão e da definição dos 
parâmetros necessários para uma especificação completa de um modelo, cada curva pode apresentar uma gama infinita de parametrizações.

No capítulo 12 há a definição das equações das cônicas como uma consequência da relação entre o conceito geométrico e o algébrico. Mostra-se que dado cone quando seccionado por um plano, existe uma ou duas esferas que são tangentes ao plano e ao cone, simultaneamente. Estas são conhecidas como as esferas de Dandelin. Com a análise das retas tangentes, conseguiu-se encontrar os focos e verificar a propriedade focal de uma só vez.

O capítulo 13 versa sobre a definição geral das curvas cônicas. Esta trata-se de uma única expressão algébrica que relaciona a excentricidade, o foco e a diretriz e é capaz de representar todas as cônicas não degeneradas, analisando, apenas, a variação da excentricidade.

O reconhecimento de uma cônica a partir de uma equação de $2^{\circ}$ grau é tratado no capítulo 14. Em 1629, Fermat produziu um trabalho, não publicado, que circulou apenas como forma de manuscrito intitulado Introdução aos lugares geométricos planos e sólidos. Nesta obra, foi introduzida a ideia de eixos perpendiculares. Além disso, estabeleceu o principio fundamental de que uma equação de primeiro grau, no plano, representa uma reta e que uma de segundo grau representa uma cônica. Nosso objetivo é retratar o estudo de Fermat que preconiza um enfoque algébrico sobre essas curvas.

O capítulo 15 remete ao reconhecimento de uma cônica por meio de matrizes. Nele abordamos, também, os pré-requisitos de Álgebra Linear necessários para que o leitor, com pouca familiaridade no assunto, possa compreender cada etapa de seu de- 
senvolvimento.

Foi mostrado no capítulo 16 a propriedade refletora das curvas cônicas. Com um caráter, primordialmente, interdisciplinar e motivador, são demostradas interessantes aplicações de conceitos matemáticos, originados da magnífica capacidade do ser humano de criar modelos, a princípio unicamente teóricos, mas que, posteriormente, revertem-se em mecanismos concretos que contribuem para a evolução do conhecimento, da tecnologia e da ciência.

Após a exposição de diferentes enfoques teóricos, no capítulo 17, propomos uma oficina. Nela é sugerida algumas metodologias alternativas para a prática docente, incentivando os alunos a desenvolverem o raciocínio matemático e relatarem as suas próprias conclusões por meio da materialização de conceitos que, previamente, eram abstratos. Além disso, temos, também, o objetivo de fazer com que os professores sejam multiplicadores das metodologias de ensino que fujam dos mecanismos massantes e meramente teóricos, para que possamos tornar o ensino da Matemática algo prazeroso e motivador.

Os capítulos finais trazem a conclusão e as referências bibliográficas utilizadas no trabalho. 


\section{Lista de Figuras}

2.1 Os três problemas clássicos da Matemática grega . . . . . . . . . . 8

2.2 Os cortes no cone . . . . . . . . . . . . . . . . . . 9

2.3 Área da parábola . . . . . . . . . . . . . . . . . . . 10

2.4 Movimento de projéteis . . . . . . . . . . . . . . 12

2.5 As três Leis de Kepler . . . . . . . . . . . . . . . . . . . . . . . . 13

2.6 Geometria Projetiva . . . . . . . . . . . . . . . . . . . . . . 15

3.1 Elementos da elipse . . . . . . . . . . . . . . . . 16

3.2 Propriedade da elipse . . . . . . . . . . . . . . . . . 17

3.3 Variação da excentricidade da elipse . . . . . . . . . . . . . . . 18

3.4 Esboço de $\epsilon: \frac{x^{2}}{a^{2}}+\frac{y^{2}}{b^{2}}=1 \ldots \ldots \ldots \ldots \ldots$

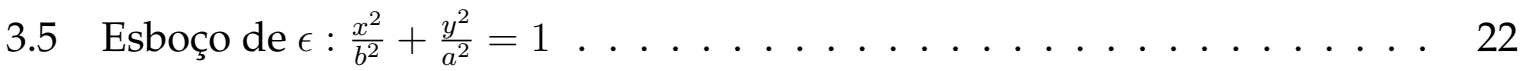

3.6 Translação dos eixos coordenados . . . . . . . . . . . . . . . . . 24

4.1 Representação de um ponto em coordenadas polares . . . . . . . . . . . 29

4.2 Elipse em coordenadas polares . . . . . . . . . . . . . . . . . 29

4.3 Parâmetro de uma elipse . . . . . . . . . . . . . . . . . . 31

5.1 Círculo $C: \mathrm{x}^{2}+y^{2}=r^{2} \ldots \ldots \ldots \ldots \ldots \ldots$

5.2 Parametrização da elipse . . . . . . . . . . . . . . . . . . . 40

6.1 Elemento característico da hipérbole . . . . . . . . . . . . . . . 43 
6.2 Hipébole com centro na origem e reta focal coincidente com o eixo OY . 47

6.3 Hipérbole transladada com reta focal paralela ao eixo OX . . . . . . . . . 49

6.4 Hipérbole com reta focal paralela ao eixo OY . . . . . . . . . . . . 51

7.1 Hipérbole em coordenadas polares . . . . . . . . . . . . . . . . . . 54

8.1 Gráfico: $\mathrm{H}=\mathrm{H}_{+} \cup H_{-} \ldots \ldots \ldots \ldots \ldots$

9.1 Elementos da parábola . . . . . . . . . . . . . . . . . . . . 59

10.1 Parábola em coordenadas polares . . . . . . . . . . . . . . 62

$11.1 \wp:(x-a)^{2}=k(y-b) \ldots \ldots \ldots \ldots \ldots \ldots \ldots \ldots \ldots \ldots \ldots \ldots \ldots \ldots \ldots$

12.1 Esferas de Dandelin: caso elipse . . . . . . . . . . . . . . . . . . . . 68

12.2 Esferas de Dandelin: caso hipérbole . . . . . . . . . . . . . . 71

12.3 Figura de apoio para o caso parábola . . . . . . . . . . . . . . . . 74

16.1 Propriedade refletora da elipse . . . . . . . . . . . . . . 110

16.2 Luminária odontológica de espelho elíptico . . . . . . . . . . . . . . . . . 112

16.3 Galeria dos sussurros . . . . . . . . . . . . . . . . . . . . 113

16.4 Mesa de bilhar elíptica: A sinuca perfeita! . . . . . . . . . . . . . . 113

16.5 Telescópio de reflexão . . . . . . . . . . . . . . . . . 116

16.6 Estrutura de uma antena parabólica . . . . . . . . . . . . . . 118

16.7 Estrutura de um farol de automóvel . . . . . . . . . . . . . . . . . . . 119

16.8 Ponte suspensa por estruturas metálicas formando um arco de parábola 119

18.1 Layout do software . . . . . . . . . . . . . . . . 128

18.2 Elipse construída no GeoGebra . . . . . . . . . . . . . . . . 129

18.3 Gráfico mostrando a opinião dos alunos . . . . . . . . . . . . . . . . . 130

18.4 Gráfico mostrando a opinião dos alunos . . . . . . . . . . . . . . . . 131

18.5 Gráfico mostrando a opinião dos alunos . . . . . . . . . . . . . . . . . 131 
18.6 Hipérbole construída no GeoGebra . . . . . . . . . . . . . . . . . 133

18.7 Gráfico mostrando a opinião dos alunos . . . . . . . . . . . . . . . 134

18.8 Gráfico mostrando a opinião dos alunos . . . . . . . . . . . . . . . . 134

18.9 Gráfico mostrando a opinião dos alunos . . . . . . . . . . . . . 136

18.10Gráfico mostrando a opinião dos alunos . . . . . . . . . . . . . . 136

19.1 Traços da elipse em dobraduras . . . . . . . . . . . . . . . . . . . . 140

19.2 Mediatriz da elipse . . . . . . . . . . . . . . . . . . . . . . . 140

19.3 Traços da hipérbole em dobradura . . . . . . . . . . . . . . . . . . 142

19.4 Mediatriz da hipérbole . . . . . . . . . . . . . . . . . . . . . . 143

19.5 Figura de apoio para confirmação que a curva obtida é uma hipérbole 144

19.6 Comprovação geométrica que a figura construída é uma hipérbole . . 145

19.7 Dobradura parábola . . . . . . . . . . . . . . . . . . . . 146

19.8 Figura de apoio na construção de parábolas por dobradura . . . . . . . 146

19.9 Figura de apoio reta tangente à parabola . . . . . . . . . . . . . . . 147

19.10Gráfico mostrando a opinião dos alunos ～. . . . . . . . . . . . 148

19.11Gráfico mostrando a opinião dos alunos . . . . . . . . . . . . . . 148

19.12Gráfico mostrando a opinião dos alunos . . . . . . . . . . . . . . . 149

20.1 Método de construção da elipse . . . . . . . . . . . . . . . . . . 153

20.2 Simetria na elipse . . . . . . . . . . . . . . . . . . . . . . . 154

20.3 Resultado da construção da hipérbole com barbantes . . . . . . . . 157

20.4 Resultado da construção da parábola . . . . . . . . . . . . . . . . 158 


\section{Sumário}

1 INTRODUÇÃO 2

2 BREVE HISTÓRICO

3 A ELIPSE EM COORDENADAS CARTESIANAS 16

3.0.1 EQUAÇÃO CANÔNICA DA ELIPSE COM CENTRO NA ORIGEM E RETA FOCAL COINCIDENTE COM O EIXO OX: ... 19

3.0.2 EQUAÇÃO CARTESIANA DA ELIPSE COM CENTRO NA ORIGEM E RETA FOCAL COINCIDENTE COM O EIXO OY . . . . . 21

3.0.3 EQUAÇÃO CARTESIANA DA ELIPSE COM CENTRO EM UM PONTO $O^{\prime}=\left(x_{0}, y_{0}\right) \ldots \ldots \ldots \ldots \ldots \ldots$

4 A ELIPSE EM COORDENADAS POLARES 28

4.0.4 ELIPSE EM COORDENADAS POLARES: UMA ANÁLISE TRIGONOMÉTRICA . . . . . . . . . . . . . . . . . 29

4.0.5 EQUAÇÃO POLAR DA ELIPSE: UMA ANÁLISE A PARTIR DA EQUAÇÃO CANÔNICA . . . . . . . . . . . . . . . . . 32

5 EQUAÇÕES PARAMÉTRICAS DA ELIPSE 38

5.0.6 PARAMETRIZAÇÃO DO CÍRCULO . . . . . . . . . . . 39

5.0 .7 PARAMETRIZAÇÃO DA ELIPSE . . . . . . . . . . . . . . 40 
6 A HIPÉRBOLE EM COORDENADAS CARTESIANAS

6.0.8 EQUAÇÃO CARTESIANA DA HIPÉRBOLE COM CENTRO NA ORIGEM E RETA FOCAL COINCIDENTE COM EIXO OY . . . . 47

6.0.9 EQUAÇÃO CARTESIANA DA HIPÉRBOLE COM CENTRO EM $\mathrm{UM}^{\mathrm{PONTO}} \mathrm{O}^{\prime}=\left(\mathrm{x}_{0}, y_{0}\right) \ldots \ldots \ldots \ldots \ldots$

7 EQUAÇÃO DA HIPÉRBOLE EM COORDENADAS POLARES 53

8 EQUAÇÕES PARAMÉTRICAS DA HIPÉRBOLE

9 A PARÁBOLA EM COORDENADAS CARTESIANAS 59

10 A PARÁBOLA EM COORDENADAS POLARES 62

11 EQUAÇÕES PARAMÉTRICAS DA PARÁBOLA

12 CÔNICAS E AS ESFERAS DE DANDELIN 66

12.0.10 A ELIPSE E AS ESFERAS DE DANDELIN . . . . . . . . . 68

12.0.11 A HIPÉRBOLE E AS ESFERAS DE DANDELIN . . . . . . . . . 70

12.0.12 A PARÁBOLA E AS ESFERAS DE DANDELIN . . . . . . . . 73

13 ESTUDO DAS CÔNICAS POR MEIO DA SUA DEFINIÇÃO GERAL 76

13.0.13 RELAÇÃO ENTRE A ELIPSE E A EXCENTRICIDADE . . . . . . 78

13.0.14 A RELAÇÃO ENTRE A HIPÉRBOLE E A EXENTRICIDADE . . 79

13.0.15 A RELAÇÃO ENTRE A PARÁBOLA E A EXCENTRICIDADE . 80

14 RECONHECIMENTO DE UMA CÔNICA A PARTIR DO ESTUDO DE UMA EQUAÇÃO DE $2^{\circ}$ GRAU

15 RECONHECIMENTO DE UMA CÔNICA POR MEIO DE MATRIZES 92

15.0.16 NOÇÕES PRELIMIMARES DE ÁLGEBRA LINEAR . . . . . . . . 93 
15.0.17 ANÁLISE DE UMA CÔNICA COM COEFICIENTE $B=0 \ldots 103$ 15.0.18 PROCEDIMENTO GERAL PARA A CLASSIFICAÇÃO DAS CÔNICAS:104 15.0.19 EXEMPLO PRÁTICO DO RECONHECIMENTO DE UMA CÔNICA POR MEIO DE OPERAÇÕES COM MATRIZES . . . . . . . . . 107

16 PROPRIEDADE DAS CÔNICAS 109

16.1 PROPRIEDADE REFLETORA DA ELIPSE . . . . . . . . . . . . . . . . 109

16.2 PROPRIEDADE REFLETORA DA HIPÉRBOLE . . . . . . . . . . . . . 113

16.3 PROPRIEDADE REFLETORA DA PARÁBOLA - TEOREMA DE PON-

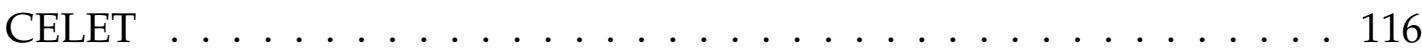

17 OFICINA SOBRE CÔNICAS - Uma proposta lúdica e construtivista 120 17.0.1 METODOLOGIA APLICADA NAS OFICINAS . . . . . . . . . 124

18 CONSTRUÇÃO DAS CÔNICAS POR MEIO DO SOFTWARE GEOGEBRA 127 18.0.2 CONSTRUINDO ELIPSES . . . . . . . . . . . . . . . . . . . . . 129 18.0.3 CONSTRUINDO HIPÉRBOLES . . . . . . . . . . . . . . 132 18.0.4 CONSTRUINDO PARÁBOLAS . . . . . . . . . . . . . . . . 134 18.0.5 CONSIDERAÇÕES FINAIS SOBRE A APLICAÇÃO DESTE MÓDULO

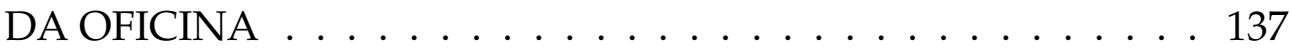

19 CONSTRUÇÃO DAS CÔNICAS POR DOBRADURAS: MÉTODO DE VAN SCHOOTEN 138

19.0.6 CONSTRUÇÃO DA ELIPSE POR DOBRADURAS . . . . . . . . . 139

19.0.7 CONSTRUÇÃO DA HIPÉRBOLE POR DOBRADURAS ... . . 141

19.0.8 CONSTRUINDO PARÁBOLA POR DOBRADURAS $\ldots \ldots$. . . 145

19.0.9 CONSIDERAÇÕES FINAIS SOBRE A APLICAÇÃO DESTE MÓDULO DA OFICINA . . . . . . . . . . . . . . . . . . . . . . 149 
20 CONSTRUÇÃO DE MATERIAL CONCRETO

20.0.10 CONSTRUINDO UMA ELIPSE COM LÁPIS, PAPEL, BARBANTE

E PERCEVEJOS . . . . . . . . . . . . . . . . . . . . . 152

20.0.11 CONSTRUINDO UMA HIPÉRBOLE COM PAPEL E BARBANTE: 154 20.0.12 CONSTRUINDO PARÁBOLA COM LÁPIS, RÉGUA E BARBANTE

- MÉTODO DE KEPLER ．. . . . . . . . . . . . . . . . . . 157

20.0.13 CONSIDERAÇÕES FINAIS SOBRE A APLICAÇÃO DESTE MÓDULO

DA OFICINA . . . . . . . . . . . . . . . . . . . . . . 159

21 CONSIDERAÇÕES FINAIS

160

Referências

165 


\section{Capítulo 1}

\section{INTRODUÇÃO}

Podemos afirmar, categoricamente, que as curvas conhecidas como cônicas são estudadas, exaustivamente, desde antiguidade até os tempos atuais.

Tal interesse por essas curvas vem do fato de que suas propriedades desempenham um papel relevante em vários campos do conhecimento, tais como: astronomia, física, engenharia e arquitetura.

Apesar de toda a sua importância histórica e de seu relevante papel no desenvolvimento tecnológico, o estudo das cônicas, nos tempos atuais, acabou caindo em esquecimento.

Em uma breve pesquisa bibliográfica nos principais livros de Matemática adotados na Educação Básica ${ }^{1} 23$, verificou-se que a abordagem feita nesses textos trata essas curvas sob o ponto de vista meramente algébrico com uma gama infinita de

\footnotetext{
${ }^{1}$ Dante, Luiz Roberto: MATEMÁTICA - CONTEXTO E APLICAÇÕES - VOLUME ÚNICO - Ensino Médio - Integrado;

${ }^{2}$ Iezzi, Gelson e Outros: MATEMÁTICA - VOLUME ÚNICO - Ensino Médio - Integrado;

${ }^{3}$ Machado, Antônio dos Santos: MATEMÁTICA - VOLUME ÚNICO - Ensino Médio.
} 
fórmulas que devem ser decoradas pelo aluno.

No que tange aos esboços das cônicas, estes são tratados como um gráfico de uma função que dificulta a percepção destas curvas enquanto lugar geométrico.

Sendo assim, não é extrapolação afirmar que o estudo deste conteúdo é tratado, atualmente, de uma maneira superficial e meramente mecânica. Não sendo dada a atenção apropriada aos detalhes e contextualizações que podem se tornar extremamente relevantes para uma devida compreensão ao tema.

No artigo intitulado Tradução comentada da obra "Novos elementos das secções cônicas" (Philippe de la Hire-1679) e sua relevância para o ensino da Matemática, Franciso Quaranta Neto e Luiz Carlos Guimarães tecem o seguinte comentário:

"Atualmente, o ensino de cônicas, no Brasil, tem uma abordagem que costuma se limitar ao universo da Geometria Analítica. A partir da propriedade bifocal, são deduzidas as equações. Além disso, quase nada é apresentado.

Para reconhecer uma elipse, por exemplo, é possivel somente através de sua equação. Nenhuma outra propriedade é apresentada, explorada ou provada. 
Normalmente, a sequência didática mais executada pelos livros do Ensino Médio, quando se propõem a ensinar as curvas elipse, parábola e hipérbole - é a seguinte: são apresentadas no plano cartesiano através das propriedades bifocais e assim surgem as formas geométricas das curvas. A seguir vêm os exercícios.

O ensino de cônicas no Ensino Médio no Brasil, provavelmente, não acontece para a maioria dos alunos. E, quando acontece, se restringe normalmente a um curto periodo ( uma a duas semanas) no terceiro ano do Ensino Médio. A forma que se ensina é geralmente a que foi citada acima.

Exceção feita à parábola, que por ser a única a se enquadrar com o conceito de função, é estudada como função quadrática ou polinomial do segundo grau, na oitava série do Ensino Fundamental ${ }^{a}$ e no primeiro do Ensino Médio. Serve como bom exemplo de função, mas a sua intima ligação com o universo das cônicas, costuma ser ignorada pelos professores na sua apresentação.

${ }^{a}$ Pelo novo currículo da educação refere-se ao nono ano 
Sendo o estudo de cônicas muito mais antiga que o estudo das funções, constata-se que diminuiu a importância dada para o ensino das cônicas. (as funções só aparecem com François Viète, no século XVI)."(Quaranta, Guimarães, p.1-2)"

Neste panorama de fracasso dos livros didáticos, esbarramos, também, em outro problema que talvez seja maior que o primeiro: os próprios docentes, muitas vezes, desconhecem profundamente o assunto. E, como consequência, torna-se mais difícil ensinar aos seus alunos a relevância histórica e a importância desses conceitos em aplicações reais.

Diante do exposto, podemos inferir que para que se comece a pensar em reverter esta situação, devemos, primeiramente, sanar as deficiências na formação básica do professor de Matemática. Aliado a isso, devemos estimular novos enfoques no processo ensino-aprendizagem que valorizem não só a parte algébrica mas, também, a geométrica dessas curvas.

Sendo assim, no intuito de contribuir com a melhoria do Ensino da Matemática Básica, este trabalho proporá, para tanto, uma sequência didática e dinâmica para o estudo das cônicas no Ensino Médio.

Contando com um forte embasamento teórico e uma oficina, abordaremos o encanto das cônicas por meio de construções. Tal oficina tem o intuíto de estimular os estudantes a agirem reflexivamente, trocando ideias e analisando as possíveis soluções, além de construir os seus próprios conceitos significativos como uma forma de valorização de seu conhecimento. E com isso, pode-se obter um salto qualitativo no 
processo ensino-aprendizagem sobre o tema. 


\title{
Capítulo 2
}

\section{BREVE HISTÓRICO}

\author{
“Creio que não é possível compreender a Matemática de hoje se não se tiver, \\ pelo menos, uma ideia sumária da sua história." Jean Dieudonné. (1906- \\ 1992)
}

Incontestavelmente, conhecer a evolução de uma ciência, a sua história e os seus instrumentos é o ponto de partida para bem compreendê-la.

A teoria das cônicas que teve seu início no século IV a.C. vem se desenvolvendo ininterruptamente até os dias atuais.

De acordo com Boyer (1996) ${ }^{1}$, o período de 477 a 375 a.C. ficou conhecido como a Idade Heróica da Matemática. Nesta época, surgiram três problemas da Matemática grega:

- A quadratura do círculo: Dado um círculo de raio $r$, determinar o lado $L$ de um quadrado com área igual a do círculo. Isso utilizando uma régua não graduada e

\footnotetext{
${ }^{1}$ Boyer, Carl B. :A HISTÓRIA DA MATEMÁTICA, pg. 122
} 
um compasso.

- A duplicação do cubo: Dado um cubo de aresta $a$, determinar a medida da aresta de outro cubo que possuísse o dobro do volume. Também utilizando uma régua não graduada e um compasso.

- A trissecção do ângulo: Dado um ângulo qualquer $\widehat{A V C}$, determinar, com régua não graduada e compasso, um ângulo $\widehat{C V B}$ com um terço da amplitude do ângulo $\widehat{A V C}$.

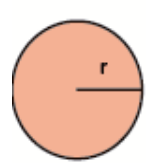

QUADRATURA DO CÍRCULO

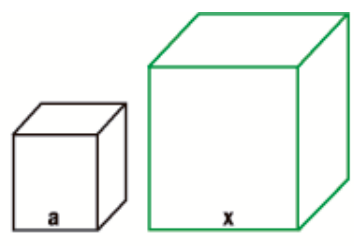

DUPLICAÇÃO DO CUBO

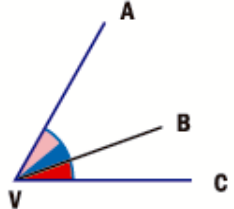

TRISERCÇÃO DO ÂNGULO

Figura 2.1: Os três problemas clássicos da Matemática grega

Segundo Courant and Robbins (1996) ${ }^{2} 3$, desde o século XIX, sabemos que estes problemas não podem ser resolvidos somente com a régua e o compasso.

Contudo, na tentativa de resolvê-los surgiram descobertas geniais, dentre as quais podemos destacar as cônicas.

Os primeiros relatos sobre o estudo das cônicas surgem, em aproximadamente, 350 a.C. . Seu protagonista foi um aluno de Eudóxio chamado Menaechmus.

\footnotetext{
${ }^{2}$ COURANT, Richard and Herbert ROBBINS: What is mathematics? New York: Oxford University Press, 1996.

${ }^{3}$ Outras referências sobre o assunto podem ser encontradas em: BUNT, JONES and BEDIENT, 1988, pp. 89-121.
} 
Menaechmus foi o primeiro a mostrar que ao cortar um cone por um plano não paralelo à base pode-se obter as curvas: elipse, hipérbole ou parábola.

Em seu estudo, as cônicas foram obtidas seccionando um cone circular reto de uma folha com um plano perpendicular a uma geratriz do cone, obtendo três tipos distintos de curvas, conforme a seção meridiana do cone fosse um ângulo agudo, um ângulo reto ou um ângulo obtuso.

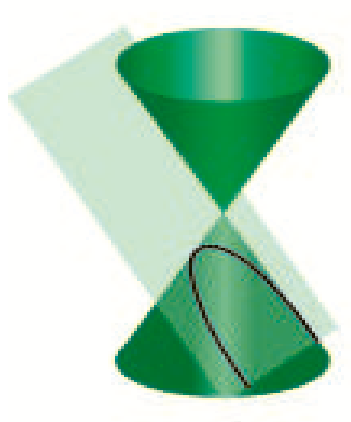

Parábola

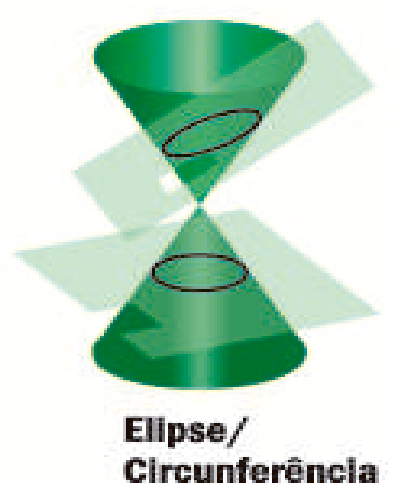

Elipse/
Circunferência

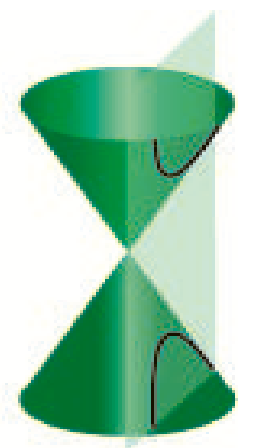

Hipérbole

Figura 2.2: Os cortes no cone

Nos escritos de Papus de Alexandria, credita-se ao geômetra grego Aristeu (370300 a.C) a publicação do primeiro tratado sobre as cônicas.

Contudo, é atribuído a Arquimedes ( 287 a.C. 212 a.C. ) a primeira série de teoremas sobre as seções cônicas confirmados.

A partir de seus estudos, ele provou que a área determinada pela intersecção de um arco de parábola com um segmento de reta é igual a $\frac{4}{3}$ da área de um triângulo cuja base é o mesmo segmento de reta e o terceiro vértice é a intersecção de uma tangente à parábola que seja paralela ao segmento dado, ou seja, de acordo com a figura 
abaixo, a área abaixo da curva que passa pelos pontos $A D B$ é quatro terços da área do triângulo $A D B$.

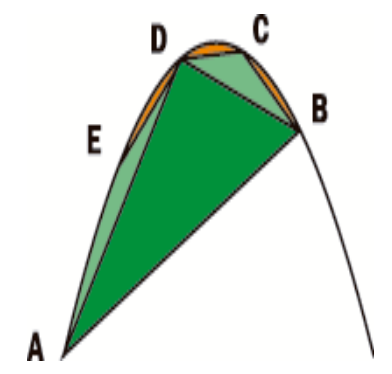

Figura 2.3: Área da parábola

Coube a Apolônio (262 a.C. - 190, a.C.) produzir o primeiro grande estudo científico sobre as cônicas. Apolônio de Perga, também conhecido como $O$ grande geômetra, foi contemporâneo de Arquimedes. E, juntamente com Euclides, formam a tríade dos maiores matemáticos gregos da antiguidade.

Com a publicação do tratado sobre cônicas, Apolônio superou todas as biografias semelhantes já existentes, inclusive as produzidas por Euclides.

A sua obra sobre cônicas era formada por oito livros. Os quatro primeiros formavam uma introdução elementar sobre o assunto enquanto nos quatro últimos há um grande aprofundamento ao tema. Infelizmente, devido ao incêndio na biblioteca de Alexandria, só sete chegaram aos nossos dias.

No livro 1 são estudadas relações entre as retas tangentes e as propriedades derivadas. No livro 2, são investigadas as relações entre as hipérboles e suas assíntotas e é apresentado um método para desenhar tangentes. No livro 3, Apolônio propõe importantes teoremas que, segundo ele, completariam o que faltava em Os Elementos 
de Euclides, sobre o estudo dos lugares geométricos com três ou quatro retas. Os livros de 5, 6 e 7 ele discute as normais às cônicas e mostra como podem ser desenhadas a partir de um ponto dado.

Somente em 1710, Edmund Halley fez uma tradução latina dos seus livros, surgindo posteriormente traduções em outras línguas.

Em sua obra Espelho Ardente, ele discutiu as propriedades focais de um espelho parabólico e demonstrou, como já havia sido imaginado, que raios de luz paralelos convergem para um foco.

Apolônio também fez várias aplicações de seu vasto conhecimento sobre cônicas; entre elas o hemicyclium - uma espécie de relógio de Sol onde há retas desenhadas na superfície de uma secção cônica, dando maior precisão.

O italiano Galileu (1564-1642) foi o primeiro cientista a estudar o movimento de projéteis. Baseado em fatos experimentais ele enunciou o primeiro o Princípio da Independência dos Movimentos.

Este princípio afirmava que o movimento de um projétil pode se decompor em movimento uniforme na direção horizontal e movimento uniformemente variado na direção vertical.

No que se refere a cônicas, Galileu provou que o movimento de um projétil segue uma curva bem definida: uma parábola.

Johannes Kepler (1571 - 1630) foi um dos grandes expoentes da revolução ci- 


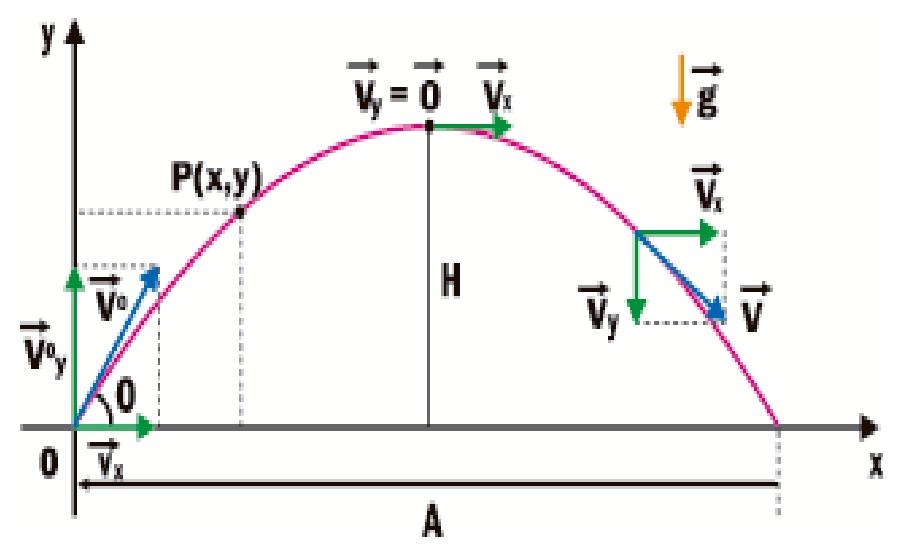

Figura 2.4: Movimento de projéteis

entífica do século XVII. Aprimorou o modelo heliocêntrico de Nicolau Copérnico. Este afirmava que os planetas giravam ao redor do Sol em órbitas circulares, já Kepler conseguiu provar que, na verdade, essas órbitas eram elípticas.

Com base em vinte anos de estudo feitos por Tycho Brahe, astrônomo que estudou rigorosamente a posição planetária, Kepler conseguiu determinar três leis que podem ser assim descritas:

- $1^{\text {a }}$ Lei de Kepler: Conhecida como lei das trajetórias elípticas, afirma que a órbita de cada planeta é uma elipse com o Sol no seu foco.

- $2^{\mathrm{a}}$ Lei de Kepler: Conhecida como a lei das áreas, determina que o segmento de reta que une o Sol a um planeta varre áreas iguais em tempos iguais em qualquer lugar da sua órbita elíptica.

- $3^{\mathrm{a}}$ Lei de Kepler: Conhecida como a lei do tempo, determina que o quociente entre o quadrado do período orbital pelo cubo do semieixo maior da órbita elíptica é constante. 

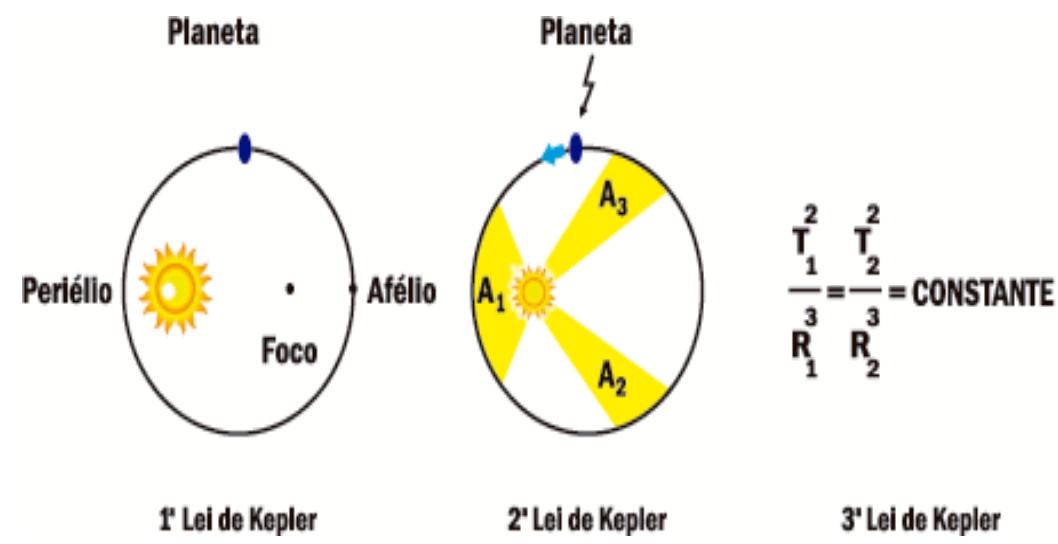

Figura 2.5: As três Leis de Kepler

Desargues (1591-1661) foi o precursor da Geometria Projetiva. Amigo dos principais expoentes matemáticos de sua época, tais como: Marin Mersenne, Rene Descartes, Étienne Pascal, Blaise Pascal e Abraham Bosse, viveu em uma época de intercâmbio de ideias. Tornou-se professor universitário e ensinava a técnica da perspectiva linear com a utilização do conceito de ponto de fuga.

A obra mais importante Desargues intitulada Brouillon projet d'une atteinteaux événements des rencontres dún cone avec un plan (1639), versa sobre as propriedades imutáveis dos círculos. E, em decorrência desta publicação, Desargues é conhecido hoje como o profeta da Geometria Projetiva.

Fermat (1601-1665) foi o primeiro matemático a estudar as cônicas a partir de equações de segundo grau com duas variáveis.

Utilizando técnicas de rotação e translação, mostrava que, excetuando os casos degenerados, a curva definida por $A x^{2}+B x y+C y^{2}+D x+E y+F=0$ pode ser definida como uma elipse, parábola, hipérbole ou circunferência. 
Os estudos de Fermat e Descartes fizeram uma conexão entre a álgebra e a geometria e assim estabelecendo um ramo da matemática chamado de Geometria Analítica.

Frans Van Shooten (1615-1660), de origem holandesa, foi o primeiro matemático que descreveu instrumentos que permitam desenhar as diversas seções cônicas. Em seu livro chamado de Organica conicarum sectionum in plano descriptione tratactus podem ser encontradas tais descrições.

As técnicas de Frans Van Schooten serão utilizadas na oficina proposta neste trabalho.

Jean Poncelet (1788-1867) foi engenheiro do exército napoleônico e criador da obra Ensaio sobre as projetivas das seções cônicas. Neste trabalho, ele versava sobre polígonos inscritos e circunscritos em cônicas.

Posteriormente, retomou a obra de Desargues e transformou a perspectiva em parte de uma nova geometria denominada Geometria Projetiva ou Geometria da Visão.

Após Poncelet, outros grandes nomes surgiram na Geometria Projetiva, como Michel Chasles (1798-1867), Jacob Steiner (1796-1863), Karl Christian e Von Staudt (17981867). Enfim, no final do século XIX, a Geometria Projetiva estava definitivamente solidificada.

Mas, afinal, a Geometria Projetiva se preocupa com o quê exatamente? É mais fácil responder essa pergunta fazendo uma pequena analogia com a geometria que conhecemos desde o Ensino Fundamental, a Euclidiana: Enquanto a Geometria Euclidiana se preocupa com o mundo em que vivemos, a Geometria Projetiva lida com o 
mundo que vemos. Na prática, os trilhos de trem não são retas paralelas, mas retas que se encontram no horizonte, no infinito. Essa é uma das características marcantes da Geometria Projetiva, duas retas quaisquer sempre se intersectam.

Como destaque entre os postulados da Geometria Projetiva com relação às cônicas, podemos citar o teorema da Bi-razão e o Teorema de Menelaus-Pascal. ${ }^{1}$

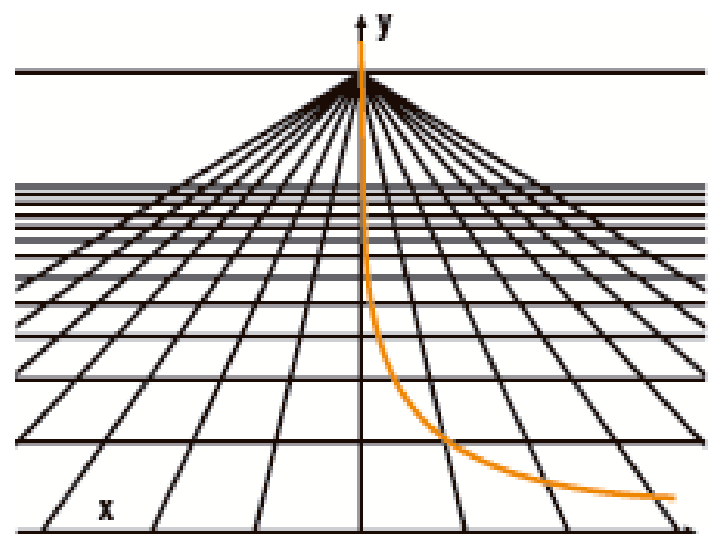

Figura 2.6: Geometria Projetiva

\footnotetext{
${ }^{1}$ Para conhecer melhor sobre o assunto acesse:
}

http:/ / bit.profmat-sbm.org.br/xmlui/handle/123456789/851 


\section{Capítulo 3}

\section{A ELIPSE EM COORDENADAS CARTESIANAS}

\section{ELEMENTOS CARACTERÍSTICOS DE UMA ELIPSE}

Observe a figura:

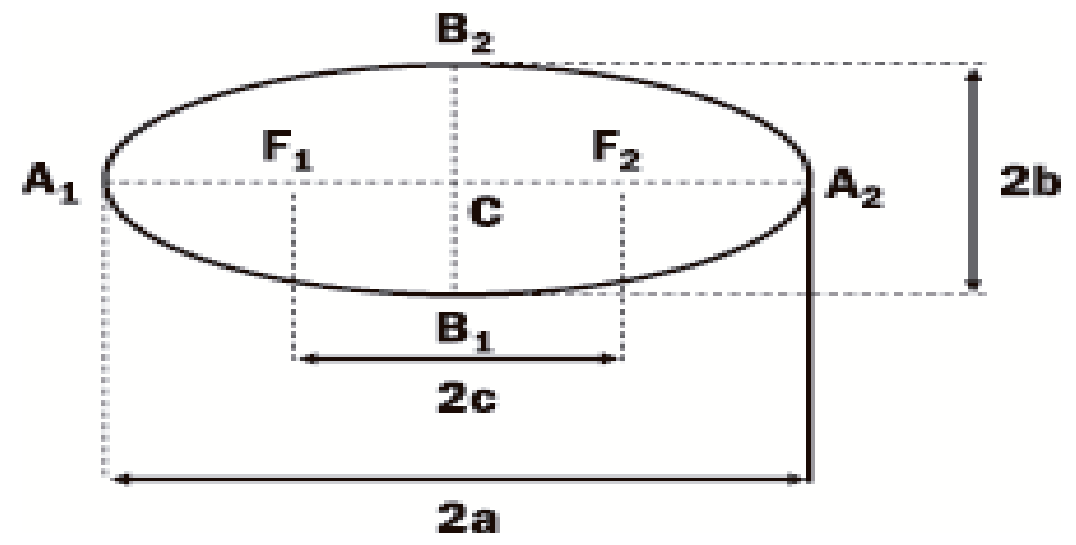

Figura 3.1: Elementos da elipse

Definimos os focos como os pontos $F_{1}$ e $F_{2}$; 
Denominamos distância focal (2c) como a distância entre os focos $F_{1}$ e $F_{2}$;

O ponto $C$ é o centro da elipse e, também, é o ponto médio entre os focos $F_{1} \mathrm{e}$ $F_{2} ;$

Os pontos $A_{1}, A_{2}, B_{1}$ e $B_{2}$ são os vértices da elipse, onde:

- 2a - eixo maior da elipse, dado pelos segmento $\overline{A_{1} A_{2}}$

- $2 \mathrm{~b}$ - eixo menor da elipse, dado pelo segmento $\overline{B_{1} B_{2}}$

Com base no exposto, observe o triângulo $\mathrm{B}_{2} \mathrm{CF}_{2}$.

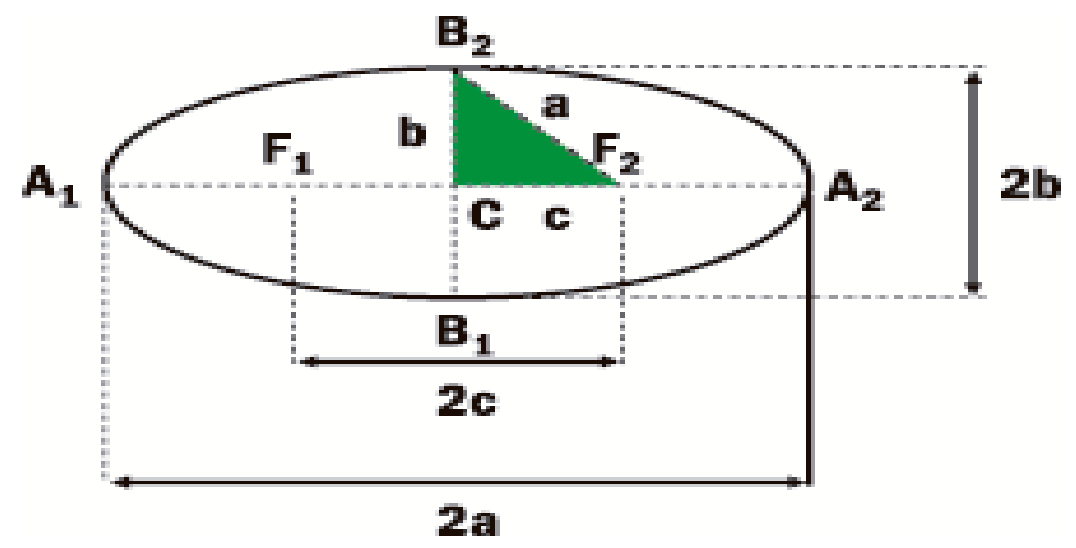

Figura 3.2: Propriedade da elipse

Por Pitágoras, deduzimos a seguinte relação:

$$
a^{2}=b^{2}+c^{2}
$$

A excentricidade da elipse é definida como:

$$
e=\frac{c}{a}
$$


Como $a$ e $c$ são positivos e, por hipótese, $c<a$, então $0<e<1$.

Sendo assim, é fácil verificar que quanto mais próximo de zero for o valor de $e$, mais a elipse se aproxima de uma circunferência.

Por outro lado, quanto mais achatada for a elipse, mais o valor de $e$ se aproxima de 1.

Uma vez fixo o valor do semi-eixo maior $a$, há uma correspondência entre o valor de $e$ e a distância focal $2 c$.

Ou seja, quanto mais a elipse se aproxima de uma circunferência, menor a distância entre os focos. E, quanto mais achatada for a elipse, maior a distância entre os focos.

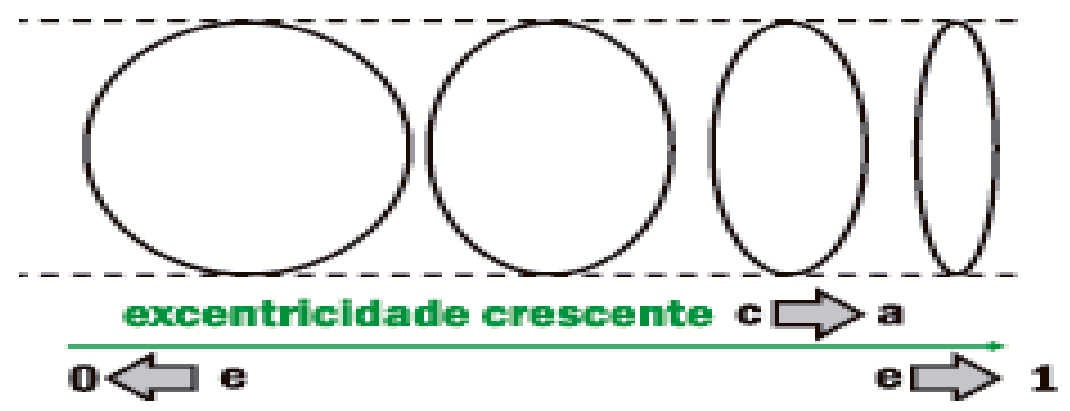

Figura 3.3: Variação da excentricidade da elipse

Desta forma, uma vez já identificados os elementos característicos da elipse, segue a definição. 
Definição: Uma elipse $\epsilon$ de focos $F_{1}$ e $F_{2}$ é um conjunto de pontos $P$ do plano cuja soma das distâncias a $F_{1}$ e $F_{2}$ é igual a uma constante $2 a>0$, a qual é maior do que a distância entre os focos $2 c \geq 0$. Ou seja, sendo $0 \leq c<a$ e $d\left(F_{1}, F_{2}\right)=2 c$,

$$
\epsilon=\left\{P \mid d\left(P, F_{1}\right)+d\left(P, F_{2}\right)=2 a\right\}
$$

A partir da definição de elipse, podemos obter uma equação relacionada ao sistema de eixos ortogonais $O X Y$, como segue abaixo:

\subsubsection{EQUAÇÃO CANÔNICA DA ELIPSE COM CENTRO NA ORI- GEM E RETA FOCAL COINCIDENTE COM O EIXO OX:}

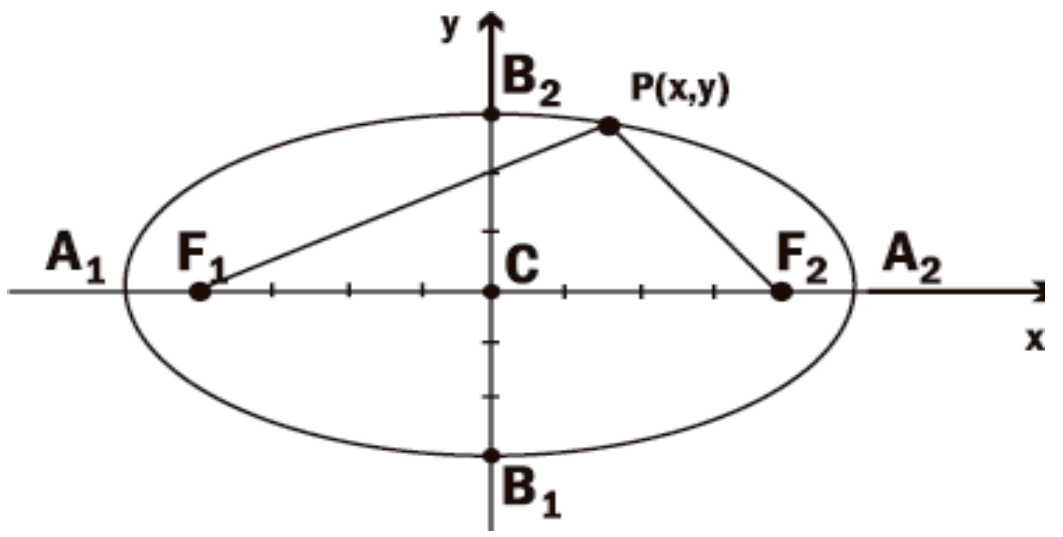

Figura 3.4: Esboço de $\epsilon: \frac{x^{2}}{a^{2}}+\frac{y^{2}}{b^{2}}=1$

De fato,

$$
P=(x, y) \in \epsilon \Leftrightarrow d\left(P, F_{1}\right)+d\left(P, F_{2}\right)=2 a
$$

Como a distância de $P$ aos focos $F_{1}$ e $F_{2}$ são: 


$$
\begin{aligned}
& \overline{P F_{1}}=\sqrt{(x+c)^{2}+y^{2}} \\
& \overline{P F_{2}}=\sqrt{(x-c)^{2}+y^{2}}
\end{aligned}
$$

Substituindo (3.4) e (3.5) em (3.3), temos:

$$
\begin{gathered}
\sqrt{(x+c)^{2}+y^{2}}+\sqrt{(x-c)^{2}+y^{2}}=2 a \Leftrightarrow \\
\sqrt{(x+c)^{2}+y^{2}}=2 a-\sqrt{(x-c)^{2}+y^{2}}
\end{gathered}
$$

Elevando ambos os membros ao quadrado:

$$
\begin{gathered}
(x+c)^{2}+y^{2}=4 a^{2}-4 a \sqrt{(x-c)^{2}+y^{2}}+(x-c)^{2}+y^{2} \Leftrightarrow \\
x^{2}+2 x c+c^{2}+y^{2}=4 a^{2}+x^{2}-2 x c+c^{2}+y^{2}-4 a \sqrt{(x-c)^{2}+y^{2}}
\end{gathered}
$$

Cancelando os termos:

$$
\begin{gathered}
4 a \sqrt{(x-c)^{2}+y^{2}}=4 a^{2}-4 x c \Leftrightarrow \\
a \sqrt{(x-c)^{2}+y^{2}}=a^{2}-x c
\end{gathered}
$$

Elevando, novamente, ambos os membros ao quadrado, temos:

$$
\begin{gathered}
a^{2}\left(x^{2}-2 x c+c^{2}+y^{2}\right)=a^{4}-2 a^{2} x c+x^{2} c^{2} \Leftrightarrow \\
a^{2} x^{2}-2 a^{2} x c+a^{2} c^{2}+a^{2} y^{2}=a^{4}-2 a^{2} x c+x^{2} c^{2} \Leftrightarrow
\end{gathered}
$$


Cancelando os termos:

$$
a^{2} x^{2}+x^{2} c^{2}+a^{2} y^{2}=a^{4}+x^{2} c^{2}
$$

Arrumando os termos de forma conveniente:

$$
\begin{gathered}
a^{2} x^{2}-x^{2} c^{2}+a^{2} y^{2}=a^{4}-a^{2} c^{2} \Leftrightarrow \\
x^{2}\left(a^{2}-c^{2}\right)+a^{2} y^{2}=a^{2}\left(a^{2}-c^{2}\right)
\end{gathered}
$$

Como na elipse vale a relação (3.1):

$$
a^{2}=b^{2}+c^{2}
$$

Substituindo (3.1) em (3.6):

$$
x^{2} b^{2}+a^{2} y^{2}=a^{2} b^{2}
$$

Dividindo ambos os termos por $a^{2} b^{2}$ :

$$
\frac{x^{2}}{a^{2}}+\frac{y^{2}}{b^{2}}=1
$$

Sendo assim, temos a forma canônica de uma elipse $\epsilon$ de centro na origem e reta focal coincidente com o eixo $O X$.

\subsubsection{EQUAÇÃO CARTESIANA DA ELIPSE COM CENTRO NA ORI- GEM E RETA FOCAL COINCIDENTE COM O EIXO OY}

Analogamente, podemos pensar em uma elipse com centro na origem e reta focal coincidente com o eixo $O Y$. 
Neste caso, temos que os focos e os vértices da elipse terão as seguintes coordenadas, conforme verificado na figura abaixo:

$$
\begin{aligned}
& F_{1}=(0, c) \\
& F_{2}=(0,-c) \\
& A_{1}=(0, a) \\
& A_{2}=(0,-a) \\
& B_{1}=(-b, 0) \\
& B_{2}=(b, 0)
\end{aligned}
$$

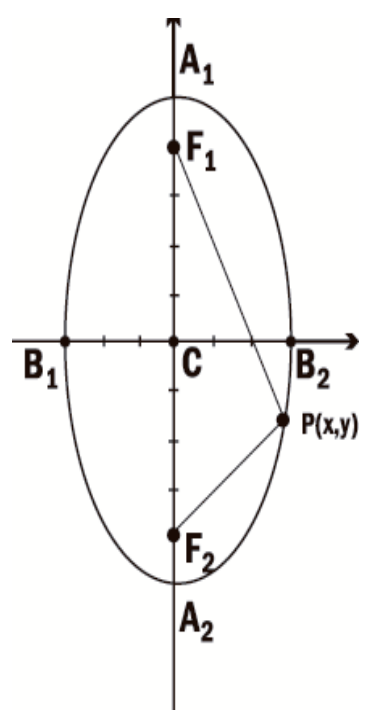

Figura 3.5: Esboço de $\epsilon: \frac{x^{2}}{b^{2}}+\frac{y^{2}}{a^{2}}=1$

Desenvolvendo o raciocínio análogo ao caso anterior, veremos que a equação canônica da elipse $\epsilon$ com centro na origem e reta focal coincidente ao eixo $O Y$ será dada por:

$$
\frac{x^{2}}{b^{2}}+\frac{y^{2}}{a^{2}}=1
$$




\subsubsection{EQUAÇÃO CARTESIANA DA ELIPSE COM CENTRO EM UM PONTO $O^{\prime}=\left(x_{0}, y_{0}\right)$}

Para demonstrarmos a equação cartesiana da elipse com centro em um ponto $O^{\prime}=\left(x_{0}, y_{0}\right)$, deveremos incialmente ter a ideia de translação de eixos coordenados.

Para isso, observe a explicação abaixo:

\subsubsection{TRANSLAÇÃO DE EIXOS NO R ${ }^{2}$}

Sejam $O X$ e $O Y$ os eixos primitivos do sistema cartesiano de eixos coordenados.

Tome $O=(0,0)$ como a origem do sistema.

Esse sistema de eixos ortogonais é conhecido como $O X Y$.

Neste contexto, no processo de translação de eixos coordenados, definiremos o novo sistema $O^{\prime} X^{\prime} Y^{\prime}$ com origem $O^{\prime}=(h, k)$ e cujos eixos $O X^{\prime}$ e $O Y^{\prime}$ são paralelos aos eixos $O X$ e $O Y$.

Seja $P=(x, y)$ um ponto qualquer do sistema primitivo. Portanto, o mesmo ponto $P$ terá coordenadas $P\left(x_{1}, y_{1}\right)$, em relação ao novo sistema.

Pela figura abaixo temos que: 


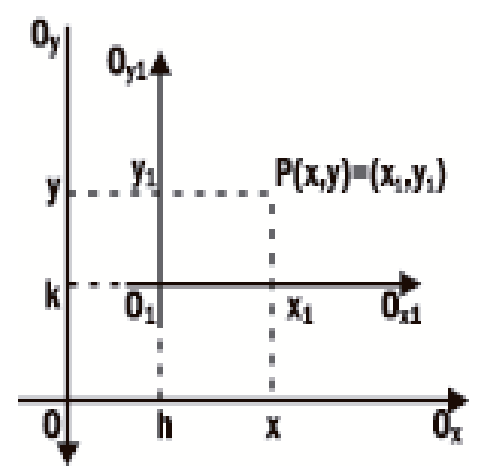

Figura 3.6: Translação dos eixos coordenados

Podemos inferir que as novas coordenadas do ponto $P$ será dada por:

- $\left\{\begin{array}{l}x=x_{1}+h \\ y=y_{1}+k\end{array}\right.$

Desta forma, utilizando a técnica de translação dos eixos coordenados explicitada acima, podemos obter uma equação de elipse cuja reta focal é horizontal ou vertical.

Considere o sistema $O X Y$, translade-o para a nova origem $O^{\prime}=\left(x_{0}, y_{0}\right)$, obtendo assim o sistema ortogonal $O^{\prime} X^{\prime} Y^{\prime}$.

Façamos, agora, as seguintes análises de caso:

\section{$1^{\circ}$ CASO - RETA FOCAL PARALELA AO EIXO OX:}

Se $O^{\prime}$ é o centro da elipse e $l: y=y_{0}$ é a reta focal (pois, a reta focal é paralela ao eixo $O X$ e passa pelo ponto $O^{\prime}=\left(x_{0}, y_{0}\right)$ 
Tome:

- $F_{1}=\left(x_{0}-c, y_{0}\right)$

e

- $F_{2}=\left(x_{0}+c, y_{0}\right)$

como focos da elipse (pois $d\left(F_{1}, O^{\prime}\right)=d\left(F_{2}, O^{\prime}\right)=c$ ).

Temos que um ponto $P=(x, y)=\left(x^{\prime}+x_{0}, y^{\prime}+y_{0}\right)$ pertence à elipse se, e somemente se,

$$
d\left(P, F_{1}\right)+d\left(P, F_{2}\right)=2 a
$$

Ou seja,

$$
\begin{gathered}
d\left(\left(x^{\prime}+x_{0}, y^{\prime}+y_{0}\right),\left(x_{0}-c, y_{0}\right)\right)+d\left(\left(x^{\prime}+x_{0}, y^{\prime}+y_{0}\right),\left(x_{0}+c, y_{0}\right)\right)=2 a \Longleftrightarrow \\
d\left(\left(x^{\prime}, y^{\prime}\right),(-c, 0)\right)+d\left(\left(x^{\prime}, y^{\prime}\right),(c, 0)\right)=2 a \Longleftrightarrow \\
\frac{x^{\prime 2}}{a^{2}}+\frac{y^{\prime 2}}{b^{2}}=1 \Longleftrightarrow \\
\frac{\left(x-x_{0}\right)^{2}}{a^{2}}+\frac{\left(y-y_{0}\right)^{2}}{b^{2}}=1
\end{gathered}
$$

Ou seja, a equação da elipse $\epsilon$ com centro no ponto $\left(x_{0}, y_{0}\right)$ na forma canônica é dada por: 


$$
\epsilon: \frac{\left(x-x_{0}\right)^{2}}{a^{2}}+\frac{\left(y-y_{0}\right)^{2}}{b^{2}}=1
$$

Onde:

$$
a^{2}=b^{2}+c^{2}
$$

\section{$\underline{2^{\circ} \text { CASO - RETA FOCAL PARALELA AO EIXO OY: }}$}

Analogamente ao caso anterior, verifica-se que a equação na forma canônica de uma elipse $\epsilon$ com o centro no ponto $\left(x_{0}, y_{0}\right)$ será:

$$
\epsilon: \frac{\left(x-x_{0}\right)^{2}}{b^{2}}+\frac{\left(y-y_{0}\right)^{2}}{a^{2}}=1
$$

Perceba que para chegarmos nesse resultado, devemos adotar:

Reta focal:

- $l: x=x_{0}$ (pois deve ser paralela ao eixo OY e passar pelo ponto $\left(x_{0}, y_{0}\right)$;

Reta não focal:

- $l^{\prime}: y=y_{0}$;

Focos:

- $F_{1}=\left(x_{0}, y_{0}-c\right)$ 
e,

- $F_{2}=\left(x_{0}, y_{0}+c\right)$

Vértices sobre a reta focal:

- $A_{1}=\left(x_{0}, y_{0}-a\right)$

$\mathrm{e}$

- $A_{2}=\left(x_{0}, y_{0}+a\right)$;

Vérices sobre a reta não focal:

- $B_{1}=\left(x_{0}-b, y_{0}\right)$

e

- $B_{2}=\left(x_{0}+b, y_{0}\right)$. 


\section{Capítulo 4}

\section{A ELIPSE EM COORDENADAS}

\section{POLARES}

Um sistema de coordenadas polares no plano consiste em um ponto fixo $O$, chamado de pólo (ou origem) e de um raio $\overline{O P}$ que parte do pólo, chamado de eixo polar.

Nesse sistema de coordenadas, podemos associar a cada ponto $P$ do plano um par de coordenadas polares $(r, \theta)$, onde $r$ é a distância de $P$ ao pólo e $\theta$ é o ângulo entre o eixo polar e o raio .

O número $r$ é chamado de coordenada radial de $P$, enquanto $\theta$ que é a coordenada angular (ou ângulo polar) de $P$.

Definição: Dado um ponto $P$ do plano, suas coordenadas nesse sistema são $r$ e $\theta$, onde $r$ é a distância de $\overline{O P}$ e $\theta$ é a medida do ângulo do eixo polar para a semireta $\overrightarrow{O P}$. Denotamos assim:

$$
P=(r, \theta)
$$




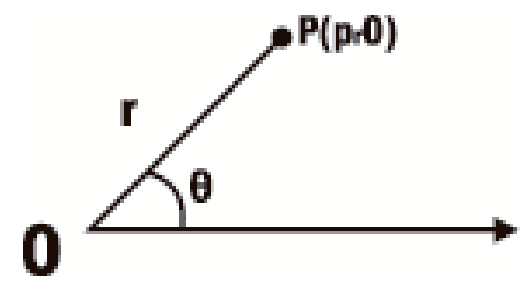

Figura 4.1: Representação de um ponto em coordenadas polares

\subsubsection{ELIPSE EM COORDENADAS POLARES: UMA ANÁLISE TRI- GONOMÉTRICA}

Considere uma elipse de eixo maior horizontal $\overline{A_{1} A_{2}}=2 a$, eixo menor $\overline{B_{1} B_{2}}=2 b$, distância focal $\overline{F_{1} F_{2}}=2 c$ e centro $C(m, n)$, como na figura abaixo.

Seja $P(\rho, \theta)$ um ponto qualquer da elipse, na qual fazemos coincidir o pólo $p$ com o foco $F_{1}$ e o eixo polar com o eixo maior da elipse.

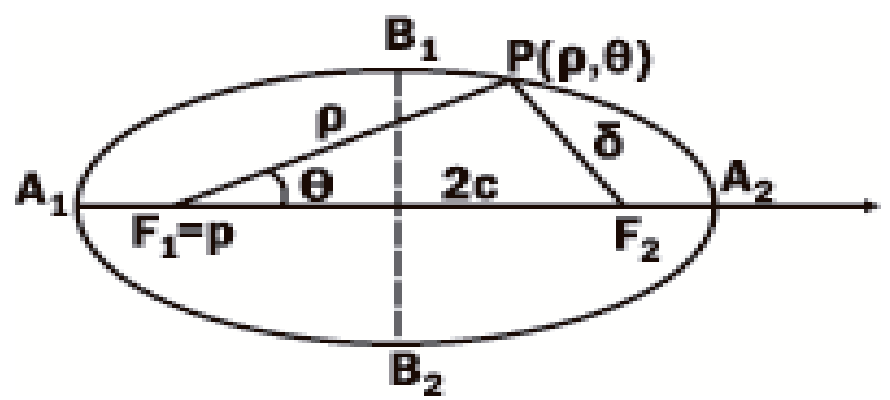

Figura 4.2: Elipse em coordenadas polares

Aplicando a Lei dos Cossenos no triângulo $F_{1} F_{2} P$ :

$$
\delta^{2}=\rho^{2}+4 c^{2}-4 c \cdot \rho \cdot \cos \theta
$$

Pela definição de elipse temos que $\left|\overline{P F_{1}}\right|+\left|\overline{P F_{2}}\right|=2 a$ 
Ou seja:

$$
\delta+\rho=2 a
$$

Assim:

$$
\delta=2 a-\rho
$$

Substituindo na expressão da Lei dos Cossenos vem que:

$$
\begin{gathered}
(2 a-\rho)^{2}=\rho^{2}+4 c^{2}-4 \operatorname{coc} \cos \theta \Rightarrow \\
4 a^{2}-4 a \rho+\rho^{2}=\rho^{2}+4 c^{2}-4 \operatorname{coc} \cos \theta
\end{gathered}
$$

Como na elipse vale a relação notável:

$$
a^{2}=b^{2}+c^{2}
$$

Então:

$$
\begin{gathered}
a^{2}-c^{2}=\rho(a-\cos \theta) \Rightarrow \\
b^{2}=\rho(a-\cos \theta) \Rightarrow \\
\rho=\frac{b^{2}}{a-\cos \theta}
\end{gathered}
$$

Para termos a equação polar da elipse como normalmente conhecemos, faremos as seguintes manipulações: 
Tome $\mathbf{L}=\frac{b^{2}}{a}$ como sendo o parâmetro da elipse e, $\mathbf{e}=\frac{c}{a}$ sua excentricidade.

Sabe-se que, por definição, parâmetro da elipse é a metade da corda focal perpendicular ao eixo maior.

Uma observação que deve ser feita é que para chegarmos à conclusão da expressão algébrica que define o parâmetro da elipse, devemos proceder da seguinte maneira:

Sabemos que $\overline{P F_{2}}$ pode ser obtido pela relação $\overline{P F_{1}}=2 a-P F_{2}$

Tome $\overline{P F_{2}}=L$.

Observe a figura:

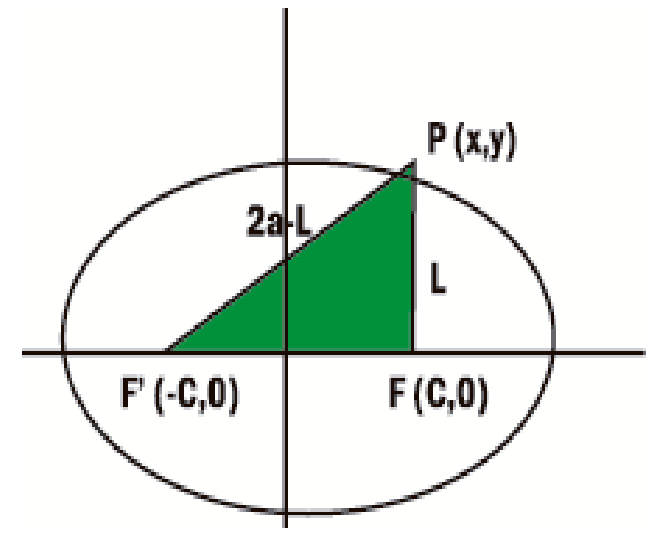

Figura 4.3: Parâmetro de uma elipse

Aplicando Pitágoras, temos:

$$
{\overline{P F_{1}}}^{2}={\overline{P F_{2}}}^{2}+{\overline{F_{1} F_{2}}}^{2}
$$




$$
\begin{gathered}
(2 a-L)^{2}=(2 c)^{2}+L^{2} \\
4 a^{2}-4 a L=4 c^{2} \\
L=\frac{a^{2}-c^{2}}{a}=\frac{b^{2}}{a}
\end{gathered}
$$

Sendo assim, uma vez demonstrado que o parâmetro da elipse é dado pela expressão $\frac{b^{2}}{a}$ :

Divida os termos da equação $\rho=\frac{b^{2}}{a-\cos \theta}$ por $a$ :

$$
\rho=\frac{\frac{b^{2}}{a}}{\frac{a}{a}-\frac{c \cos \theta}{a}}
$$

Tome $\mathbf{L}=\frac{b^{2}}{a}$ como sendo o parâmetro da elipse e $\mathbf{e}=\frac{c}{a}$ o seu parâmetro.

Assim, a equação polar da elipse será dada por:

$$
\rho=\frac{L}{1-e \cos \theta}
$$

\subsubsection{EQUAÇÃO POLAR DA ELIPSE: UMA ANÁlISE A PARTIR DA EQUAÇÃO CANÔNICA}

Para deduzirmos a equação da elipse em coordenadas polares é conveniente transladarmos um dos focos da elipse para a origem $O$ do plano cartesiano. E considerar as seguintes igualdades: 
- $e=\frac{c}{a}$, onde $e$ é a excentricidade da elipse;

- $L=\frac{b^{2}}{a}=a\left(1-e^{2}\right)$, onde $L$ é o seu parâmetro;

- $x=r \cos (\theta)$ e $y=r \operatorname{sen}(\theta), \operatorname{com} r \geq 0$ e $\theta \in[0,2 \pi]$

- $r^{2}=x^{2}+y^{2}$

No sistema de coordenadas polares e com as constantes $e$ e $L$ definidas acima, pode-se deduzir a equação da elipse em coordenadas polares, como segue:

\section{AFIRMAÇÃO}

Tome como base a equação cartesiana da elipse com um dos focos transladados para o centro, assim, teremos:

$$
\begin{gathered}
\frac{(x+c)^{2}}{a^{2}}+\frac{y^{2}}{b^{2}}=1 \Leftrightarrow \\
\frac{x^{2}+2 x c+c^{2}}{a^{2}}+\frac{y^{2}}{b^{2}}=1 \Leftrightarrow
\end{gathered}
$$

Adicionando e subtraindo o termo $\frac{c^{2}}{a^{2}}$, temos:

$$
\begin{gathered}
\frac{x^{2}+2 x c+c^{2}}{a^{2}}-\frac{c^{2}}{a^{2}}+\frac{y^{2}}{b^{2}}+\frac{c^{2}}{a^{2}}=1 \Leftrightarrow \\
\frac{b^{2} x^{2}+2 b^{2} x c+b^{2} c^{2}-b^{2} c^{2}+y^{2} a^{2}+c^{2} b^{2}}{a^{2} b^{2}}=\frac{a^{2} b^{2}}{a^{2} b^{2}} \Leftrightarrow
\end{gathered}
$$




$$
b^{2} x^{2}+2 b^{2} x c+y^{2} a^{2}+c^{2} b^{2}=a^{2} b^{2}
$$

Como:

$$
b^{2}=a^{2}-c^{2}
$$

Substituindo (4.5) em (4.4), temos:

$$
\begin{aligned}
& \left(a^{2}-c^{2}\right) x^{2}+2 b^{2} x c+y^{2} a^{2}+c^{2} b^{2}=a^{2} b^{2} \Leftrightarrow \\
& a^{2} x^{2}-c^{2} x^{2}+2 b^{2} x c+y^{2} a^{2}+c^{2} b^{2}=a^{2} b^{2} \Leftrightarrow \\
& a^{2} x^{2}-c^{2} x^{2}+2 b^{2} x c+y^{2} a^{2}=a^{2} b^{2}-c^{2} b^{2} \Leftrightarrow \\
& a^{2} x^{2}-c^{2} x^{2}+2 b^{2} x c+y^{2} a^{2}=b^{2}\left(a^{2}-c^{2}\right) \Leftrightarrow
\end{aligned}
$$

Organizando convenientemente:

$$
\begin{aligned}
& a^{2} x^{2}-c^{2} x^{2}+2 b^{2} x c+y^{2} a^{2}=b^{4} \Leftrightarrow \\
& a^{2}\left(x^{2}+y^{2}\right)-c^{2} x^{2}+2 b^{2} x c=b^{4} \Leftrightarrow
\end{aligned}
$$

Dividindo ambos os membros por $a^{2} b^{2}$ :

$$
\begin{aligned}
& \frac{\left(x^{2}+y^{2}\right)}{b^{2}}-\frac{c^{2} x^{2}}{a^{2} b^{2}}+\frac{2 x c}{a^{2}}=\frac{b^{2}}{a^{2}} \Leftrightarrow \\
& \frac{\left(x^{2}+y^{2}\right)}{b^{2}}=\left(\frac{c x}{a b}\right)^{2}-\frac{2 x c}{a^{2}}+\left(\frac{b}{a}\right)^{2}
\end{aligned}
$$


Como $r^{2}=x^{2}+y^{2}$, temos:

$$
\frac{r^{2}}{b^{2}}=\left(\frac{c x}{a b}\right)^{2}-\frac{2 x c}{a^{2}}+\left(\frac{b}{a}\right)^{2}
$$

Multiplicando e dividindo por $b$ o termo $\frac{2 x c}{a^{2}}$ :

$$
\begin{gathered}
\frac{r^{2}}{b^{2}}=\left(\frac{c x}{a b}\right)^{2}-\frac{2 x c}{a^{2}} \cdot \frac{b}{b}+\left(\frac{b}{a}\right)^{2} \Leftrightarrow \\
\frac{r^{2}}{b^{2}}=\left(\frac{c x}{a b}\right)^{2}-\frac{2 x c}{a b} \cdot \frac{b}{a}+\left(\frac{b}{a}\right)^{2} \Leftrightarrow \\
\frac{r^{2}}{b^{2}}=\left(\frac{c x}{a b}-\frac{b}{a}\right)^{2} \Leftrightarrow \\
\frac{r^{2}}{b^{2}}=\left(\frac{c x-b^{2}}{a b}\right)^{2} \Longleftrightarrow \\
r^{2}=b^{2}\left(\frac{c x-b^{2}}{a b}\right)^{2} \Longleftrightarrow \\
r= \pm b\left(\frac{c x-b^{2}}{a b}\right)
\end{gathered}
$$

Substituindo os valores de e e L, temos:

$$
r= \pm b\left(\frac{c x-b^{2}}{a b}\right)= \pm(x e-L)
$$

Fazendo análise dos dois casos, verificamos:

- CASO 1: $r=(x e-L)$ 
Como em coordenadas polares podemos podemos definir:

- $\left\{\begin{array}{l}x=r \cos \theta \\ y=r \operatorname{sen} \theta\end{array}\right.$

Temos:

$$
\begin{gathered}
r=(x e-L)=e \cdot r \cdot \cos \theta-L \Longleftrightarrow \\
-L=r-e \cdot r \cdot \cos \theta=r(1-e \cdot \cos \theta) \Longleftrightarrow \\
r=\frac{L}{e \cdot \cos \theta-1}
\end{gathered}
$$

- CASO 2: $r=-(x e-L)$

Analogamente:

$$
r=-(x e-L)=\frac{L}{e \cdot \cos \theta+1}
$$

Contudo, se levarmos em consideração os dois casos acima, mesmo assim, ainda temos que fazer a seguinte análise:

Como $0<e<1$, pois $0<c<a$, então:

$$
-1 \leq \cos \theta \leq 1, \forall \theta \in[0,2 \pi]
$$


Logo:

$$
e \cdot \cos \theta \leq e \leq 1 \Longrightarrow e \cdot \cos \theta \leq 1 \Longrightarrow e \cdot \cos \theta-1 \leq 0
$$

Por outro lado:

$$
-e \leq e \cdot \cos \theta \Longrightarrow 0 \leq e \cdot \cos \theta+e<e \cdot \cos \theta+1 \Longrightarrow 1+e \cdot \cos \theta>0
$$

Como, por definição, $r \geq 0$, podemos chegar a conclusão que a equação polar da elipse com exentricidade $e$ é dada por:

$$
\epsilon: r=\frac{L}{e \cdot \cos \theta+1}
$$




\section{Capítulo 5}

\section{EQUAÇÕES PARAMÉTRICAS DA}

\section{ELIPSE}

Definição: Seja $\varphi$ uma curva plana. Dizemos que uma aplicação $\gamma: D \rightarrow \mathbb{R}^{2}$, $\gamma(t)=(x(t), y(t))$ é uma parametrização de $\varphi$ se a sua imagem $\gamma(D)$ coincide $\operatorname{com} \varphi$, ou seja:

$$
\varphi=\gamma(D)=\{(x(t), y(t)) \mid t \in D\}
$$

. onde $D$ é um subconjunto de $\mathbb{R}$.

A imagem de $\gamma(D) \subset \mathbb{R}^{2}$ é chamada de traço de $\gamma$.

Sendo assim, cada curva pode apresentar infinitas parametrizações, tudo depende do processo de decisão e definição dos parâmetros necessários para uma especificação completa ou relevante para um modelo. 


\subsubsection{PARAMETRIZAÇÃO DO CÍRCULO}

Tome a equação geral do círculo, com centro na origem e raio $r>0$ :

$$
C: x^{2}+y^{2}=r^{2}
$$

Seja $\theta$ a medida de um ângulo, em radianos, tomado em sentido positivo, do ângulo $\widehat{P_{0} O P}$, conforme a figura abaixo:

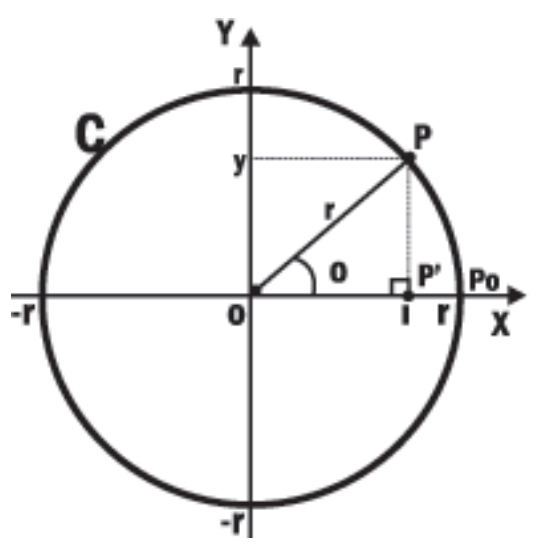

Figura 5.1: Círculo $C: \mathrm{x}^{2}+y^{2}=r^{2}$

Se $O$ é a origem do sistema cartesino, $P_{0}$ possui coordenadas $(r, 0)$.

Assim, tome $P^{\prime}=(x, 0)$ e $P=(x, y)$.

Nesse caso, o triângulo $O P P^{\prime}$ é retângulo em $P^{\prime}$ e as coordenadas do ponto $P$ em função do parâmetro $\theta$ podem ser expressas por:

- $C:\left\{\begin{array}{l}x=r \cos \theta \\ y=r \operatorname{sen} \theta\end{array}, \operatorname{com} \theta \in \mathbb{R}\right.$ 


\subsubsection{PARAMETRIZAÇÃO DA ELIPSE}

Para a parametrização de elipse, observe a figura abaixo e considere a sua equação canônica:

$$
\epsilon: \frac{x^{2}}{a^{2}}+\frac{y^{2}}{b^{2}}=1
$$

\subsubsection{1 $1{ }^{\circ}$ CASO: ELIPSE COM CENTRO NA ORIGEM:}

Sejam $\epsilon: \frac{x^{2}}{a^{2}}+\frac{y^{2}}{b^{2}}=1$ a equação canônica da elipse com centro na origem e $C: \alpha^{2}+\beta^{2}=1$ a equação de um cículo com centro na origem e $r=1$.

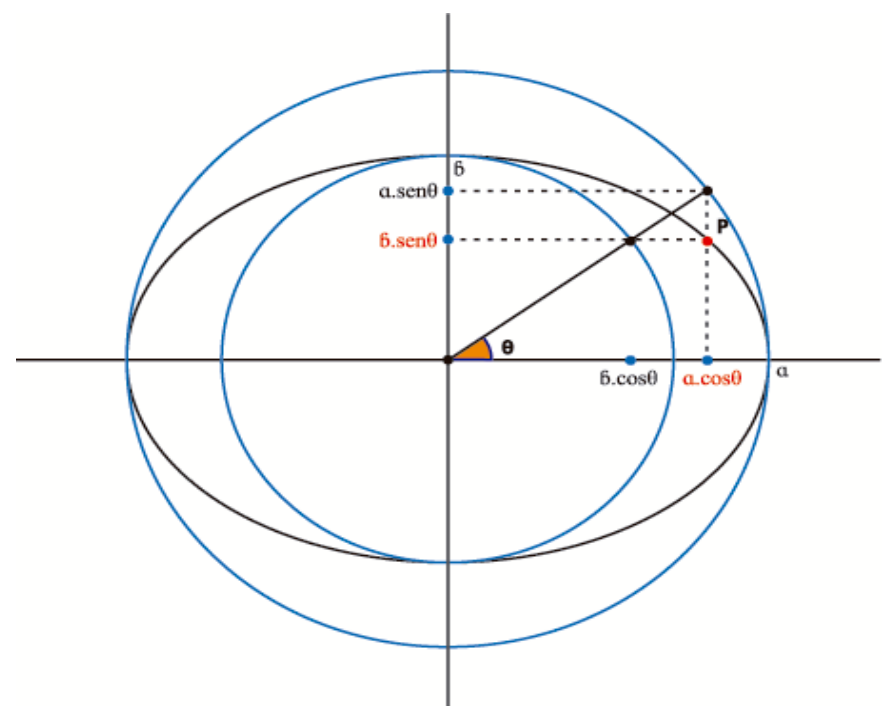

Figura 5.2: Parametrização da elipse

De fato, se a parametrização da circunferência, como demonstrado acima, é dada por:

$$
C=\left\{\begin{array}{l}
\alpha=\cos \theta \\
\beta=\operatorname{sen} \theta
\end{array} ; \operatorname{com} \theta \in \mathbb{R}\right.
$$


Então $(x, y) \in \epsilon$ se, e somente se, $(\alpha, \beta)=\left(\frac{x}{a}, \frac{y}{b}\right) \in C$.

Logo, uma possível parametrização para a elipse poderá ser dada por:

$\epsilon=\left\{\begin{array}{l}x=a \cdot \cos \theta \\ y=b \cdot \operatorname{sen} \theta\end{array} ; \operatorname{com} \theta \in \mathbb{R}\right.$.

\subsubsection{2 $2^{\circ}$ CASO: ELIPSE COM CENTRO EM UM PONTO $P=\left(x_{0}, y_{0}\right)$ :}

Faça uma translação dos eixos coordenados, de tal modo que seja obtido um novo sistema $O^{\prime} X^{\prime} Y^{\prime}$, onde $O^{\prime}=\left(x_{0}, y_{0}\right)$ será o centro da nova elipse.

Sendo assim, nas novas coordenadas, podemos dizer que a equação cartesiana da elipse será dada por:

$$
\epsilon^{\prime}: \frac{x^{\prime 2}}{a^{2}}+\frac{y^{\prime 2}}{b^{2}}=1
$$

E, de acordo com o que foi demonstrado na seção acima, podemos definir a equação paramétrica da elipse como:

$$
\epsilon^{\prime}=\left\{\begin{array}{l}
x^{\prime}=a \cdot \cos \theta \\
y^{\prime}=b \operatorname{sen} \theta
\end{array} ; \operatorname{com} \theta \in \mathbb{R} .\right.
$$

Contudo, essa parametrização é válida para o sistema cartesino transladado $O^{\prime} X^{\prime} Y^{\prime}$.

Mas, como sabemos que:

$$
\text { - }\left\{\begin{array}{l}
x=x^{\prime}+x_{0} \\
y=y^{\prime}+y_{0}
\end{array}\right.
$$


Podemos obter uma possível parametrização da elipse com centro em $\left(x_{0}, y_{0}\right)$, com a seguinte substituição:

$$
\epsilon^{\prime}=\left\{\begin{array}{l}
x=x_{0}+a \cdot \cos \theta \\
y=y_{0}+b \cdot \operatorname{sen} \theta
\end{array} ; \operatorname{com} \theta \in \mathbb{R}\right.
$$




\section{Capítulo 6}

\section{A HIPÉRBOLE EM COORDENADAS CARTESIANAS}

\section{ELEMENTOS CARACTERÍSTICOS DA HIPÉRBOLE:}

Observe a figura:

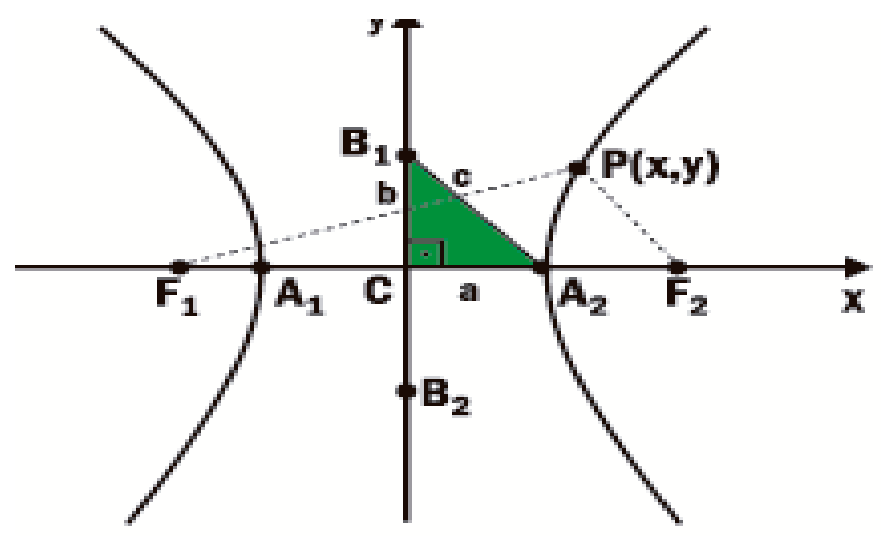

Figura 6.1: Elemento característico da hipérbole

Eixo focal coincide com o eixo $O X$;

Eixo normal coincide com o eixo $O Y$; 
Centro $C$ coincide com a origem $O$ do plano cartesiano.

Os focos com as coordenadas $F_{1}=(-c, 0)$ e $F_{2}=(c, 0)$.

Definição: Uma hipérbole $H$ de focos $F_{1}$ e $F_{2}$ é um conjunto de pontos $P$ do plano para os quais o módulo da diferença de suas distâncias a $F_{1}$ e $F_{2}$ é igual a uma constante $2 a>0$, a qual é menor que a distância entre os focos $2 c>0$.

$$
H=\left\{P /\left|d\left(P, F_{1}\right)-d\left(P, F_{2}\right)\right|=2 a, 0<a<c, d\left(F_{1}, F_{2}\right)=2 c\right\}
$$

A partir da definição de hipérbole, podemos obter uma relação no sistema de eixos ortogonais $O X Y$, como segue abaixo:

\section{AFIRMAÇÃO:}

Seja $P(x, y)$ um ponto da hipérbole, então:

Como a distância de $P$ aos focos $F_{1}$ e $F_{2}$ é:

$$
\overline{P F_{1}}=\sqrt{(x+c)^{2}+y^{2}}
$$

e,

$$
\overline{P F_{2}}=\sqrt{(x-c)^{2}+y^{2}}
$$

E além disso:

$$
\left|\overline{P F_{1}}-\overline{P F_{2}}\right|=2 a
$$


Então, substituindo (6.1) e (6.2) em (6.3), obtemos:

$$
\begin{gathered}
\left|\sqrt{(x+c)^{2}+y^{2}}-\sqrt{(x-c)^{2}+y^{2}}\right|=2 a \\
\sqrt{(x+c)^{2}+y^{2}}= \pm 2 a+\sqrt{(x-c)^{2}+y^{2}}
\end{gathered}
$$

Elevando ambos os membros ao quadrado, temos:

$$
\begin{gathered}
(x+c)^{2}+y^{2}=4 a^{2} \pm 4 a \sqrt{(x-c)^{2}+y^{2}}+(x-c)^{2}+y^{2} \Leftrightarrow \\
x^{2}+2 x c+c^{2}+y^{2}=4 a^{2}+x^{2}-2 x c+c^{2}+y^{2} \pm 4 a \sqrt{(x-c)^{2}+y^{2}}
\end{gathered}
$$

Cancelando os termos:

$$
\begin{gathered}
\pm 4 a \sqrt{(x-c)^{2}+y^{2}}=4 x c-4 a^{2} \Leftrightarrow \\
\pm a \sqrt{(x-c)^{2}+y^{2}}=x c-a^{2}
\end{gathered}
$$

Elevando, novamente, ambos os membros ao quadrado, temos:

$$
\begin{gathered}
a^{2}\left(x^{2}-2 x c+c^{2}+y^{2}\right)=x^{2} c^{2}-2 a^{2} x c+a^{4} \Leftrightarrow \\
a^{2} x^{2}-2 a^{2} x c+a^{2} c^{2}+a^{2} y^{2}=a^{4}-2 a^{2} x c+x^{2} c^{2} \Leftrightarrow
\end{gathered}
$$

Cancelando os termos:

$$
a^{2} x^{2}+a^{2} c^{2}+a^{2} y^{2}=a^{4}+x^{2} c^{2}
$$

Arrumando os termos de forma conveniente: 


$$
\begin{aligned}
& a^{2} y^{2}=a^{4}-a^{2} c^{2}+x^{2} c^{2}-a^{2} x^{2} \\
& a^{2} y^{2}=a^{2}\left(a^{2}-c^{2}\right)+x^{2}\left(c^{2}-a^{2}\right)
\end{aligned}
$$

Escolhendo $b>0$ e satisfazendo a igualdade:

$$
b^{2}=c^{2}-a^{2}
$$

Substituindo (6.5) em (6.4), temos:

$$
a^{2} y^{2}=-a^{2} b^{2}+x^{2} b^{2}
$$

Dividindo os dois lados da igualdade por $a^{2} b^{2}$ e organizando convenientemente:

$$
H: \frac{x^{2}}{a^{2}}-\frac{y^{2}}{b^{2}}=1
$$

Sendo assim, temos a forma canônica de uma hipérbole de centro na origem e reta focal coincidente com o eixo $O X$.

Como as assíntotas de $H$ são as retas que passam pela origem (centro) e têm inclinação $\pm b a$ em relação a reta focal, podemos afirmar que as suas equações são:

$$
y= \pm \frac{b}{a} \cdot x
$$

Ou seja,

$$
b x-a y=0
$$

$\mathrm{e}$

$$
b x+a y=0
$$




\subsubsection{EQUAÇÃO CARTESIANA DA HIPÉRBOLE COM CENTRO NA ORIGEM E RETA FOCAL COINCIDENTE COM EIXO OY}

Analogamente, podemos pensar em uma hipérbole com centro na origem e reta focal coincidente com o eixo $O Y$.

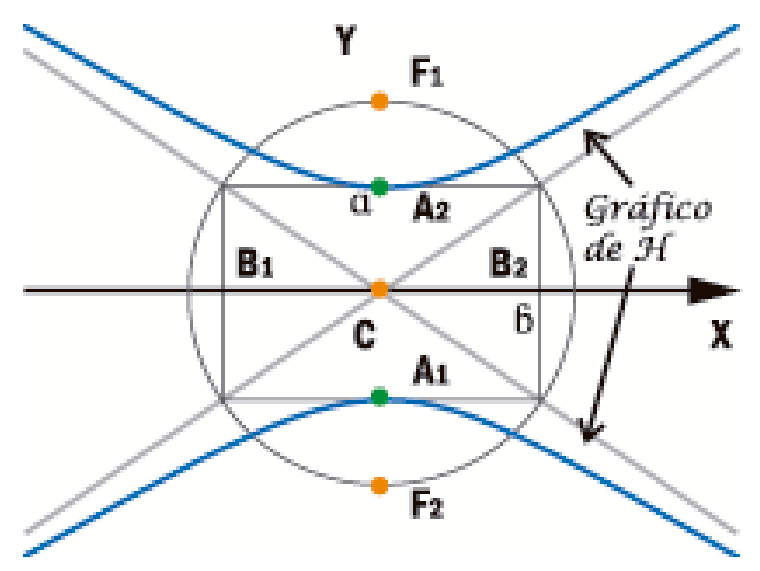

Figura 6.2: Hipébole com centro na origem e reta focal coincidente com o eixo OY

Neste caso, temos que os focos e os vértices da elipse terão as seguintes coordenadas:

$$
\begin{aligned}
& F_{1}=(0,-\mathrm{c}) \\
& F_{2}=(0, \mathrm{c}) \\
& A_{1}=(0,-\mathrm{a}) \\
& A_{2}=(0, \mathrm{a}) \\
& B_{1}=(-\mathrm{b}, 0) \\
& B_{2}=(\mathrm{b}, 0)
\end{aligned}
$$

Onde $b$ satisfaz:

$$
b^{2}=c^{2}-a^{2}
$$


Desenvolvendo o raciocínio conforme o caso anterior, veremos que a equação canônica da hipérbole com centro na origem e reta focal paralela ao eixo $O Y$ será dada por:

$$
H: \frac{y^{2}}{a^{2}}-\frac{x^{2}}{b^{2}}=1
$$

\subsubsection{EQUAÇÃO CARTESIANA DA HIPÉRBOLE COM CENTRO EM UM PONTO O' $=\left(\mathbf{x}_{0}, y_{0}\right)$}

Como vimos na subseção 3.0.2, que se refere a translação de eixos coordenados, utilizando essa técnica podemos obter uma equação de hipérbole cuja reta focal é horizontal ou vertical.

Considere o sistema $O X Y$, translade-o para a nova origem $O^{\prime}=\left(x_{0}, y_{0}\right)$, obtendo assim o sistema ortogonal $O^{\prime} X^{\prime} Y^{\prime}$.

Façamos, agora, as seguintes análises de caso:

\section{$1^{\circ}$ CASO - RETA FOCAL PARALELA AO EIXO OX:}

Observe a figura:

Seja $O^{\prime}$ é o centro da hipérbole e $l: y=y_{0}$ é a reta focal (pois, a reta focal é paralela ao eixo $O X$ e passa pelo ponto $\left.O^{\prime}=\left(x_{0}, y_{0}\right)\right)$. 


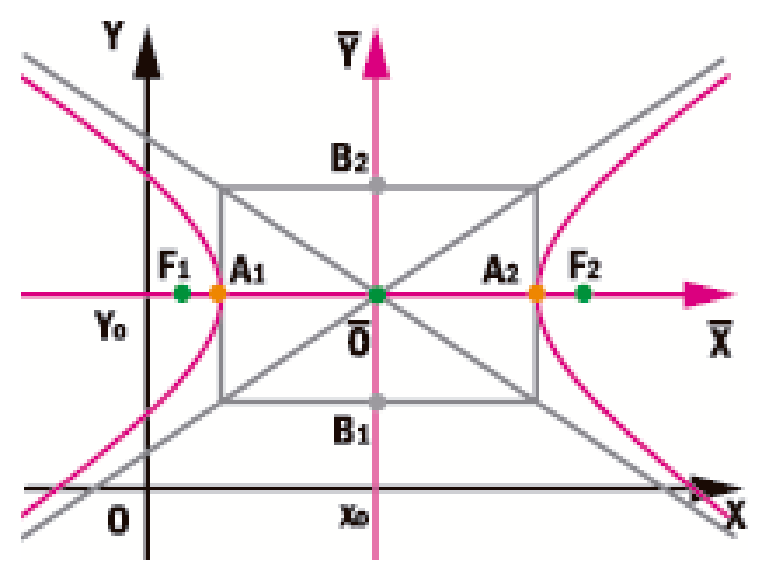

Figura 6.3: Hipérbole transladada com reta focal paralela ao eixo OX

Considere $F_{1}=\left(x_{0}-c, y_{0}\right)$ e $F_{2}=\left(x_{0}+c, y_{0}\right)$ como focos da hipérbole $\left[d\left(F_{1}, O^{\prime}\right)=\right.$ $\left.d\left(F_{2}, O^{\prime}\right)=c\right]$.

Temos que um ponto $P=(x, y)=\left(x^{\prime}+x_{0}, y^{\prime}+y_{0}\right)$ pertence à hipérbole se, $\mathrm{e}$ somente se,

$$
\left|d\left(P, F_{1}\right)-d\left(P, F_{2}\right)\right|=2 a
$$

Ou seja,

$$
\begin{gathered}
\left|d\left(\left(x^{\prime}+x_{0}, y^{\prime}+y_{0}\right),\left(x_{0}-c, y_{0}\right)\right)-d\left(\left(x^{\prime}+x_{0}, y^{\prime}+y_{0}\right),\left(x_{0}+c, y_{0}\right)\right)\right|=2 a \Longleftrightarrow \\
\left|d\left(\left(x^{\prime}, y^{\prime}\right),(-c, 0)\right)-d\left(\left(x^{\prime}, y^{\prime}\right),(c, 0)\right)\right|=2 a \Longleftrightarrow \\
\frac{x^{\prime 2}}{a^{2}}-\frac{y^{\prime 2}}{b^{2}}=1 \Longleftrightarrow
\end{gathered}
$$




$$
\frac{\left(x-x_{0}\right)^{2}}{a^{2}}-\frac{\left(y-y_{0}\right)^{2}}{b^{2}}=1
$$

Sendo assim, a equação da hipérbole $H$ com centro no ponto $\left(x_{0}, y_{0}\right)$ na forma canônica é dada por:

$$
H: \frac{\left(x-x_{0}\right)^{2}}{a^{2}}-\frac{\left(y-y_{0}\right)^{2}}{b^{2}}=1
$$

Onde:

$$
b^{2}=c^{2}-a^{2}
$$

\section{$2{ }^{\circ}$ CASO - RETA FOCAL PARALELA AO EIXO OY:}

Observe a figura:

Analogamente ao caso anterior, verifica-se que a equação na forma canônica de uma hipérbole $H$ com o centro no ponto $\left(x_{0}, y_{0}\right)$ e reta focal paralela ao eixo OY será:

$$
H: \frac{\left(y-y_{0}\right)^{2}}{a^{2}}-\frac{\left(x-x_{0}\right)^{2}}{b^{2}}=1
$$




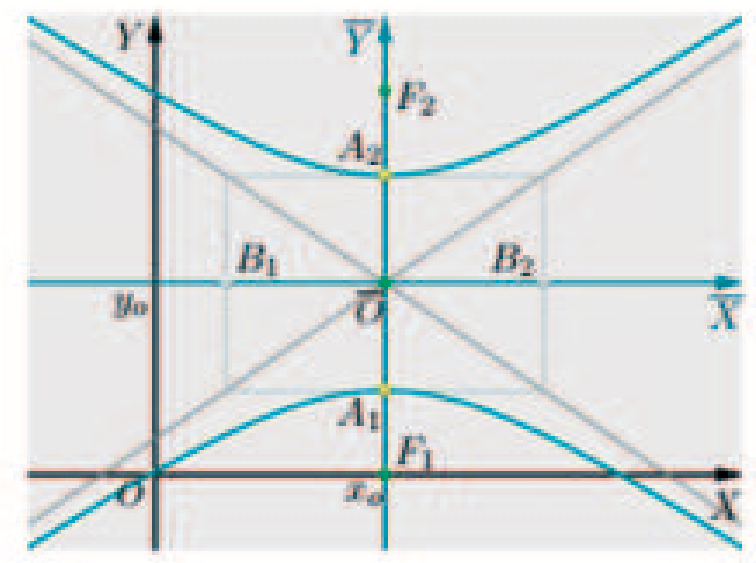

Figura 6.4: Hipérbole com reta focal paralela ao eixo OY

Perceba que para chegarmos nesse resultado, devemos adotar:

Reta focal:

- $l: x=x_{0}$ (pois deve ser paralela ao eixo OY e passar pelo ponto $\left(x_{0}, y_{0}\right)$;

Reta não focal:

- $l^{\prime}: y=y_{0}$;

Focos:

- $F_{1}=\left(x_{0}, y_{0}-c\right)$

$\mathrm{e}$

- $F_{2}=\left(x_{0}, y_{0}+c\right)$;

Vértices sobre a reta focal:

- $A_{1}=\left(x_{0}, y_{0}-a\right)$ 
e

- $A_{2}=\left(x_{0}, y_{0}+a\right)$;

Vértices sobre a reta não focal:

- $B_{1}=\left(x_{0}-b, y_{0}\right)$

e

- $B_{2}=\left(x_{0}+b, y_{0}\right)$; 


\section{Capítulo 7}

\section{EQUAÇÃO DA HIPÉRBOLE EM COORDENADAS POLARES}

Considere uma hipérbole com as seguintes características:

Eixo maior horizontal $\overline{A_{1} A_{2}}=2 a$;

Eixo menor $\overline{B_{1} B_{2}}=2 b$;

Distância focal $\overline{F_{1} F_{2}}=2 c$;

Centro $C(m, n)$.

Convenientemente, faça coincidir o pólo $p$ com o foco $F_{2}$.

E, além disso, faça coincidir o eixo polar com o eixo real da hipérbole.

Seja $P(\rho, \theta)$, um ponto pertencente a hipérbole. 
Observe a figura abaixo:

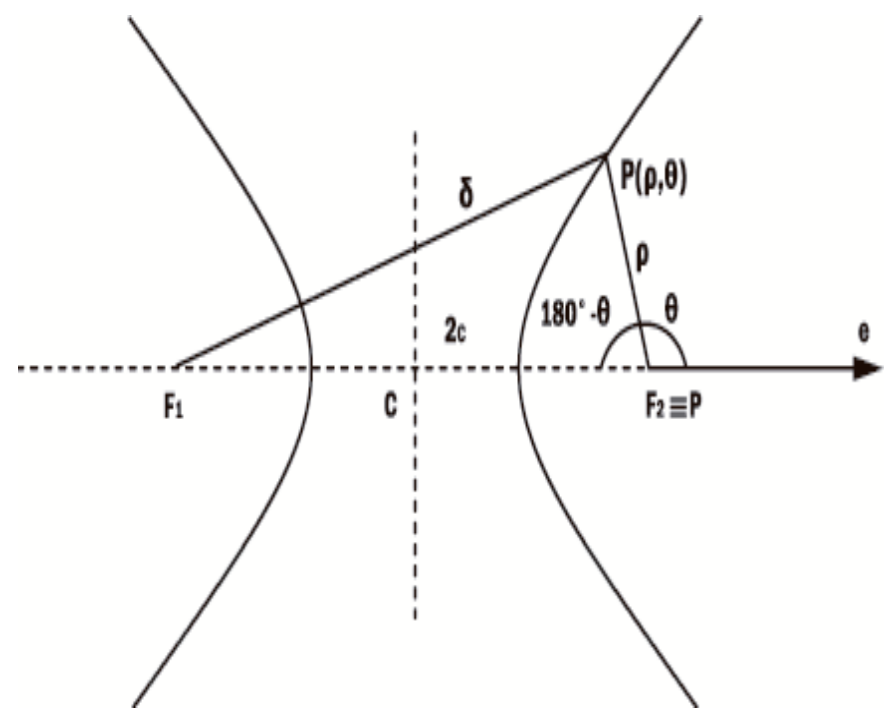

Figura 7.1: Hipérbole em coordenadas polares

Observando o triângulo formado pelos pontos $P F_{1} F_{2}$, aplique Lei dos Cossenos.

Assim teremos:

$$
\delta^{2}=\rho^{2}+4 c^{2}-4 \operatorname{cocos}\left(180^{\circ}-\theta\right)
$$

Pela definição de hipérbole, temos que:

$$
\begin{gathered}
\left|\overline{P F_{1}}-\overline{P F_{2}}\right|=2 a \\
\delta-\rho=2 a
\end{gathered}
$$

Ou seja:

$$
\delta=2 a+\rho
$$

Substituindo a equação (7.2) em (7.1), temos: 


$$
\begin{gathered}
(2 a+\rho)^{2}=\rho^{2}+4 c^{2}-4 \operatorname{cocos}\left(180^{\circ}-\theta\right) \Leftrightarrow \\
4 a^{2}+4 a \rho+\rho^{2}=\rho^{2}+4 c^{2}-4 \operatorname{cocos}\left(180^{\circ}-\theta\right)
\end{gathered}
$$

Simplificando os termos:

$$
\begin{gathered}
4 a^{2}+4 a \rho=4 c^{2}-4 \operatorname{cocos}\left(180^{\circ}-\theta\right) \Leftrightarrow \\
a^{2}+a \rho=c^{2}-\operatorname{cocos}\left(180^{\circ}-\theta\right)
\end{gathered}
$$

Organizando, convenientemente, os termos:

$$
\begin{gathered}
c^{2}-a^{2}=a \rho+c \rho \cos \left(180^{\circ}-\theta\right) \Leftrightarrow \\
c^{2}-a^{2}=a \rho-\operatorname{cocos}(\theta) \Leftrightarrow \\
c^{2}-a^{2}=\rho(a-c \cdot \cos (\theta)) \Leftrightarrow
\end{gathered}
$$

Como, na hipérbole, vale a igualdade:

$$
b^{2}=c^{2}-a^{2}
$$

Então:

$$
b^{2}=\rho(a-c \cdot \cos \theta)
$$

Portanto, a equação polar da hipérbole será dada por:

$$
\rho=\frac{b^{2}}{(a-c \cdot \cos \theta)}
$$


Como a excentricidade de uma hipérbole é dada por:

$$
e=\frac{c}{a}
$$

e, seu parâmetro,

$$
L=\frac{b^{2}}{a}
$$

Tome a equação polar da hipérbole e a divida os termos do segundo membro por $a$.

Assim:

$$
\rho=\frac{\frac{b^{2}}{a}}{\frac{a-c . \cos \theta}{a}}
$$

Sendo assim, temos a equação polar da hipérbole de centro na origem e reta focal coincidente com o eixo $O X$.

$$
\rho=\frac{b^{2}}{a+c \cdot \cos \theta}
$$

Substituindo os valores da excentricidade e do parâmetro, temos:

$$
\rho=\frac{L}{1-e \cos \theta}
$$

Sendo esta a equação polar da hipóerbole como usualmente é conhecida. 


\section{Capítulo 8}

\section{EQUAÇÕES PARAMÉTRICAS DA HIPÉRBOLE}

Considere uma hipérbole equilátera, ou seja, uma hipérbole que possui semi-eixos de medidas $a$ e $b$ iguais.

Tome-a com centro na origem e com reta focal coincidente com o eixo $O X$.

Observe a figura:

Sabemos que o cosseno hiperbólico e o seno hiperbólico podem ser definidos, respectivamente, por:

- $\left\{\begin{array}{l}\cosh \theta=\frac{e^{\theta}+e^{-\theta}}{2} \\ \operatorname{senh} \theta=\frac{e^{\theta}-e^{-\theta}}{2}\end{array}, \operatorname{com} \theta \in \mathbb{R}\right.$.

Os pontos $(\cosh \theta, \operatorname{senh} \theta)$ e $(-\cosh \theta, \operatorname{senh} \theta)$ pertencem à hipérbole $H$, uma vez que: 


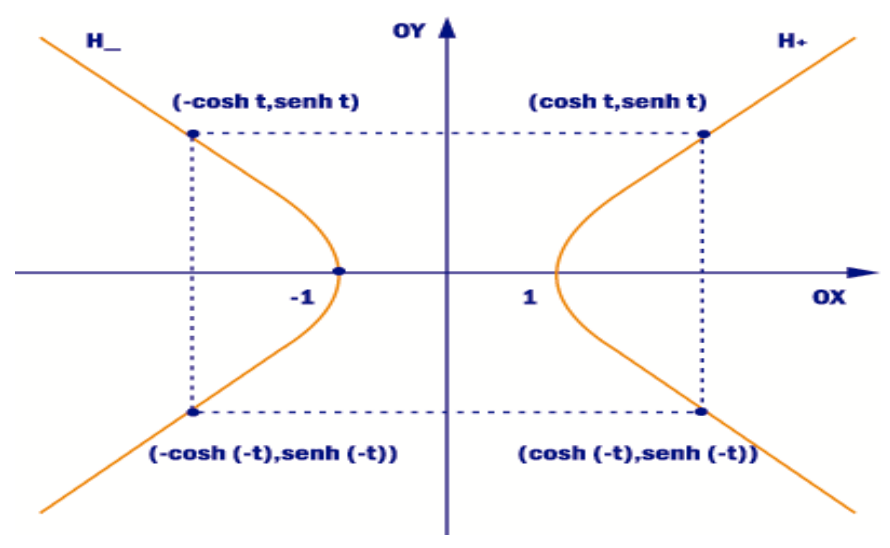

Figura 8.1: Gráfico: $\mathrm{H}=\mathrm{H}_{+} \cup H_{-}$

$(\cosh \theta)^{2}-(\operatorname{senh} \theta)^{2}=\frac{e^{2 \theta}+2+e^{-2 \theta}}{4}-\frac{e^{2 \theta}-2+e^{-2 \theta}}{4}=1$, para todo $\theta \in \mathbb{R}$.

Além disso, se variarmos $\theta$ em $\Re$ temos que $x= \pm \cosh \theta$ percorre os valores que estão no intervalo $(-\infty, 1] \cup[1, \infty)$, enquanto $y=\operatorname{senh} \theta$ percorre todos os valores reais.

Sendo assim, podemos concluir que:

- $\left\{\begin{array}{l}x=\cosh (\theta) \\ y=\operatorname{senh}(\theta)\end{array}, \operatorname{com} \theta \in \mathbb{R}\right.$.

É uma possível parametrização para o ramo de $H_{+}$de $H$ que intersepta o semieixo positivo $O X$.

e

- $\left\{\begin{array}{l}x=-\cosh (\theta) \\ y=\operatorname{senh}(\theta)\end{array}, \operatorname{com} \theta \in \mathbb{R}\right.$.

É uma possível parametrização para o ramo de $H_{-}$de $H$ que intersepta o semieixo negativo $O X$. 


\section{Capítulo 9}

\section{A PARÁBOLA EM COORDENADAS CARTESIANAS}

ELEMENTOS CARACTERÍSTICOS DE UMA PARÁBOLA

Observe a figura:

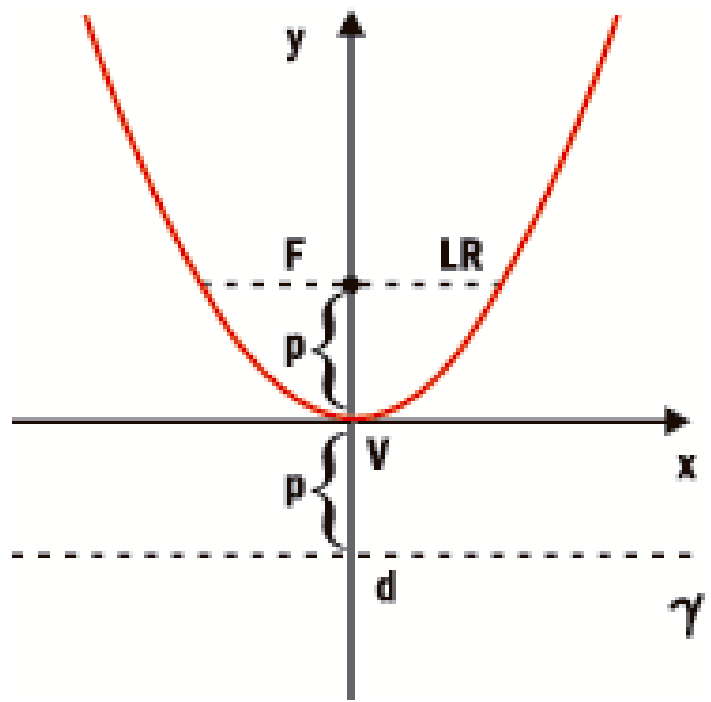

Figura 9.1: Elementos da parábola 
Definição: Sejam $\gamma$ uma reta e $F$ em ponto do plano não pertencente a $\gamma$. A parábola $\wp$ de foco $F$ e diretriz $\gamma$ é o conjunto de todos os pontos do plano cuja a distância a $F$ é igual a sua distância a $\gamma$.

$$
\wp=\{P \mid d(P, F)=d(P, \gamma)\}
$$

A partir da definição de parábola, podemos obter uma equação em relação ao sistema de eixos ortogonais $O X Y$, como segue abaixo:

Considere a parábola com vértice na origem do sistema cartesiano e o eixo focal coincidente com o eixo das abscissas.

Sejam $F$ seu foco e $\gamma$ a sua diretriz.

Tome $P(x, y)$ um ponto pertencente à parábola.

Considera-se parâmetro da parábola $(p)$ como sendo a distância entre o vértice a diretriz.

Sabemos que, por definição, se $P$ é um ponto pertencente à parábola, então:

$$
\overline{P F}=\overline{P \gamma}
$$

Por outro lado, a distância entre os pontos $P$ e $F$ é dada por:

$$
\overline{P F}=\sqrt{(x-p)^{2}+y^{2}}
$$

Além disso, a distância entre $P$ e $\gamma$ é dada por: 


$$
\overline{P \gamma}=x+p
$$

Substituindo (9.2) e (9.3) em (9.1), temos:

$$
\sqrt{(x-p)^{2}+y^{2}}=x+p
$$

Elevando os dois membros ao quadrado:

$$
\begin{gathered}
(x-p)^{2}+y^{2}=(x+p)^{2} \Leftrightarrow \\
x^{2}-2 x p+p^{2}+y^{2}=x^{2}+2 x p+p^{2} \\
y^{2}=4 x p
\end{gathered}
$$

Sendo assim, essa é a equação da parábola com o centro na origem e eixo focal coincidente com o eixo $O X$. 


\section{Capítulo 10}

\section{A PARÁBOLA EM COORDENADAS POLARES}

Observe a figura abaixo:

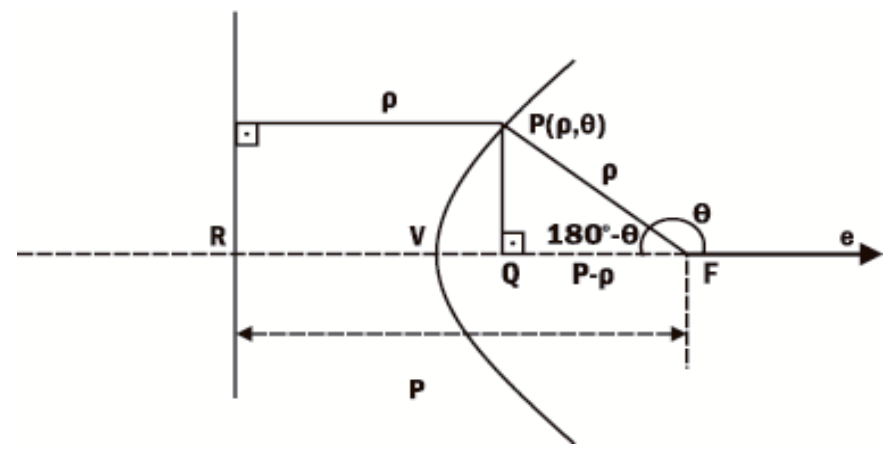

Figura 10.1: Parábola em coordenadas polares

Considere uma parábola com eixo de simetria horizontal e vértice em um ponto $V$.

Defina seu foco $F$ e $\overline{R F}=p$. 
Seja $P(\rho, \theta)$ um ponto qualquer da parábola.

Convenientemente, faça coincidir o polo $p$ como o foco $F$ e o eixo polar com o eixo de simetria da parábola.

No triângulo $\triangle P Q F$ temos que:

$$
\begin{gathered}
\cos \left(180^{\circ}-\theta\right)=-\cos \theta=\frac{p-\rho}{\rho} \Leftrightarrow \\
-\rho \cdot \cos \theta=p-\rho \Leftrightarrow \\
\rho(1-\cos \theta)=p \Leftrightarrow \\
\rho=\frac{p}{1-\cos \theta}
\end{gathered}
$$

Sendo esta a equação da parábola na sua forma polar. 


\section{Capítulo 11}

\section{EQUAÇÕES PARAMÉTRICAS DA}

\section{PARÁBOLA}

As equações cartesianas canônicas da parábola se caracterizam por apresentarem uma de suas variáveis no primeiro grau. Este fato, permite expressar essa variável como dependente da variável de segundo grau.

Tome, por exemplo, uma parábola $\wp$ de equação:

$$
y=\frac{1}{k}(x-a)^{2}+b
$$

De fato, a parábola acima possui vértice com coordenada $(a, b)$ e reta focal paralela ao eixo $O Y$.

Escolhendo o parâmetro $p$ como sendo $(x-a)$, a variável $y$ será expressa por:

$$
y=\frac{1}{k} p^{2}+b
$$

Portanto, uma equação paramétrica de $\wp$ pode ser dada por: 
- $\wp=\left\{\begin{array}{l}x=p+a \\ y=\frac{1}{k} p^{2}+b\end{array}\right.$

O gráfico da função acima é dado por:

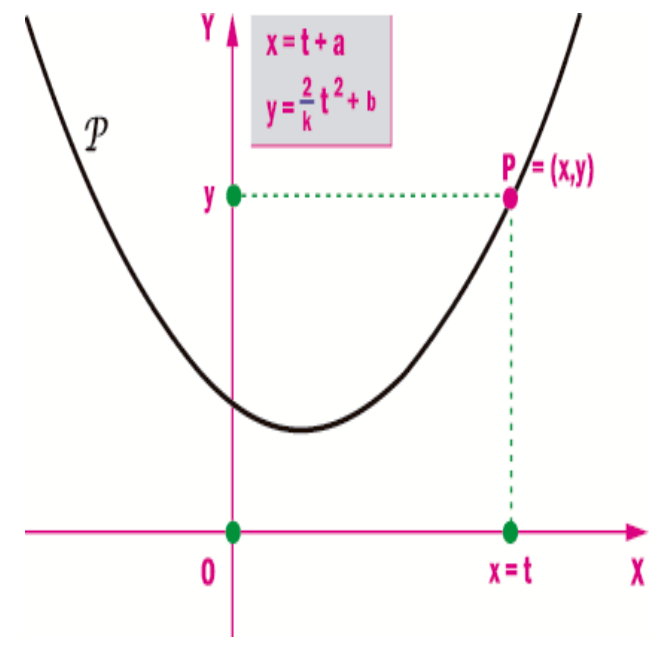

Figura 11.1: $\wp:(x-a)^{2}=k(y-b)$ 


\section{Capítulo 12}

\section{CÔNICAS E AS ESFERAS DE}

\section{DANDELIN}

“Enquanto a Álgebra e a Geometria estiveram separadas, o seu progresso foi lento e o seu uso limitado; mas uma vez que estas ciências se uniram, elas deram uma à outra um apoio mútuo e rapidamente avançaram juntos para a perfeição." Joseph Louis Lagrange (1736 - 1813).

Nesse capítulo, definiremos as equações das cônicas como uma consequência da relação entre o conceito geométrico e o algébrico.

Para isso, seguiremos os passos propostos pelo matemático francês, naturalizado belga, Germinal Pierre Dandelin (1794 - 1847).

Sabe-se que as definições de cônicas utilizadas, atualmente, foram provadas por Dandelin de forma muito clara no século XIX e constituem os chamados teoremas belgas para as cônicas.

Em seu estudo, Dandelin mostrou que em um determinado cone quando secci- 
onado por um plano, existe uma ou duas esferas que são tangentes ao plano e ao cone, simultaneamente. Estas esferas são as esferas de Dandelin.

A genialidade do seu trabalho vem do fato que utilizando a propriedade das retas tangentes a uma esfera, Dandelin consegue encontrar os focos e verificar a propriedade focal de uma só vez.

Neste aspecto, cabe uma ressalva na propriedade focal para das parábola, pois esta não foi demonstrada em seu estudo. Contudo, Pierce Morton, em 1829, usou uma construção semelhante a de Dandelin para provar esta propriedade. Diferentemente da elipse e da hipérbole, na demonstração da parábola só haverá uma esfera tangente ao cone e o plano de corte $\pi$. 


\subsubsection{A ELIPSE E AS ESFERAS DE DANDELIN}

Teorema: Consideremos um cone circular reto e um plano que intercepta apenas uma das folhas do cone. Se esse plano não passa pelo vértice e não é paralelo a nenhuma geratriz do cone, a curva obtida é a elipse.

Observe a figura:
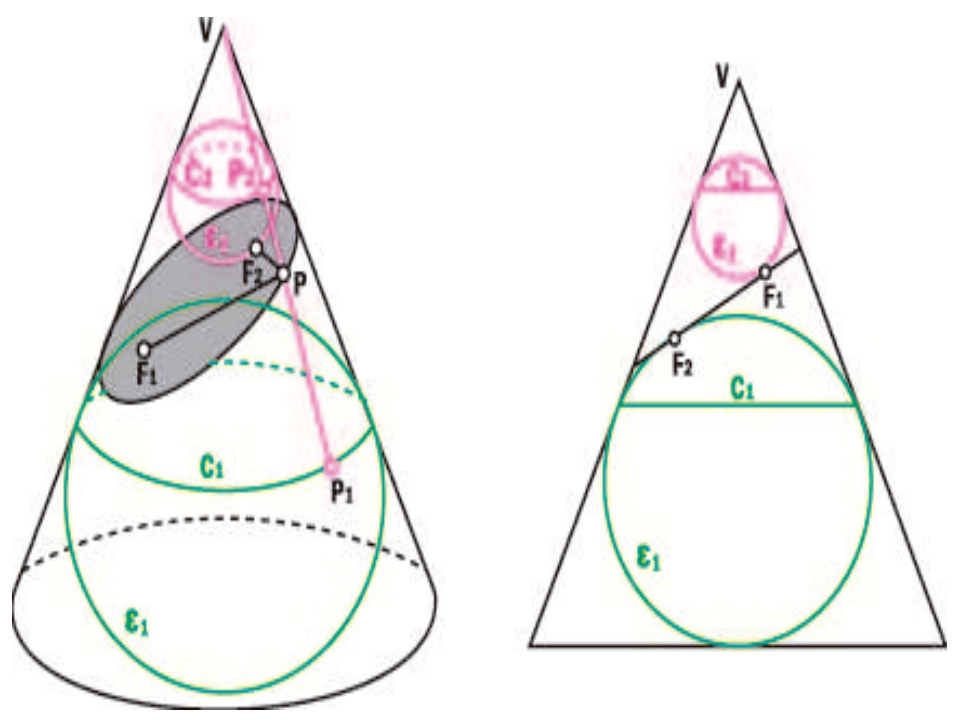

Figura 12.1: Esferas de Dandelin: caso elipse

Se uma cônica é um elipse de focos $F_{1}$ e $F_{2}$ e $P$ um ponto qualquer da elipse, então:

$$
\overline{P F_{1}}+\overline{P F_{2}}=K
$$

Sendo $K$ uma constante.

Sejam $\epsilon_{1}$ e $\epsilon_{2}$ duas esferas inscritas em um cone e tangente ao plano secante da cônica (conforme a figura). 
Como a reta $\overline{V P}$ é uma geratriz do cone, logo ela é tangente às esferas $\epsilon_{1} \mathbf{e} \epsilon_{2}$ nos pontos $P_{1}$ e $P_{2}$.

Sejam $F_{1}$ e $F_{2}$ os respectivos pontos de intersecção das esferas $\epsilon_{1}$ e $\epsilon_{2}$ com o plano.

Desta forma, pela propriedade de potência de pontos ${ }^{1}$ :

$$
\overline{P P_{1}}=\overline{P F_{1}}
$$

e

$$
\overline{P P_{2}}=\overline{P F_{2}}
$$

Somando a equação (12.1) e (12.2), membro a membro, temos:

$$
\overline{P P_{1}}+\overline{P P_{2}}=\overline{P F_{1}}+\overline{P F_{2}}
$$

Mas, como $\overline{P P_{1}}+\overline{P P_{2}}$ é uma constante, pois se trata de um distância fixa entre $\overline{P P_{1}}$ e $\overline{P P_{2}}$.

Podemos garantir que, $d\left(P, F_{1}\right)+d\left(P, F_{2}\right)=\overline{P_{1} P_{2}}=2 a$, para qualquer $P$ na intersecção do plano com o cone.

Logo, a curva característica é uma elipse.

\footnotetext{
${ }^{1}$ Se $\overline{A P}$ e $\overline{B P}$ são segmentos de reta tangentes à esfera nos ponto $A$ e $B$, então esses segmentos $\overline{A P} \mathrm{e}$ $\overline{B P}$ são congruentes.
} 


\subsubsection{A HIPÉRBOLE E AS ESFERAS DE DANDELIN}

Diferentemente do caso das elipses, para as hipérboles, Dandelin considerou duas esferas e um cone.

Assim, sejam um cone circular reto e um plano que o intersecta de tal modo que existam duas esferas que tangenciam simultaneamente o plano e o cone.

Se $F_{1}$ e $F_{2}$ são os pontos de intersecção das esferas com os planos, então qualquer ponto $P$ da intersecção do cone com o plano é tal que $\left|\overline{P F_{1}}-\overline{P F_{2}}\right|$ não depende de $P$.

Teorema: Sejam um cone circular reto e um plano que o intersecta de tal modo que existam duas esferas que tangenciam simultaneamente o plano e o cone. Se $F_{1}$ e $F_{2}$ são os pontos de intersecção das esferas com os planos, então qual- . quer ponto $P$ da intersecção do cone com o plano é tal que $\left|\overline{P F_{1}}-\overline{P F_{2}}\right|$ não depende de $P$. 
Observe a figura:
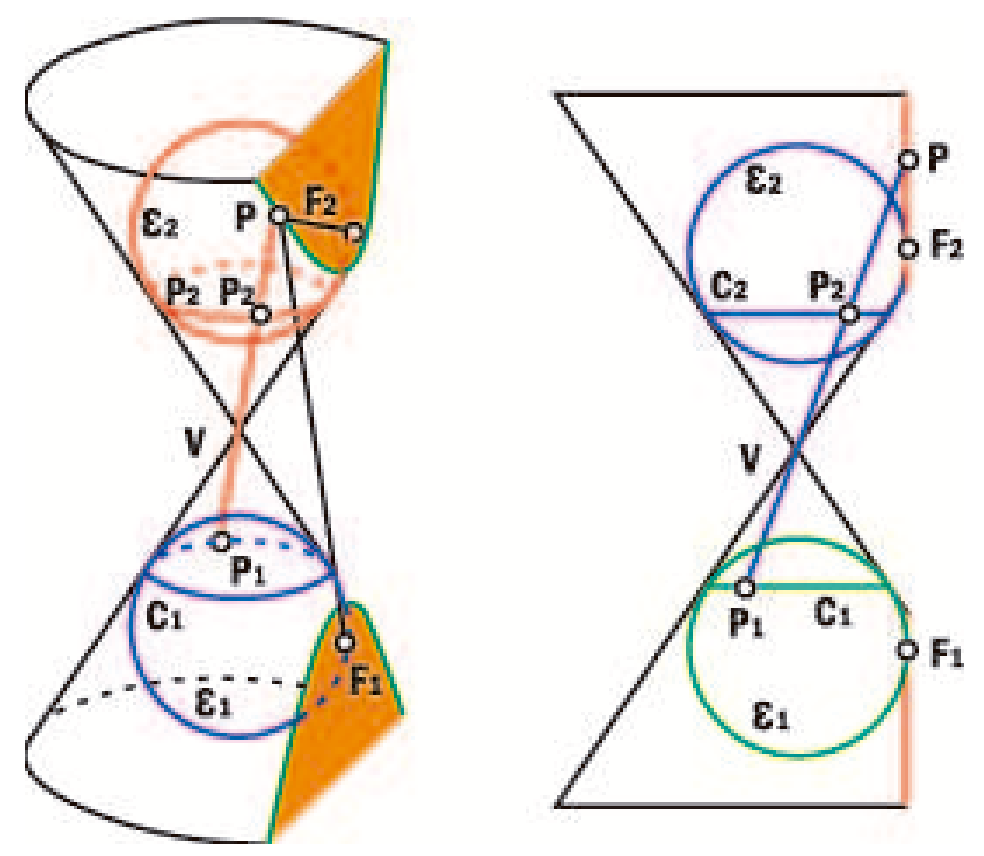

Figura 12.2: Esferas de Dandelin: caso hipérbole

\section{DEMONSTRAÇÃO:}

Considere duas esferas $\epsilon_{1}$ e $\epsilon_{2}$ inseridas em um cone de duas folhas tangenciando o plano de intersecção $\pi$ e todas as geratrizes do cone.

Seja $P$ um ponto qualquer sobre a intersecção do plano com o cone, tome a geratriz do cone passando por $P$.

Como, de fato, as esferas $\epsilon_{1} \mathrm{e} \epsilon_{2}$ são tangentes ao cone, então, podemos garantir que esta geratriz também será tangente às esferas. 
Suponha que $P_{1}$ e $P_{2}$ são esses pontos de tangencia. Seja $\overline{P_{1} P_{2}}$ o comprimento do seguimento $c_{1}$ e $c_{2}$ que passa por $V$.

Assim, pela propriedade de potência de pontos, podemos garantir que $\overline{P F_{1}}=$ $\overline{P P_{1}}$ e que $\overline{P F_{2}}=\overline{P P_{2}}$.

Então:

$$
\left|\overline{P F_{1}}-\overline{P F_{2}}\right|=\left|\overline{P P_{2}}-\overline{P P_{1}}\right|=\overline{P_{1} P_{2}}
$$

Ou seja, essa diferença sempre será constante, não importando qual o ponto $P$ escolhido sobre a intersecção do plano com o cone. 


\subsubsection{A PARÁBOLA E AS ESFERAS DE DANDELIN}

Como já foi mencionado, esse teorema não foi provado por Dandelin mas sim por Pierce Morton.

No estudo realizado por ele, em se tratando da parábola, haverá só uma esfera tangente ao cone e o plano de corte.

Teorema: Sejam um cone circular reto e um plano que o intersepta de tal modo que exista uma esfera que o tangencia, simultaneamente, o plano e o cone. Se $F$ é o ponto de interseção da esfera com o plano e $d$ a reta resultante dessa intersecção entre o plano de corte e o plano ortogonal ao eixo do cone, então qualquer ponto $P$ da intersecção do cone com o plano é tal que:

$$
d(P, F)=d(P, d)
$$


Observe a figura:

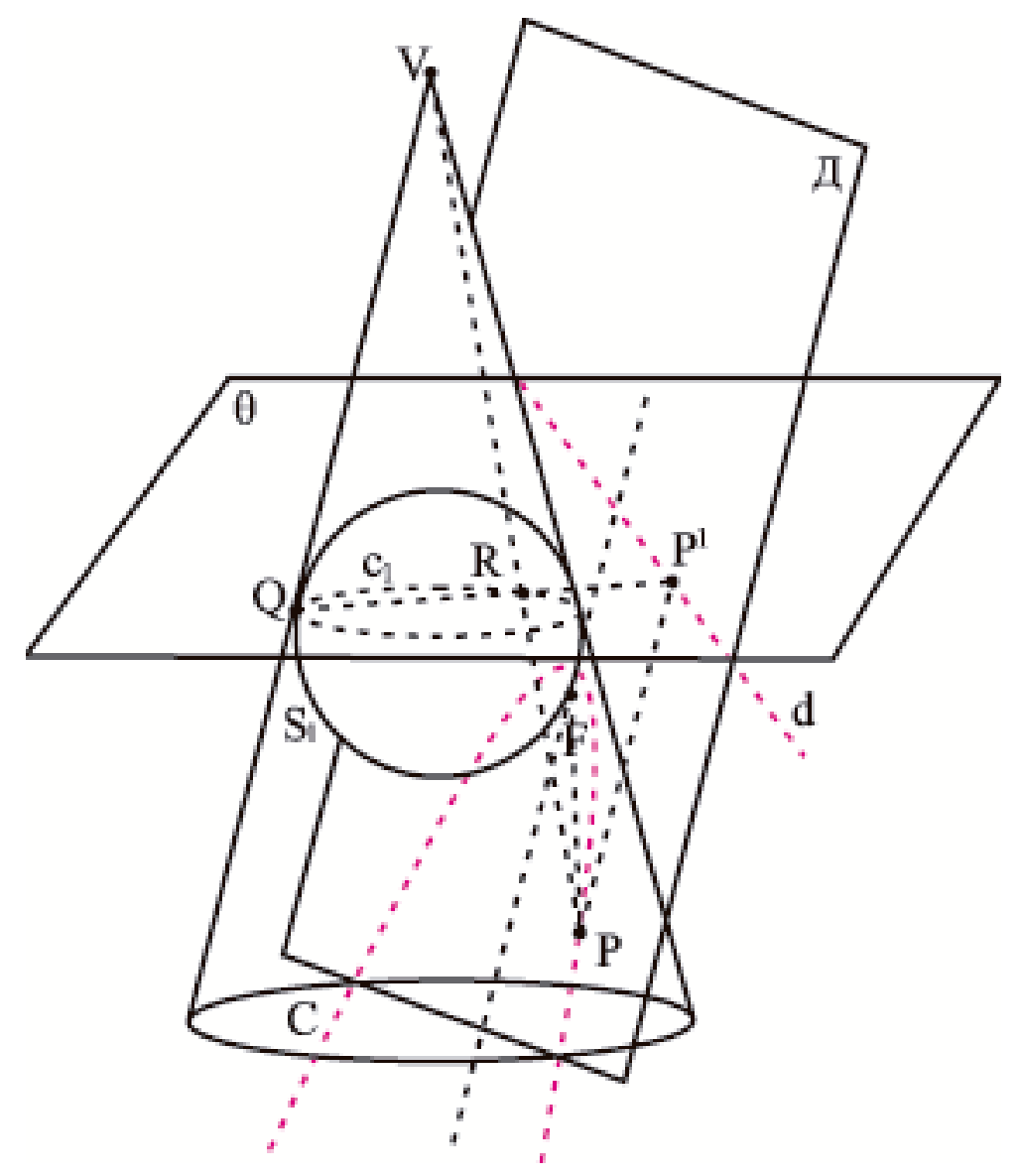

Figura 12.3: Figura de apoio para o caso parábola

\section{DEMONSTRAÇÃO:}

De fato, o ponto que a esfera intersepta o plano $\pi$ é o foco $F$ da parábola.

Seja a diretriz $d$ a resultante da intersecção entre o plano de corte $\pi$ e o plano $\theta$ que contém o círculo $c_{1}$ resultante da intersecção entre a esfera $\epsilon_{1}$ e o cone $C$. 
Seja $Q$ o ponto de intersecção do círculo $c_{1}$ com uma geratriz do cone paralela ao plano $\pi$.

Suponha que $P$ é um ponto aleatório sobre a parábola e $R$ o ponto de $c_{1}$ em que a esfera $\epsilon_{1}$ intersecta a geratriz que passa por $P$.

Seja ainda $P^{\prime}$ a projeção ortogonal do ponto $P$ sobre a reta $d$.

Pela propriedade de potência de pontos, temos que:

$$
\overline{V Q}=\overline{V R}
$$

e

$$
\overline{P R}=\overline{P F}
$$

Sendo assim, o triângulo $\triangle V Q R$ é semelhante ao triângulo $\triangle R P P^{\prime}$, logo $\overline{P P}^{\prime}$ $=\overline{P R}$.

Podemos assim concluir que $\overline{P F}=\overline{P P^{\prime}}$.

Portanto, a distância entre o ponto $P$ sobre a parábola ao foco é a mesma distância entre $P$ e $d$. 


\section{Capítulo 13}

\section{ESTUDO DAS CÔNICAS POR MEIO}

DA SUA DEFINIÇÃO GERAL

Definição: Dados uma reta $r$ e um ponto $F$ não pertencente à reta. A elipse, a hipérbole e a parábola podem ser definidas como o lugar geométrico dos pontos cuja razão das distâncias ao ponto $F$ e a reta $r$ é uma constante real positiva que depende de cada curva. Esta constante será chamada de excentricidade e A reta $r$ será chamada de diretriz e o ponto $F$ dado será chamado de foco. Ou seja,

$$
C=\{P \mid d(P, F)=e . d(P, r)\}
$$

Ou seja, partindo-se da definição acima, pode-se determinar uma única expressão algébrica capaz de representar todas as cônicas não degeneradas.

Considere o sistema de coordenadas cartesianas $O X Y$. Tome o eixo $O Y$ coincidente com reta diretriz $r$ e o eixo $O X$ seja a reta perpendicular a $r$ passando pelo foco $F$.

Faça $F=(2 p, 0)$, onde $p>0$. 
Seja $P=(x, y)$ um ponto qualquer sobre qualquer uma das cônicas, pela definição acima podemos afirmar que:

$$
\frac{d(P, F)}{d(P, r)}=e
$$

Como:

$$
d(P, F)=\sqrt{(x-2 p)^{2}+y^{2}}
$$

e,

$$
d(P, r)=|x|
$$

Reescrevendo a equação (13.1), temos:

$$
\sqrt{(x-2 p)^{2}+y^{2}}=e \cdot|x|
$$

Elevando ambos os membros ao quadrado, temos:

$$
(x-2 p)^{2}+y^{2}=e^{2} \cdot x^{2}
$$

Desenvolvendo os termos, temos:

$$
x^{2}-4 x p+4 p^{2}+y^{2}=e^{2} x^{2}
$$

Organizando convenientemente:

$$
\left(1-e^{2}\right) x^{2}-4 x p+4 p^{2}+y^{2}=0
$$

Que será conhecida como equação geral da cônica conforme definida no início do capítulo. 
Para uma análise mais detalhada, examinaremos os valores da excentricidade nos seguintes casos:

- Caso elipse: $0<e<1$;

- Caso hipérbole: $e>1$;

- Caso parábola: $e=1$.

\subsubsection{RELAÇÃO ENTRE A ELIPSE E A EXCENTRICIDADE}

De fato, se $0<e<1$, então $1-e^{2}>0$.

Dividindo ambos os termos da equação (13.4) por $1-e^{2}$, temos:

$$
x^{2}-\frac{4 p x}{1-e^{2}}+\frac{y^{2}}{1-e^{2}}=-\frac{4 p^{2}}{1-e^{2}}
$$

Completando quadrados:

$$
x^{2}-\frac{4 p x}{1-e^{2}}+\frac{4 p^{2}}{\left(1-e^{2}\right)^{2}}+\frac{y^{2}}{1-e^{2}}=-\frac{4 p^{2}}{1-e^{2}}+\frac{4 p^{2}}{\left(1-e^{2}\right)^{2}}
$$

Simplificando:

$$
\left(x-\frac{2 p}{1-e^{2}}\right)^{2}+\frac{y^{2}}{1-e^{2}}=\frac{4 p^{2} e^{2}}{\left(1-e^{2}\right)^{2}}
$$

Dividindo a equação por $\frac{4 p^{2} e^{2}}{\left(1-e^{2}\right)^{2}}=\left(\frac{2 p e}{1-e^{2}}\right)^{2}$, tem-se:

$$
\frac{\left(x-\frac{2 p}{1-e^{2}}\right)^{2}}{\left(\frac{2 p e}{1-e^{2}}\right)^{2}}+\left(\frac{y^{2}}{\frac{2 p e}{\sqrt{1-e^{2}}}}\right)^{2}=1
$$


Fazendo a translação de eixos coordenados para $X^{\prime} O^{\prime} Y^{\prime}$ com origem no ponto $O^{\prime}=$ $\left(\frac{2 p}{1-e^{2}}, 0\right)$, como definido em 3.0.2, teremos assim:

- $\left\{\begin{array}{l}x^{\prime}=x-\frac{2 p}{1-e^{2}} \\ y^{\prime}=y\end{array}\right.$

Definindo $a=\frac{2 p e}{1-e^{2}}$ e $b=\frac{2 p e}{\sqrt{1-e^{2}}}$, a equação (13.5) poderá ser escrita da forma:

$$
\frac{x^{\prime 2}}{a^{2}}+\frac{y^{\prime 2}}{b^{2}}=1
$$

Que é a equação canônica da elipse no sistema de coordenadas $O^{\prime} X^{\prime} Y^{\prime}$.

\subsubsection{A RELAÇÃO ENTRE A HIPÉRBOLE E A EXENTRICIDADE}

De fato, se $e>1$, então $1-e^{2}<0$.

Dividindo ambos os termos da equação (13.4) por $e^{2}-1$, temos:

$$
x^{2}+\frac{4 p x}{e^{2}-1}-\frac{y^{2}}{e^{2}-1}=\frac{4 p^{2}}{e^{2}-1}
$$

Completando quadrados:

$$
x^{2}+\frac{4 p x}{e^{2}-1}+\frac{4 p^{2}}{\left(e^{2}-1\right)^{2}}-\frac{y^{2}}{e^{2}-1}=\frac{4 p^{2}}{e^{2}-1}+\frac{4 p^{2}}{\left(e^{2}-1\right)^{2}}
$$

Simplificando:

$$
\left(x+\frac{2 p}{e^{2}-1}\right)^{2}-\frac{y^{2}}{e^{2}-1}=\frac{4 p^{2} e^{2}}{\left(e^{2}-1\right)^{2}}
$$

Dividindo a equação por $\frac{4 p^{2} e^{2}}{\left(e^{2}-1\right)^{2}}=\left(\frac{2 p e}{e^{2}-1}\right)^{2}$, tem-se: 


$$
\frac{\left(x+\frac{2 p}{e^{2}-1}\right)^{2}}{\left(\frac{2 p e}{e^{2}-1}\right)^{2}}-\left(\frac{y^{2}}{\frac{2 p e}{\sqrt{e^{2}-1}}}\right)^{2}=1
$$

Fazendo a translação de eixos coordenados para $O^{\prime} X^{\prime} Y^{\prime}$ com origem no ponto $O^{\prime}=$ $\left(-\frac{2 p}{e^{2}-1}, 0\right)$, como definido em 3.0.2, teremos assim:

- $\left\{\begin{array}{l}x^{\prime}=x+\frac{2 p}{e^{2}-1} \\ y^{\prime}=y\end{array}\right.$

Definindo $a=\frac{2 p}{e^{2}-1} e b=\frac{2 p e}{\sqrt{e^{2}-1}}$, a equação (13.6) poderá ser escrita da forma:

$$
\frac{x^{\prime 2}}{a^{2}}-\frac{y^{\prime 2}}{b^{2}}=1
$$

Que é a equação canônica da hipérbole no sistema de coordenadas $X^{\prime} O^{\prime} Y^{\prime}$.

\subsubsection{A RELAÇÃO ENTRE A PARÁBOLA E A EXCENTRICIDADE}

De fato, se $e=1$, então a equação (13.4) ficará assim expressa:

$$
-4 p x+y^{2}+4 p^{2}=0
$$

Isolando o y:

$$
y^{2}=4 p(x-p)
$$


Considere o novo sistema de coordenadas $X^{\prime} O^{\prime} Y^{\prime}$, onde $O^{\prime}=(p, 0)$ é a origem. Fazendo a translação de eixos:

- $\left\{\begin{array}{l}x^{\prime}=x-p \\ y^{\prime}=y\end{array}\right.$

Assim, observamos que a equação (13.4) pode ser reescrita como:

$$
y^{\prime 2}=4 p x^{\prime}
$$

Que é a equação canônica da parábola no sistema de coordenadas $X^{\prime} O^{\prime} Y^{\prime}$. 


\section{Capítulo 14}

\section{RECONHECIMENTO DE UMA}

\section{CÔNICA A PARTIR DO ESTUDO DE}

\section{UMA EQUAÇÃO DE $2^{\circ}$ GRAU}

Pierre de Fermat $(1601$ - 1665), ficou conhecido como o Príncipe dos Amadores, pois se dedicava à Matemática nas horas de folga. Pai da Geometria Analítica, dentre os seus inúmeros feitos classificou as curvas planas de acordo com o seu grau.

Em 1629, Fermat produziu um trabalho não publicado que circulou apenas como forma de manuscrito intitulado Introdução aos lugares geométricos planos e sólidos. Nesta obra, foi introduzida a ideia de eixos perpendiculares. Além disso, estabeleceu o principio fundamental de que uma equação de primeiro grau, no plano, representa uma reta e que uma de segundo grau representa uma cônica.

Com base nos estudos de Fermat, esse capítulo trará um enfoque algébrico para as cônicas. 


\section{$\underline{1^{\circ} \text { caso: ELIPSE: }}$}

Considere a equação do $2^{\circ}$ grau abaixo:

$$
A x^{2}+B x y+C y^{2}+D x+E y+F=0
$$

Proposição: Se $B=0$ e os coeficientes $A$ e $C$ têm o mesmo sinal, então a equação acima representa um dos seguintes conjuntos:

- Uma elipse com eixos paralelos aos eixos coordenados;

- Um ponto - (caso degenerado da elipse);

- Um conjunto vazio - (caso degenerado da elipse).

Sendo assim, para o estudo deste caso, partiremos da equação canônica da elipse $\epsilon$ com centro no ponto $\left(x_{0}, y_{0}\right)$ e reta focal paralela ao eixo $O X$.

Conforme já demonstrado no capítulo anterior, podemos definir a equação da elipse como:

$$
\epsilon: \frac{\left(x-x_{0}\right)^{2}}{a^{2}}+\frac{\left(y-y_{0}\right)^{2}}{b^{2}}=1
$$

Ao desenvolvermos essa equação, temos:

$$
\begin{gathered}
\frac{x^{2}-2 x \cdot x_{0}+x_{0}^{2}}{a^{2}}+\frac{y^{2}-2 y \cdot y_{0}+y_{0}^{2}}{b^{2}}=1 \Longleftrightarrow \\
b^{2} x^{2}-2 b^{2} x \cdot x_{0}+b^{2} x_{0}^{2}+a^{2} y^{2}-2 a^{2} y \cdot y_{0}+a^{2} y_{0}^{2}=a^{2} b^{2} \Longleftrightarrow
\end{gathered}
$$


Arrumando os termos convenientemente:

$$
b^{2} x^{2}+a^{2} y^{2}-2 b^{2} x_{0} x-2 a^{2} y_{0} y+b^{2} x_{0}^{2}+a^{2} y_{0}^{2}-a^{2} b^{2}=0
$$

De fato, essa expressão é da forma:

$$
A x^{2}+B x y+C y^{2}+D x+E y+F=0
$$

$\operatorname{Com} A=b^{2}, B=0, C=a^{2}, D=-2 b^{2} x_{0}, E=-2 a^{2} y_{0}, F=b^{2} x_{0}^{2}+a^{2} y_{0}^{2}-a^{2} b^{2}$.

Então, em particular, $B=0$ e $A$ e $C$ têm o mesmo sinal.

Perceba que raciocínio análogo serve para a equação da elipse com reta focal paralela ao eixo $O Y$.

Sendo assim, podemos concluir que para a equação do $2^{\circ}$ grau $A x^{2}+C y^{2}+$ $D x+E y+F=0$ ser um dos casos acima devemos ter $B=0 A C>0$.

Por outro lado, tome a equação acima e divida pelo termo $A C$, obtendo assim:

$$
\begin{gathered}
\frac{A x^{2}}{A C}+\frac{C y^{2}}{A C}+\frac{D x}{A C}+\frac{E y}{A C}+\frac{F}{A C}=0 \Leftrightarrow \\
\frac{x^{2}}{C}+\frac{y^{2}}{A}+\frac{D x}{A C}+\frac{E y}{A C}+\frac{F}{A C}=0 \Leftrightarrow \\
\frac{x^{2}+\frac{D x}{A}}{C}+\frac{y^{2}+\frac{E y}{C}}{A}=-\frac{F}{A C}
\end{gathered}
$$

Completando quadrado: 


$$
\begin{gathered}
\frac{x^{2}+\frac{D x}{A}+\frac{D^{2}}{4 A^{2}}}{C}+\frac{y^{2}+\frac{E y}{C}+\frac{E^{2}}{4 C^{2}}}{A}=-\frac{F}{A C}+\frac{D^{2}}{4 A^{2} C}+\frac{E^{2}}{4 A C^{2}} \Leftrightarrow \\
\frac{\left(x+\frac{D}{2 A}\right)^{2}}{C}+\frac{\left(y+\frac{E}{2 C}\right)^{2}}{A}=\frac{C D^{2}+A E^{2}-4 A F C}{4 A^{2} C^{2}}
\end{gathered}
$$

Para simplificar a análise, faça:

$$
K=C D^{2}+A E^{2}-4 A F C
$$

Assim:

$$
\frac{\left(x+\frac{D}{2 A}\right)^{2}}{C}+\frac{\left(y+\frac{E}{2 C}\right)^{2}}{A}=\frac{K}{4 A^{2} C^{2}}
$$

Se $K=0$, então a equação representa o ponto

$$
\left(\frac{-D}{2 A}, \frac{-E}{2 C}\right)
$$

Se $K \neq 0$, podemos dividir a equação por $\frac{K}{4 A^{2} C^{2}}$ :

$$
\frac{\left(x+\frac{D}{2 A}\right)^{2}}{\frac{K}{4 A^{2} C}}+\frac{\left(y+\frac{E}{2 C}\right)^{2}}{\frac{K}{4 A C^{2}}}=1
$$

Como $A C>0$, se $K A>0$ a equação acima representa um elipse com centro no ponto $\left(-\frac{D}{2 A},-\frac{E}{2 C}\right)$;

Da mesma forma, se $K A<0$ e equação representará o conjunto vazio, uma vez que como $A C>0$, seria impossível termos a igualdade:

$$
\frac{\left(x+\frac{D}{2 A}\right)^{2}}{\frac{K}{4 A^{2} C}}+\frac{\left(y+\frac{E}{2 C}\right)^{2}}{\frac{K}{4 A C^{2}}}=1
$$




\section{2 ${ }^{\circ}$ caso: HIPÉRBOLE:}

Considere a equação do $2^{\circ}$ grau abaixo:

$$
A x^{2}+B x y+C y^{2}+D x+E y+F=0
$$

Proposição: Se $B=0$ e os coeficientes $A$ e $C$ têm sinais opostos, então a equação acima representa um dos seguintes conjuntos:

- uma hipérbole de eixos paralelos aos eixos coordenados;

- um par de retas concorrentes - (caso degenerado da hipérbole).

Sendo assim, para o estudo deste caso, partiremos da equação canônica da hipérbole $H$ com centro no ponto $\left(x_{0}, y_{0}\right)$ e reta focal paralela ao eixo $O X$.

Conforme já demonstrado no capítulo anterior, podemos definir a equação da hipérbole como:

$$
H: \frac{\left(x-x_{0}\right)^{2}}{a^{2}}-\frac{\left(y-y_{0}\right)^{2}}{b^{2}}=1
$$

Ao desenvolvermos essa equação, temos:

$$
\begin{gathered}
\frac{x^{2}-2 x \cdot x_{0}+x_{0}^{2}}{a^{2}}-\left(\frac{y^{2}-2 y \cdot y_{0}+y_{0}^{2}}{b^{2}}\right)=1 \Longleftrightarrow \\
b^{2} x^{2}-2 b^{2} x \cdot x_{0}+b^{2} x_{0}^{2}-\left(a^{2} y^{2}-2 a^{2} y \cdot y_{0}+a^{2} y_{0}^{2}\right)=a^{2} b^{2} \Longleftrightarrow
\end{gathered}
$$


Arrumando os termos convenientemente, temos:

$$
b^{2} x^{2}-a^{2} y^{2}-2 b^{2} x_{0} x+2 a^{2} y_{0} y+b^{2} x_{0}^{2}-a^{2} y_{0}^{2}-a^{2} b^{2}=0
$$

De fato, essa expressão é da forma:

$$
A x^{2}+B x y+C y^{2}+D x+E y+F=0
$$

$\operatorname{Com} A=b^{2}, B=0, C=-a^{2}, D=-2 b^{2} x_{0}, E=2 a^{2} y_{0}, F=b^{2} x_{0}^{2}-a^{2} y_{0}^{2}-a^{2} b^{2}$.

Então, em particular, $B=0$ e $A$ e $C$ têm sinais opostos.

Perceba que raciocínio análogo serve para a equação da hipérbole com reta focal paralela ao eixo $O Y$.

Por outro lado, tome a equação $A x^{2}+C y^{2}+D x+E y=-F$ e sem perda de generalidade, suponha que $A>0$ e $C<0$, então:

$$
\begin{gathered}
A x^{2}+D x-\left(-C y^{2}-E y\right)=-F \Leftrightarrow \\
\frac{x^{2}+\frac{D x}{A}}{-C}-\frac{y^{2}+\frac{E y}{C}}{A}=\frac{F}{A C} \Leftrightarrow
\end{gathered}
$$

Completando quadrado, temos:

$$
\begin{gathered}
\frac{\left(x+\frac{D}{2 A}\right)^{2}}{-C}-\frac{\left(y+\frac{E}{2 C}\right)^{2}}{A}=\frac{F}{A C}-\frac{D^{2}}{4 A^{2} C}-\frac{E^{2}}{4 A C^{2}} \Leftrightarrow \\
\frac{\left(x+\frac{D}{2 A}\right)^{2}}{-C}-\frac{\left(y+\frac{E}{2 C}\right)^{2}}{A}=\frac{4 A C F-C D^{2}-A E^{2}}{4 A^{2} C^{2}}
\end{gathered}
$$

Para simplificar a análise, faça $K=4 A C F-C D^{2}-E^{2} A$ : 


$$
\frac{\left(x+\frac{D}{2 A}\right)^{2}}{-C}-\frac{\left(y+\frac{E}{2 C}\right)^{2}}{A}=\frac{K}{4 A^{2} C^{2}}
$$

Se $K=0$, então a equação representa um par de retas concorrentes, uma vez que:

$$
\begin{gathered}
\frac{\left(x+\frac{D}{2 A}\right)^{2}}{-C}-\frac{\left(y+\frac{E}{2 C}\right)^{2}}{A}=0 \Leftrightarrow \\
\frac{\left(y+\frac{E}{2 C}\right)^{2}}{A}=\frac{\left(x+\frac{D}{2 A}\right)^{2}}{-C} \Rightarrow \\
y+\frac{E}{2 C}= \pm \sqrt{\frac{-A}{C}}\left(x+\frac{D}{2 A}\right)
\end{gathered}
$$

Sendo assim, no caso que $B=0$ e $A C<0$ o par de retas concorrentes é chamado de caso degenerado da parábola.

Se $K \neq 0$, podemos dividir a equação por $\frac{K}{4 A^{2} C^{2}}$.

$$
\frac{\left(x+\frac{D}{2 A}\right)^{2}}{-C}-\frac{\left(y+\frac{E}{2 C}\right)^{2}}{A}=1
$$

Logo, a equação representa uma hipérbole.

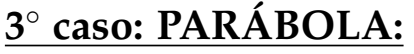

Considere a equação do $2^{\circ}$ grau abaixo:

$$
A x^{2}+B x y+C y^{2}+D x+E y+F=0
$$


Proposição: Se $B=0, A=0$ e $C \neq 0$, então a equação acima representa um dos seguintes conjuntos:

- uma parábola cuja a reta focal é paralela ao eixo $O X$, se $D \neq 0$;

- Um par de retas paralelas ao eixo $O X$, se $D=0$ e $E^{2}-4 C F>0$ - (caso degenerado da parábola);

- Um conjunto vazio - (caso degenerado da parábola).

Sendo assim, para o estudo deste caso, partiremos da equação canônica da parábola $\wp$ com vértice no ponto $\left(x_{0}, y_{0}\right)$ e reta focal paralela ao eixo $O X$.

Conforme já demonstrado no capítulo anterior, podemos definir a equação da parábola como:

$$
\left(y-y_{0}\right)^{2}= \pm 4 p\left(x-x_{0}\right)
$$

Desenvolvendo os termos e agrupando convenientemente, temos:

$$
y^{2} \pm 4 p x-2 y y_{0}+y_{0}^{2} \pm 4 p x_{0}=0
$$

De fato, essa expressão é da forma:

$$
A x^{2}+B x y+C y^{2}+D x+E y+F=0
$$

$\operatorname{Com} A=0, B=0, C=1, D= \pm 4 p, E=-2 y_{0}, F=y_{0}^{2} \pm 4 p x_{0}$.

Então, em particular, $A=0, B=0$ e $C \neq 0$, temos por consequência $A C=0$. 
Analisaremos, primeiramente, o caso que $A=0, C \neq 0$ e $D \neq 0$.

Tome a equação $A x^{2}+B x y+C y^{2}+D x+E y+F=0$ e a divida por $C$ :

$$
y^{2}+\frac{E y}{C}+\frac{D x}{C}+\frac{F}{C}=0
$$

Completando quadrados, temos:

$$
\left(y+\frac{E}{2 C}\right)^{2}+\frac{D x}{C}+\frac{F}{C}-\frac{E^{2}}{4 C^{2}}=0
$$

Como, por hipótese, $D \neq 0$, podemos reescrever a fórmula colocando o termos $\frac{D}{C}$ em evidência, obtendo:

$$
\left(y+\frac{E}{2 C}\right)^{2}+\frac{D}{C}\left(x+\frac{C}{D}\left(\frac{F}{C}-\frac{E^{2}}{4 C^{2}}\right)=0\right.
$$

Perceba que a equação acima representa uma parábola que possui reta focal paralela ao eixo $O X$ é vértice com coordenadas $\left(-\frac{4 C^{2} F-C E^{2}}{4 C^{2} D},-\frac{E}{2 C}\right)$.

Uma segunda análise pode ser feita quando $D=0$.

Neste caso, como por hipótese, $A=0$, a equação $A x^{2}+B x y+C y^{2}+D x+E y+$ $F=0$ se reduziria a:

$$
C y^{2}+E y+F=0
$$

Ou seja:

$$
y=\frac{-E \pm \sqrt{E^{2}-4 C F}}{2 C}
$$

Analisando a equação acima, podemos afirmar que: 
- Caso $E^{2}-4 C F>0$, teremos duas retas paralelas ao eixo $O X$. E, como ressaltamos, este é um caso degenerado da parábola.

- Caso $E^{2}-4 C F=0$, teremos uma reta paralela ao eixo $O X$.

Pois perceba que nesse caso, $y=\frac{-E}{C}$, sendo caracterizado, também, um caso degenerado da parábola.

- Caso $E^{2}-4 C F<0$ teremos como resultado o conjunto vazio.

Observe que todas as demonstrações acima valem para o caso $C=0$ e $A \neq 0$, contudo devemos considerar que, nesse caso, a parábola será paralela ao eixo $O Y$. 


\section{Capítulo 15}

\section{RECONHECIMENTO DE UMA CÔNICA POR MEIO DE MATRIZES}

Considere a equação geral de uma cônica.

$$
A x^{2}+B x y+C y^{2}+D x+E y+F=0
$$

Com $A, B, C$ e $D$ números reais, $A$ e $C$ são diferentes de zero e $x$ e $y$ são variáveis reais.

Observe que esta equação envolve a forma quadrática $Q(x, y)=A x^{2}+B x y+$ $C y^{2}$, uma forma linear $L(x, y)=D x+E y$ e uma constante $F$.

Perceba que nos casos que $B=0$, ao completarmos quadrados, facilmente pode-se identificar qual curva representa e equação.

Contudo, se $B \neq 0$ a identificação da cônica se torna não trivial. 
Neste capítulo, demonstraremos um método para a identificação das cônicas com auxílio da Álgebra Linear.

Para isso, deve-se considerar a equação geral acima escrita, convenientemente, da seguinte maneira:

$$
A x^{2}+B x y+C y^{2}=\left(\begin{array}{ll}
x & y
\end{array}\right) \cdot\left(\begin{array}{cc}
A & \frac{B}{2} \\
\frac{B}{2} & C
\end{array}\right) \cdot\left(\begin{array}{c}
x \\
y
\end{array}\right)
$$

e,

$$
D x+E y=\left(\begin{array}{cc}
D & E
\end{array}\right) \cdot\left(\begin{array}{l}
x \\
y
\end{array}\right)
$$

Para prosseguimento do estudo, precisamos das seguintes noções preliminares:

\subsubsection{NOÇÕES PRELIMIMARES DE ÁLGEBRA LINEAR}

\subsubsection{AUTOVALORES E AUTOVETORES}

Considere uma transformação linear de um espaço vetorial $T: V \rightarrow V$, devemos determinar um vetor, não nulo, $\vec{v} \in V$ e um escalar $\lambda \in \mathbb{R}$, tais que:

$$
T(\vec{v})=\lambda \vec{v}
$$

Definimos assim, o escalar $\lambda$ o autovalor de $T$ e o vetor $\vec{v}$ um autovetor de $T$. 
Sejam $A=\left(\begin{array}{ll}a_{11} & a_{12} \\ a_{21} & a_{22}\end{array}\right)$ uma matriz real do tipo $2 \times 2$ e $\vec{v}=(x, y)$ um vetor em $\mathbb{R}^{2}$.

Definimos como $A \vec{v}$ como sendo a combinação linear representada pelo vetor $\left(a_{11} x+a_{12} y, a_{21} x+a_{22} y\right)$, uma vez que:

$$
A \vec{v}=\left(\begin{array}{ll}
a_{11} & a_{12} \\
a_{21} & a_{22}
\end{array}\right) \cdot\left(\begin{array}{l}
x \\
y
\end{array}\right)=\left(a_{11} x+a_{12} y, a_{21} x+a_{22} y\right)
$$

Sendo assim, podemos afirmar que um número real $\lambda$ é um autovalor de uma matriz $A$ se existir um vetor $\vec{v}$, não nulo, tal que $A \vec{v}=\lambda \vec{v}$.

Em outras palvras, podemos afirmar que:

$$
\left\{\begin{array} { l } 
{ a _ { 1 1 } x + a _ { 1 2 } y = \lambda x } \\
{ a _ { 2 1 } x + a _ { 2 2 } y = \lambda y }
\end{array} \Leftrightarrow \left\{\begin{array}{l}
\left(\lambda-a_{11}\right) x-a_{12} y=0 \\
-a_{21} x+\left(\lambda-a_{22}\right) y=0
\end{array}\right.\right.
$$

Desta forma, um número real $\lambda$ é autovalor da matriz $A$ se, e somente se, o sistema acima tem solução não trivial. Uma vez que o vetor nulo é um autovetor relativo a qualquer autovalor, mas um número real só é autovalor se ele possuir um autovetor não nulo.

Resolvendo o sistema acima, sabemos que ele admitirá uma solução não nula se, e somente se, 


$$
\left|\begin{array}{cc}
\lambda-a_{11} & -a_{12} \\
-a_{21} & \lambda-a_{22}
\end{array}\right|=0
$$

Ou seja,

$$
\left(\lambda-a_{11},-a_{21}\right) x+\left(-a_{12}, \lambda-a_{22}\right) y=0 \text { possui uma solução }(x, y) \neq(0,0) \text { se, e somente }
$$
se , um dos vetores $\left(\lambda-a_{11},-a_{21}\right)$ e $\left(-a_{12}, \lambda-a_{22}\right)$ é múltiplo do outro.

Defina, então:

$$
p(\lambda)=\left|\begin{array}{cc}
\lambda-a_{11} & -a_{12} \\
-a_{21} & \lambda-a_{22}
\end{array}\right|=\left(\lambda-a_{11}\right)\left(\lambda-a_{22}\right)-a_{12} a_{21}
$$

como polinômio característico da matriz $A$.

Fazendo simples manipulações algébricas, é fácil verificar que o polinômio característico, também, pode ser escrito como:

$$
p(\lambda)=\operatorname{det}(A-\lambda . I)
$$

onde $I$ é a matriz identidade.

\subsubsection{EXISTÊNCIA DE AUTOVETORES ORTONORMAIS RELATIVOS À AU- TOVALORES $\lambda_{1}$ E $\lambda_{2}$ :}

Proposição: Autovetores associados a autovalores distintos de um operador $T: V \rightarrow V$ são linearmente independentes.

Sem perda de generalidade, considere $\lambda_{1}$ e $\lambda_{2}$ autovalores distintos. 
Segue que a prova para $\eta$ autovalores distintos é feita de modo análogo ao modo a seguir.

\section{Sejam:}

- $\left\{\begin{array}{l}T\left(v_{1}\right)=\lambda_{1} v_{1} \\ T\left(v_{2}\right)=\lambda_{2} v_{2}\end{array} ; \operatorname{com} \lambda_{1} \neq \lambda_{2}\right.$.

Considere a igualdade:

$$
a_{1} v_{1}+a_{2} v_{2}=0
$$

Pela linearidade de $T$, temos que:

$$
a_{1} T\left(v_{1}\right)+a_{2} T\left(v_{2}\right)=0
$$

ou

$$
a_{1} \lambda_{1} v_{1}+a_{2} \lambda_{2} v_{2}=0
$$

Tome a equação (15.10) e multiplique a por $\lambda_{1}$, assim:

$$
a_{1} \lambda_{1} v_{1}+a_{2} \lambda_{1} v_{2}=0
$$

Subtraia a equação (15.3) de (15.12), assim teremos:

$$
\begin{gathered}
\left(a_{1} \lambda_{1} v_{1}+a_{2} \lambda_{1} v_{2}\right)-\left(a_{1} \lambda_{1} v_{1}+a_{2} \lambda_{2} v_{2}\right)=0 \Leftrightarrow \\
a_{2} v_{2}\left(\lambda_{2}-\lambda_{1}\right)=0
\end{gathered}
$$


Como, por hipótese:

$\lambda_{1} \neq \lambda_{2}$ e $v_{2} \neq 0$.

Então: $a_{2}=0$

Desta forma, se analisarmos a equação (15.10), perceberemos que $a_{1}=0$.

Portanto o conjunto $\left\{v_{1}, v_{2}\right\}$ é linearmente independente.

\section{OBSERVAÇÕES:}

i) Sempre que tivermos um operador $T: \mathbb{R}^{2} \rightarrow \mathbb{R}^{2}$ com $\lambda_{1} \neq \lambda_{2}$, o conjunto $\left\{v_{1}, v_{2}\right\}$ formado pelos autovetores associados, será uma base em $\mathbb{R}^{2}$.

Portanto, dado um operador linear $T$ em $\mathbb{R}^{2}$ que possui autovalores distintos $\lambda_{1}$ e $\lambda_{2}$ esse conjunto $P=\left\{v_{1}, v_{2}\right\}$ será uma base.

ii) $\mathrm{O}$ operador $T$ é representado na base $P$ dos autovetores pela matriz diagonal:

$$
[T]_{P}=\left(\begin{array}{cc}
\lambda_{1} & 0 \\
0 & \lambda_{2}
\end{array}\right)
$$

Desta maneira, dada uma forma quadrática $f: \mathbb{R}^{2} \rightarrow \mathbb{R}^{2}, f(x, y)=A x^{2}+B x y+$ $C y^{2}$ considere a matriz real do tipo $2 \times 2$, como: 


$$
A=\left(\begin{array}{cc}
A & \frac{B}{2} \\
\frac{B}{2} & C
\end{array}\right)
$$

De fato, $A$ é uma matriz simétrica, uma vez que $A=A^{t}$.

Desta forma, o polinômio característico de $A$ é dado por:

$$
\begin{gathered}
p(\lambda)=\left|\begin{array}{cc}
\lambda-A & -\frac{B}{2} \\
-\frac{B}{2} & \lambda-C
\end{array}\right|= \\
(\lambda-A)(\lambda-C)-\frac{B^{2}}{4}= \\
\lambda^{2}-(A+C) \lambda+A C-\frac{B^{2}}{4}
\end{gathered}
$$

Sendo assim, calculando o discriminante dessa equação do $2^{\circ}$ grau, temos:

$$
\begin{gathered}
\Delta=(A+C)^{2}-4 \cdot 1 \cdot\left(A C-\frac{B^{2}}{4}\right) \\
\Delta=(A+C)^{2}-4 A C+B^{2}= \\
\Delta=A^{2}+2 A C+C^{2}-4 A C+B^{2}= \\
\Delta=A^{2}-2 A C+C^{2}+B^{2}= \\
\Delta=(A-C)^{2}+B^{2}
\end{gathered}
$$


Ou seja, como $\Delta$ é sempre maior ou igual a zero (pois se trata da soma de dois quadrados), podemos garantir $\lambda_{1}$ e $\lambda_{2}$ reais.

Isto é, a matriz $A$ possui dois autovalores $\lambda_{1}$ e $\lambda_{2}$, que têm multiplicidade um se $\lambda_{1} \neq \lambda_{2}$, e multiplicidade dois se, $\lambda_{1}=\lambda_{2}$.

Na mesma linha de raciocínio, podemos dizer que existe um par de autovetores ortonormais $\overrightarrow{v_{1}}$ e $\overrightarrow{v_{2}}$ aos autovalores $\lambda_{1}$ e $\lambda_{2}$, pois:

Se $\Delta=0$, temos que $A=C$ e $B=0$ portanto, a raiz do polinômimio será única e aplicando Báskara, teremos:

$$
\begin{gathered}
\lambda=\frac{(A+C) \pm \sqrt{0}}{2}= \\
\lambda=\frac{A+C}{2}=
\end{gathered}
$$

Como, por hipótese, $A=C$ :

$$
\lambda=\frac{2 A}{2}=A
$$

Ou seja, $A$ é a única raiz de $p(\lambda)=0$.

Neste caso, $A=\left[\begin{array}{cc}\lambda & 0 \\ 0 & \lambda\end{array}\right]$ e $\overrightarrow{v_{1}}=(1,0), \overrightarrow{v_{2}}=(0,1)$ são autovetores ortonormais relativos ao autovalor $\lambda$ de multiplicidade 2 .

Se $\Delta>0$, a equação $p(\lambda)=0$ tem duas raízes reais $\lambda_{1}$ e $\lambda_{2}$ distintas. 
Neste caso, deveremos provar que se $T: V \rightarrow V$ é um operador linear simétrico com autovalores distintos, então os autovetores são ortogonais.

Pois de fato, se $\overrightarrow{v_{1}}$ e $\overrightarrow{v_{2}}$ são vetores, não nulos, tais que:

$$
\text { - }\left\{\begin{array}{l}
A \overrightarrow{v_{1}}=\lambda_{1} \overrightarrow{v_{1}} \\
A \overrightarrow{v_{2}}=\lambda_{2} \overrightarrow{v_{2}}
\end{array}\right.
$$

Como $\overrightarrow{v_{1}}$ e $\overrightarrow{v_{2}}$ são autovetores, não nulos, associados a $\lambda_{1}$ e $\lambda_{2}$, respectivamente, podemos supor que $\overrightarrow{v_{1}}$ e $\overrightarrow{v_{2}}$ são vetores unitários, ou seja, $\left\|\overrightarrow{v_{1}}\right\|=\left\|\overrightarrow{v_{2}}\right\|=1$

Mostraremos que $\overrightarrow{v_{1}}, \overrightarrow{v_{2}}$ é linearmente independente.

De fato, sejam $a$ e $b$ constantes tais que:

$$
a \overrightarrow{v_{1}}+b \overrightarrow{v_{2}}=0
$$

Obtemos:

$$
a T \overrightarrow{v_{1}}+b T \overrightarrow{v_{2}}=0
$$

Isto é:

$$
a \lambda_{1} \overrightarrow{v_{1}}+b \lambda_{2} \overrightarrow{v_{2}}=0
$$

Multiplicando (15.14) por $\lambda_{1}$, obtemos:

$$
a \lambda_{1} \overrightarrow{v_{1}}+b \lambda_{1} \overrightarrow{v_{2}}=0
$$


Subtraindo (15.16) de (15.17), segue que:

$$
b\left(\lambda_{1}-\lambda_{2}\right) \overrightarrow{v_{2}}=0 \Longrightarrow b=0
$$

Concluímos de (15.14) que $a=0$ o que mostra que $\left(\overrightarrow{v_{1}}, \overrightarrow{v_{2}}\right)$ é L.I..

Sendo assim, podemos garantir que existe um par de vetores $\overrightarrow{v_{1}}$ e $\overrightarrow{v_{2}}$ ortonormais relativos aos aotovalores $\lambda_{1}$ e $\lambda_{2}$.

\subsubsection{DIAGONALIZAÇÃO DE MATRIZES SIMÉTRICAS}

Por definição, matriz diagonal é uma matriz quadrada cujos elementos exteriores à diagonal principal são nulos.

Dizemos que uma matriz quadrada $A$ é diagonalizável quando é semelhante a uma matriz diagonal.

Ou seja, existe uma matriz $D$ diagonal, tal que $A=S \cdot D \cdot S^{-1}$ com $S$ invertível.

Analogamente, seja $V$ um espaço vetorial de dimensão finita. Então um operador linear $T: V \rightarrow V$ é diagonalizável se, existe uma base de $V$ para a qual $T$ é representado por uma matriz diagonal.

A diagonalização é um processo para transformar uma matriz ou operador diagonalizável em uma matriz diagonal. 
Proposição: Se $S=\left[\begin{array}{cc}a_{1} & a_{2} \\ b_{1} & b_{2}\end{array}\right]$ é uma matriz do tipo $2 \times 2$, cuja primeira coluna é formada pelas coordenadas do vetor $\overrightarrow{v_{1}}=\left(a_{1}, b_{1}\right)$ e a segunda, pelas coordenadas do vetor $\overrightarrow{v_{2}}=\left(a_{2}, b_{2}\right)$, então:

$$
S^{t} \cdot A . S=\left[\begin{array}{cc}
\lambda_{1} & 0 \\
0 & \lambda_{2}
\end{array}\right]
$$

\section{DEMONSTRAÇÃO:}

Como:

$$
A \overrightarrow{v_{1}}=\left(A a_{1}+\frac{B}{2} b_{1}, \frac{B}{2} a_{1}+C b_{1}\right)=\left(\lambda_{2} a_{2}, \lambda_{2} b_{2}\right)
$$

$\mathrm{e}$

$$
A \overrightarrow{v_{2}}=\left(A a_{2}+\frac{B}{2} b_{2}, \frac{B}{2} a_{2}+C b_{2}\right)=\left(\lambda_{1} a_{1}, \lambda_{1} b_{1}\right)
$$

Segue que:

$$
A . S=\left[\begin{array}{cc}
A & \frac{B}{2} \\
\frac{B}{2} & C
\end{array}\right] \cdot\left[\begin{array}{cc}
a_{1} & a_{2} \\
b_{1} & b_{2}
\end{array}\right]=\left[\begin{array}{cc}
\lambda_{1} a_{1} & \lambda_{2} a_{2} \\
\lambda_{1} b_{1} & \lambda_{2} b_{2}
\end{array}\right]
$$

Além disso, sendo:

$$
\left\|\vec{v}_{1}\right\|=a_{1}^{2}+b_{1}^{2}=1
$$




$$
\left\|\overrightarrow{v_{2}}\right\|=a_{2}^{2}+b_{2}^{2}=1
$$

e

$$
\left\langle\overrightarrow{v_{1}}, \overrightarrow{v_{2}}\right\rangle=a_{1} a_{2}+b_{1} b_{2}=0
$$

Obtemos:

$S^{t} A S=\left[\begin{array}{cc}\lambda_{1} a_{1} & \lambda_{2} a_{2} \\ \lambda_{1} b_{1} & \lambda_{2} b_{2}\end{array}\right] \cdot\left[\begin{array}{cc}\lambda_{1} a_{1} & \lambda_{2} a_{2} \\ \lambda_{1} b_{1} & \lambda_{2} b_{2}\end{array}\right]=\left[\begin{array}{rr}\lambda_{1}\left(a_{1}^{2}+b_{1}^{2}\right) & \lambda_{2}\left(a_{1} a_{2}+b_{1} b_{2}\right) \\ \lambda_{1}\left(a_{1} a_{2}+b_{1} b_{2}\right) & \lambda_{2}\left(a_{2}^{2}+b_{2}\right)\end{array}\right]=\left[\begin{array}{rr}\lambda_{1} & 0 \\ 0 & \lambda_{2}\end{array}\right]$

\subsubsection{ANÁLISE DE UMA CÔNICA COM COEFICIENTE $B=0$}

Teorema: Dada uma cônica definida pela equação:

$$
A x^{2}+B x y+C y^{2}+D x+E y+F
$$

Sejam $\lambda_{1}$ e $\lambda_{2}$ autovalores associados a sua forma quadrárica, então:

i) Se $\lambda_{1} \cdot \lambda_{2}>0$ esta equação representa uma elipse, um ponto ou o conjunto vazio;

ii) Se $\lambda_{1} \cdot \lambda_{2}<0$ esta equação representa uma hipérbole ou um par de retas concorrentes;

iii) Se $\lambda_{1} \cdot \lambda_{2}=0$ esta equação representa uma parábola ou um par de retas paralelas ou uma reta ou o conjunto vazio.

Como já demonstrado, podemos afirmar que o determinante associado à forma quadrática $\left[\begin{array}{cc}A & \frac{B}{2} \\ \frac{B}{2} & C\end{array}\right]$ é igual ao produto de seus autovalores $\lambda_{1}$ e $\lambda_{2}$.

Assim, o sinal de $\lambda_{1} \cdot \lambda_{2}$ é o mesmo de $\left(\frac{B^{2}}{4}-A C\right)$, que por sua vez tem o mesmo sinal de $B^{2}-4 A C$. 
Podemos assim, reescrever o teorema anterior em função do discriminante $B^{2}-4 A C$.

Teorema: Dada uma cônica definida pela equação:

$$
A x^{2}+B x y+C y^{2}+D x+E y+F=0
$$

. $\quad$ Esta equação no plano representará:

i) Se $B^{2}-4 A C<0$ esta equação representa uma elipse, um ponto ou o conjunto vazio;

ii) Se $B^{2}-4 A C>0$ esta equação representa uma hipérbole ou um par de retas concorrentes;

iii) Se $B^{2}-4 A C=0$ esta equação representa uma parábola ou um par de retas paralelas ou uma reta ou o conjunto vazio.

\subsubsection{PROCEDIMENTO GERAL PARA A CLASSIFICAÇÃO DAS CÔNICAS:}

Dada a equação $A x^{2}+B x y+C y^{2}+D x+E y+F=0$, para achar que figura ela representa no plano, devemos proceder do seguinte modo:

- $1^{\circ}$ passo:

Escrever a equação na forma matricial:

$$
\left(\begin{array}{ll}
x & y
\end{array}\right) \cdot\left(\begin{array}{cc}
A & \frac{B}{2} \\
\frac{B}{2} & C
\end{array}\right) \cdot\left(\begin{array}{l}
x \\
y
\end{array}\right)+\left(\begin{array}{cc}
D & E
\end{array}\right) \cdot\left(\begin{array}{l}
x \\
y
\end{array}\right)+F
$$


- $2^{\circ}$ passo:

Diagonalizarmos a forma quadrática para eliminar os termos mistos.

Para isto, precisamos encontrar os autovalores $\lambda_{1}$ e $\lambda_{2}$ e os autovetores ortonormais $\overrightarrow{v_{1}}, \overrightarrow{v_{2}}$ de $\left(\begin{array}{cc}A & \frac{B}{2} \\ \frac{B}{2} & C\end{array}\right)$

- $3^{\circ}$ passo:

Obter as novas coordenadas.

$\left(\begin{array}{l}x \\ y\end{array}\right)=[I]$ autovetores na base canônica $\left(\begin{array}{l}x_{1} \\ y_{1}\end{array}\right)$

- $4^{\circ}$ passo:

Substituir as novas coordenadas na equação, obtendo a equação na nova base $\left\{\overrightarrow{v_{1}}, \overrightarrow{v_{2}}\right.$

$\left(\begin{array}{ll}x & y\end{array}\right) \cdot\left(\begin{array}{cc}\lambda_{1} & 0 \\ 0 & \lambda_{2}\end{array}\right) \cdot\left(\begin{array}{l}x \\ y\end{array}\right)+[D E][I]\left(\begin{array}{l}x_{1} \\ y_{1}\end{array}\right)+F=0$

- $5^{\circ}$ passo:

Eliminarmos os termos lineares das coordenadas cujos autovalores são não nulos.

Temos então três casos:

i) $\lambda_{1}$ e $\lambda_{2} \neq 0$

$$
\lambda_{1} x_{1}^{2}+a x_{1}+\lambda_{2} y+l a m b d a_{2} y_{1}^{2}+b y_{1}+F=0
$$




$$
\lambda_{1}\left(x_{1}+\frac{a}{2 \lambda_{1}}\right)^{2}-\frac{a^{2}}{4 \lambda_{1}}+\lambda_{2}\left(y_{1}+\frac{b}{2 \lambda_{2}}\right)^{2}-\frac{b^{2}}{4 \lambda_{2}}+F=0
$$

Seja $x_{2}=x_{1}+\frac{a}{2 \lambda_{1}}$ e $y_{2}=y_{1}+\frac{b}{2 \lambda_{2}}$, temos então:

$$
\lambda_{1} x_{2}^{2}+\lambda_{2} y_{2}^{2}+F=0
$$

ii) $\lambda_{1} \neq 0$ e $\lambda_{2}=0$

$$
\begin{gathered}
\lambda_{1} x_{1}^{2}+a x_{1}+b y_{1}+F=0 \\
\lambda_{1}\left(x_{1}+\frac{a}{2 \lambda_{1}}\right)^{2}-\frac{a^{2}}{4 \lambda_{1}}+b y_{1}+F=0
\end{gathered}
$$

Tomando $x_{2}=x_{1}+\frac{a}{2 \lambda_{1}}$ e $y_{2}=y_{1}$, temos:

$$
\lambda_{1} x_{2}^{2}+b y_{2}+F-\frac{a^{2}}{4 \lambda_{1}}=0
$$

iii) $\lambda_{1}=0$ e $\lambda_{2} \neq 0$

Similar ao caso anterior. 


\subsubsection{EXEMPLO PRÁTICO DO RECONHECIMENTO DE UMA CÔNICA POR MEIO DE OPERAÇÕES COM MATRIZES}

Considere a forma quadrática $f(x, y)=6 x^{2}+4 x y+6 y^{2}, \operatorname{com} A=C=6$ e $B=4$. Desta forma, $A=\left(\begin{array}{ll}6 & 2 \\ 2 & 6\end{array}\right)$ é a forma quadrática e, $p(\lambda)=\operatorname{det}\left(\begin{array}{cc}(\lambda-6) & -2 \\ -2 & (\lambda-6)\end{array}\right)=(\lambda-6)^{2}-4=\lambda^{2}-12 \lambda+32=0$

é a equação característica, cujas raízes são $\lambda_{1}=8$ e $\lambda_{2}=4$, isto é $\lambda_{1}$ e $\lambda_{2}$ são os autovalores da matriz $A$.

Os autovetores $(x, y)$ relativos ao autovalor $\lambda_{1}=8$ são soluções do sistema:

$$
\left\{\begin{array} { l } 
{ ( \lambda _ { 1 } - 6 ) - 2 y = 0 } \\
{ - 2 x + ( \lambda _ { 1 } - 6 ) y = 0 }
\end{array} \Leftrightarrow \left\{\begin{array}{l}
x-y=0 \\
-x+y=0
\end{array} \Leftrightarrow x=y\right.\right.
$$

Portanto, $\overrightarrow{v_{1}}=\left(\frac{1}{\sqrt{2}}, \frac{1}{\sqrt{2}}\right)=\left(\cos \frac{\pi}{4}, \operatorname{sen} \frac{\pi}{4}\right)$ é um autovetor unitário relativo ao autovalor $\lambda_{1}=8$.

Como o autovetor $\overrightarrow{v_{2}}$ é ortogonal a $\overrightarrow{v_{1}}$ basta tomar $\overrightarrow{v_{2}}=\left(-\operatorname{sen} \frac{\pi}{4}, \cos \frac{\pi}{4}\right)$.

Seja $O^{\prime} X^{\prime} Y^{\prime}$ o sistema de eixos ortogonais obtido girando os eixos $O X$ e $O Y$, no sentido positivo, um ângulo de $\frac{\pi}{4}$. Nas coordenadas $X^{\prime}$ e $Y^{\prime}$ deste sistema de eixos, a forma quadrática $f\left(x^{\prime}, y^{\prime}\right)$ é dada por:

$$
f\left(x^{\prime}, y^{\prime}\right)=\lambda_{1} x^{\prime 2}+\lambda_{2} y^{\prime 2}=8 x^{\prime 2}+4 y^{\prime 2}
$$

Portanto, a linha de nível $k$ de $f$ é: 
- um conjunto vazio se , $k<0$;

- a origem se $k=0$;

- a elipse $\frac{x^{\prime 2}}{\frac{k}{8}}+\frac{y^{\prime 2}}{\frac{k}{4}}=1$ se $k>0$.

Faça a mudança de coordenadas, novamente, para o eixo coordenado $O X Y$ para obter a elipse original. 


\section{Capítulo 16}

\section{PROPRIEDADE DAS CÔNICAS}

A elipse, a parábola e a hipérbole são curvas que possuem propriedades que as tornam importantes em várias aplicações tecnológicas. Neste capítulo, vamos tratar da propriedade refletora dessas curvas, relacionando-as com pontos especiais, os seus focos.

\subsection{PROPRIEDADE REFLETORA DA ELIPSE}

Podemos enunciar a propriedade refletora da elipse do seguinte modo: a partir de um dos focos, tracemos um segmento de reta qualquer. Este segmento encontra a elipse em um ponto e se por este traçarmos outro segmento que faça com a curva um ângulo igual ao do primeiro segmento, o segundo segmento passa, obrigatoriamente, pelo outro foco.

Assim, segue o teorema:

Teorema: Uma reta $r$, tangente à uma elipse em um ponto $P$, faz ângulos iguais com as retas que unem $P$ aos focos $F_{1}$ e $F_{2}$. 


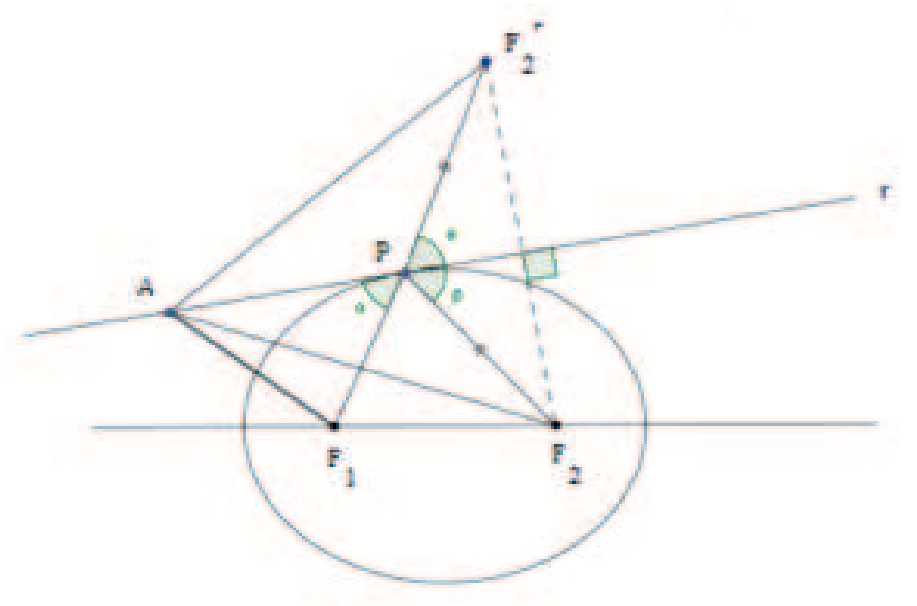

Figura 16.1: Propriedade refletora da elipse

\section{DEMONSTRAÇÃO:}

Considere a elipse $\epsilon$ de focos $F_{1}$ e $F_{2}$ e eixo maior igual a $2 a$.

Sejam $P$ um ponto pertencente à elipse $\epsilon, F_{2}^{\prime}$ um ponto da reta $P F_{1}$ tal que $\overline{P F_{2}}=\overline{P F_{2}^{\prime}}, r$ a reta bissetriz do ângulo $F_{2} P F_{2}^{\prime}$ e $A$ um ponto qualquer da reta $r$ de tal forma que $A \neq P$.

Como $P \in \epsilon$, então:

$$
d\left(P, F_{1}\right)+d\left(P, F_{2}\right)=d\left(P, F_{1}\right)+d\left(P, F_{2}^{\prime}\right)=2 a
$$

Pela desigualdade triangular em $\triangle A F_{1} F_{2}^{\prime}$, temos: 


$$
d\left(A, F_{1}\right)+d\left(A, F_{2}^{\prime}\right)>d\left(F_{1}, F_{2}^{\prime}\right)=d\left(P, F_{1}\right)+d\left(P, F_{2}\right)=d\left(P, F_{1}\right)+d\left(P, F_{2}^{\prime}\right)=2 a
$$

Logo $A$ não pertence à elipse.

Como $A$ é um ponto qualquer da reta $r$ e, por hipótese, $A \neq P$, então a reta $r$ só tem o ponto $P$ em comum com a elipse e, portanto $r$ é uma tangente à cônica em $P$.

Considere, agora, os ângulos $\alpha$ entre a reta $r$ e $\overline{P F_{1}}, \theta$ entre a reta $r$ e $\overline{P F_{2}^{\prime}}$ e $\beta$ entre a reta $r$ e o prolongamento de $\overline{P F_{2}}$.

Assim, sendo $r$ a reta bissetriz do ângulo $F_{2} P F_{2}^{\prime}$ e $\alpha$ e $\theta$ ângulos opostos pelo vértice, temos:

$$
\left\{\begin{array}{l}
\beta=\theta \\
e \\
\theta=\alpha
\end{array} \Rightarrow \beta=\alpha\right.
$$

c.q.d.

Podemos citar uma aplicação óptica dessa propriedade.

Para cuidar do sorriso dos pacientes, muitos dentistas usam uma luminária com espelho elíptico que possui a propriedade de concentrar os raios luminosos em um ponto, que é ajustado pelo dentista para iluminar o dente que está sendo tratado. Conseguem-se, assim, duas vantagens: A primeira é concentrar o máximo de luz onde se está trabalhando, e a segunda é evitar que os raios luminosos ofusquem o paciente, o que aumentaria o desconforto causado pelo tratamento dentário ${ }^{1}$.

\footnotetext{
${ }^{1}$ Adaptado do artigo "Elipses, sorrisos e sussuros" - Renato J. C. Valladares
} 


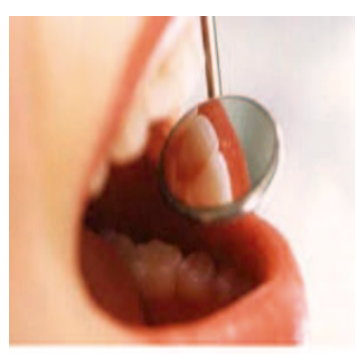

Figura 16.2: Luminária odontológica de espelho elíptico

Uma outra aplicação interessante da propriedade refletora da elipse está ligada à arquitetura e engenharia. Considere uma elipse girada ao redor de seu eixo maior para formar uma superfície de revolução conhecida como elipsóide. Então um sussuro emitido em um dos foco pode ser claramente ouvido a uma distância considerável, no outro foco, mesmo que seja inaudível em pontos intermediários, pois as ondas sonoras batem nas paredes e são refletidas dirigindo-se ao segundo foco, além de chegarem juntas, pois todas percorrem a mesma distância.

Estas construções conhecidas por "galerias de sussurros" estão presentes em certos museus americanos de Ciência e nos castelos de alguns monarcas europeus excêntricos. 


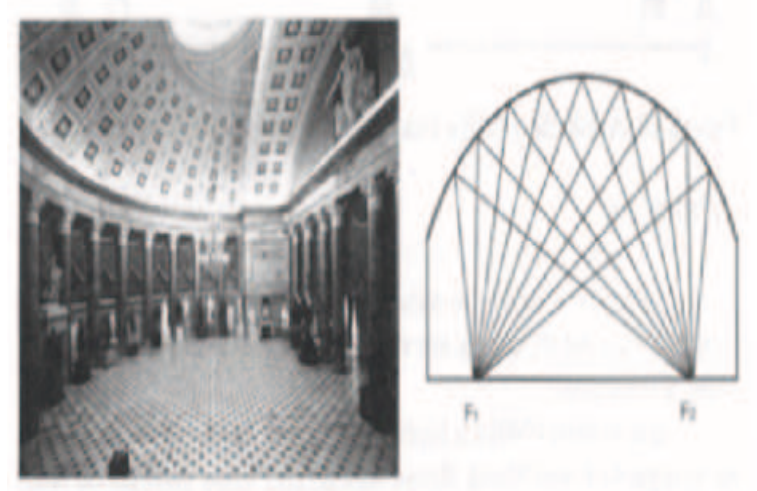

Figura 16.3: Galeria dos sussurros

Já pensou em uma mesa de bilhar perfeita? Não importa como você joga, se a bola for tacada de um foco ela vai acertar o buraco no outro foco. O formato dessa mesa deve ser elíptico!

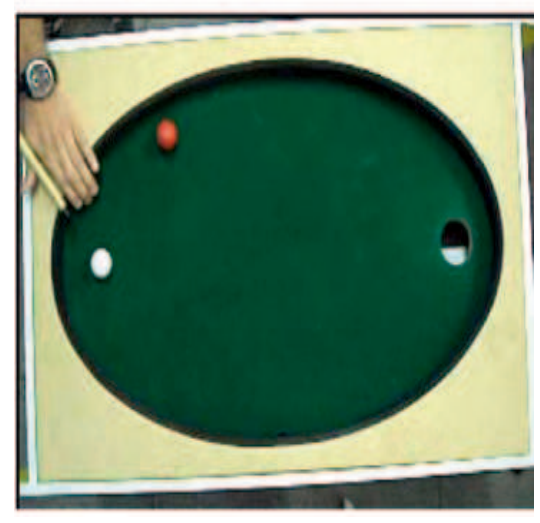

Figura 16.4: Mesa de bilhar elíptica: A sinuca perfeita!

\subsection{PROPRIEDADE REFLETORA DA HIPÉRBOLE}

A hipérbole é uma curva com dois ramos e dois focos. A propriedade de reflexão da hipérbole pode ser enunciada da seguinte maneira: A partir de um ponto qualquer 
tracemos um segmento de reta dirigido a um dos focos da hipérbole. Este segmento encontra o correspondente ramo da hipérbole em um ponto, e se a partir deste traçarmos outro segmento que faça com a curva um ângulo igual ao do primeiro segmento, o segundo segmento passa pelo outro foco.

Assim, segue o teorema:

Teorema: A reta tangente à hipérbole num ponto $P$ forma ângulos iguais com os segmentos que unem $P$ aos focos.

\section{DEMONSTRAÇÃO:}

Considere a hipérbole $H$ de focos $F_{1}$ e $F_{2}$ e eixo maior igual a $2 a$.

Sejam $P$ um ponto pertencente à hipérbole $H, F_{2}^{\prime}$ um ponto da reta $P F_{1}$ tal que $\overline{P F_{2}}=\overline{P F_{2}^{\prime}}, r$ a reta bissetriz do ângulo $F_{2} P F_{2}^{\prime}$ e $A$ um ponto qualquer da reta $r$ de tal forma que $A \neq P$.

Como $P \in H$, então:

$$
\left|d\left(P, F_{1}\right)-d\left(P, F_{2}\right)\right|=\left|d\left(P, F_{1}\right)-d\left(P, F_{2}^{\prime}\right)\right|=d\left(F_{1}, F_{2}^{\prime}\right)=2 a
$$

Pela desigualdade triangular em $\Delta A F_{1} F_{2}^{\prime}$, temos:

$d\left(A, F_{1}\right)+d\left(A, F_{2}^{\prime}\right)>d\left(F_{1}, F_{2}^{\prime}\right) \Rightarrow\left|d\left(P, F_{1}\right)-d\left(P, F_{2}^{\prime \prime}\right)\right|<d\left(F_{1}, F_{2}^{\prime \prime}\right)=2 a$

Logo $A$ não pertence à hipérbole.

Como $A$ é um ponto qualquer da reta $r$ e, por hipótese, $A \neq P$, então a reta $r$ só 
tem o ponto $P$ em comum com a hipérbole e, portanto $r$ é uma tangente à Cônica em $P$.

Considere, agora, os ângulos $\alpha$ entre a reta $r$ e $\overline{P F_{2}^{\prime}}, \beta$ entre $r$ e $P F_{2}$ e $\theta$ entre $r$ e o prolongamento de $P F_{2}$.

Assim, sendo $r$ a reta bissetriz do ângulo $F_{2} P F_{2}^{\prime}$ e $\beta$ e $\theta$ ângulos opostos pelo vértice, temos:

$$
\left\{\begin{array}{l}
\alpha=\beta \\
e \\
\beta=\theta
\end{array} \Rightarrow \alpha=\theta\right.
$$

c.q.d.

Esta propriedade faz com que a hipérbole tenha várias aplicações práticas. Um exemplo de uma aplicação óptica é o chamado telescópio de reflexão. É constituído basicamente por dois espelhos, um maior, chamado primário, que é parabólico, e outro menor, que é hiperbólico. Os dois espelhos dispõem-se de modo que os eixos da parábola e da hipérbole coincidam e que o foco da primeira coincida com um dos da segunda.

Quando os raios de luz se refletem no espelho hiperbólico pela propriedade de reflexão deste, seguem em direção ao outro foco da hipérbole. Os raios de luz passam através de um orifício no centro do espelho primário, atrás do qual está uma lenteocular que permite corrigir ligeiramente a trajetória da luz, que chega finalmente aos olhos do observador ou à película fotográfica. 


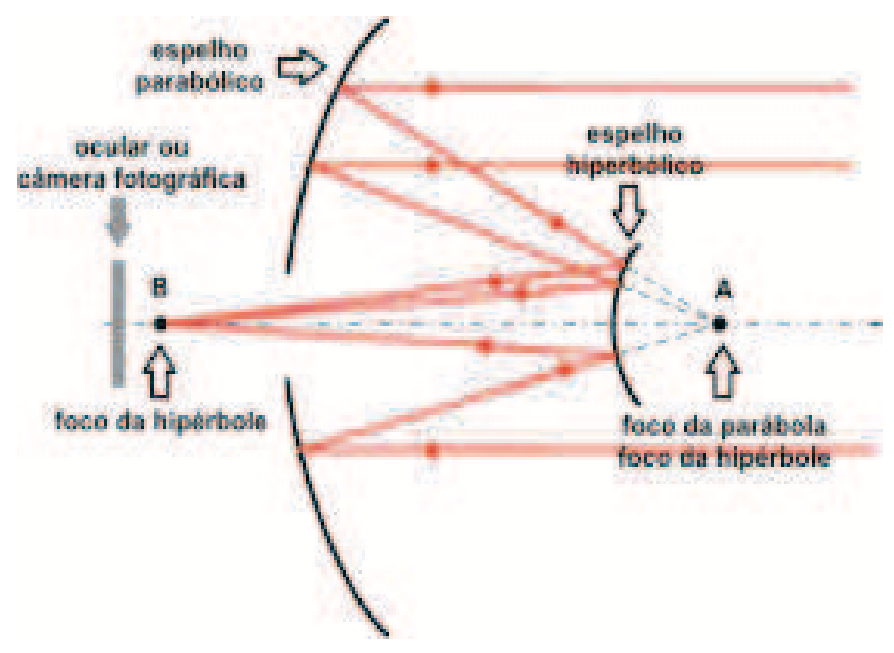

Figura 16.5: Telescópio de reflexão

\subsection{PROPRIEDADE REFLETORA DA PARÁBOLA - TE- OREMA DE PONCELET}

A utilização de objetos no cotidiano no formato de um parabolóide de revolução tais como antenas, radares e outros, é propositadamente. A simetria desses objetos com a incrível propriedade refletora da parábola são muito úteis, devido termos a necessidade em muitas vezes de amplificar esses sinais e otimizá-los.

Teorema: A reta $r$ tangente a um ponto $P$ sobre a parábola faz ângulos iguais com a reta que passa por $P$ e é paralela ao eixo de simetria e a reta que passa por $P$ e $F$.

\section{DEMONSTRAÇÃO:}

Tome $P$ um ponto qualquer da parábola de foco $F$ e diretriz $d$.

Considere, ainda, a reta $t$ bissetriz do ângulo conforme a figura. 
Devemos provar, primeiramente, que $P$ é o único ponto tangente à parábola.

No triângulo $\triangle P F D$, como $P$ é um ponto da parábola, podemos afirmar que: $\overline{P F}=\overline{P D}$.

Então, a reta $t$ é bissetriz do ângulo, além de ser mediana e altura desse triângulo. Sendo assim, $t$ é mediatriz do segmento $F D$.

Tome $Q$ como um ponto arbitrário de $t, \operatorname{com} Q \neq P$. Se $D^{\prime}$ é a projeção ortogonal de $Q$ sobre $d$, então, por desigualdade triangular, temos que:

$$
\overline{Q F}=\overline{Q D}>\overline{Q D^{\prime}}
$$

Como $Q$ é exterior à parábola, isto é, o ponto $P$ pertence à parábola e quaisquer outros pontos $Q$ são exteriores. Logo, a reta $t$ é tangente à parábola em $P$.

Prolongando-se o segmento $\overline{D P}$, obtém-se a semireta $\overline{P Y}$. deste modo, o ângulo formado pela semireta $P Y$ e a reta $t$ é congruente ao ângulo formado pelo segmento $\overline{P D}$ e $t^{2}$.

E, como $t$ é bissetriz do ângulo, então o ângulo formado pelo segmento $\overline{P F}$ e a reta $t$ é congruente ao ângulo formado pela semireta $P Y$ e $t$.

c.q.d.

Esta propriedade faz com que a parábola tenha várias aplicações práticas. Um exemplo são as conhecidas antenas parabólicas, que concentram num aparelho recep-

\footnotetext{
${ }^{2}$ Pois, se trata de ângulos O.P.V.
} 
tor os sinais vindos de um satélite de televisão. Neste sentido, todo sinal recebido na direção do eixo da parábola toma a direção do foco e vice-versa. Sendo assim, os sinais recebidos via satélites são muito fracos e é necessário captá-los em uma área relativamente grande e concentrá-los em um só ponto para que sejam amplificados.

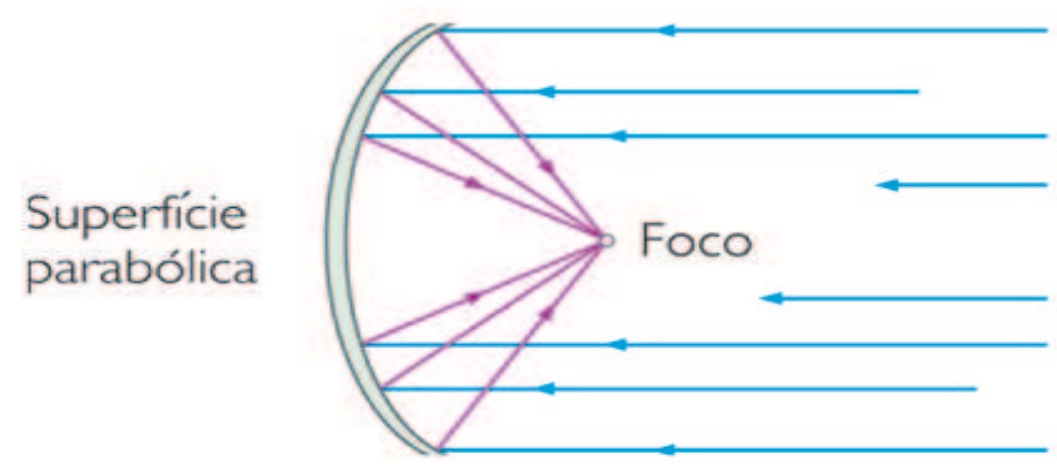

Figura 16.6: Estrutura de uma antena parabólica

Uma aplicação óptica são os faróis dos automóveis, estes são espelhados por dentro e coloca a lâmpada no foco. Sendo assim, os raios de luz que incidem na parte refletora são prolongados, em linha reta, de modo que haja maior alcance e eficiência da luminosidade. 

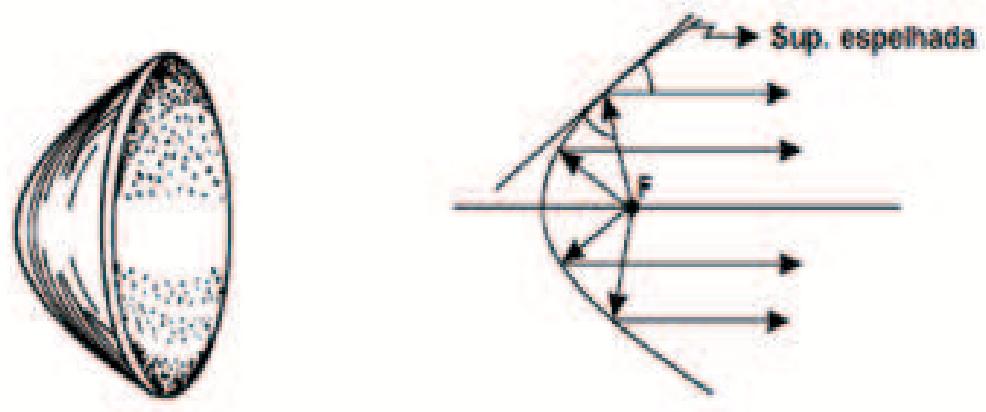

Figura 16.7: Estrutura de um farol de automóvel

Outro exemplo é o cabo de suspensão de uma ponte, quando o peso total é uniforme distribuído segundo o eixo horizontal da ponte, toma a forma de uma parábola.

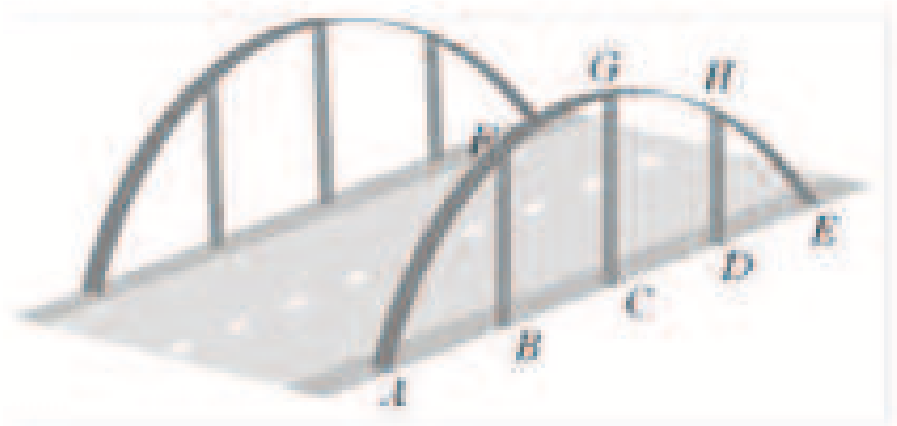

Figura 16.8: Ponte suspensa por estruturas metálicas formando um arco de parábola 


\section{Capítulo 17}

\section{OFICINA SOBRE CÔNICAS - Uma}

\section{proposta lúdica e construtivista}

"A principal meta da educação é criar homens que sejam capazes de fazer coisas novas, não simplesmente repetir o que outras gerações já fizeram. Homens que sejam criadores, inventores, descobridores. A segunda meta da educação é formar mentes que estejam em condições de criticar, verificar e não aceitar tudo que a elas se propõe." - Jean Piaget (1896-1980)

Os professores de Matemática da atualidade têm um grande desafio: ensinar e despertar o interesse estudantil em um mundo dominado pela alta tecnologia.

Ou seja, devemos ter a consciência que a presença das tecnologias trouxe nova dinâmica à maneira de se comunicar, se informar e, sobretudo, aprender.

Mas, de fato, nem todos os professores ensinam, orientam, trabalham 
da mesma maneira os conteúdos/habilidades matemáticas com seus alunos.

Cada profissional carrega consigo particularidades, metodologias e traços pessoais.

Algumas vezes é difícil para o docente encontrar recursos adequados à sua prática pedagógica, seja pela deficiência em formação ou pela estrutura disponível na escola em que trabalha.

Desta forma, no tocante à metodologia usada em sala de aula, quem acompanha o cotidiano escolar, professores, pais ou até mesmo os próprios alunos sabem que muitos dos professores seguem rotinas pedagógicas massantes, onde as aulas são apenas expositivas e não tratam o aluno como agente transformador do processo da aprendizagem.

Ou seja, há um processo de descrença da importância do conhecimento lúdico e criacionista. Negando que o conhecimento é concebido como construção ativa de um observador e não como reprodução meramente passiva.

Sendo assim, na tentativa de sair desse panorama, não podemos nos esquecer que o uso de recursos construtivistas, na tentativa de solucionar problemas, está presente no mundo matemático desde o início dos tempos.

Cabe ao professor deixar de ser um mero transmissor de conhecimentos para se posicionar como um mediador de diversas linguagens e opor- 
tunidades educativas. Contribuindo, sobretudo, para o desenvolvimento da autonomia perante o conhecimento, o que significa contribuir para a formação de cidadãos críticos e capazes de fazer uma leitura consciente das situações que os cercam.

As atividades propostas abaixo permitem a construção de seções cônicas (elipse, hipérbole e parábola) por meio do software GeoGebra, por meio de dobraduras em papel e, também, a construção de materiais concretos.

Desta forma, esta oficina terá como objetivo promover uma reflexão sobre o estudo das cônicas pelo uso de sua definição como lugar geométrico seguindo um enfoque analítico, lúdico e construtivista.

Ou seja, divulgaremos ferramentas que podem ser usadas em práticas pedagógicas que auxiliam na abordagem do assunto, uma vez que permitem a visualização dos traçados das referidas curvas, tornando o ensino da Matemática mais dinâmico, concreto e prazeroso. 


\section{OFICINA PROPOSTA:}

Tema: Diferentes aboradagens para a construção das cônicas não degeneradas (elipse, hipérbole e parábola).

\section{Módulos:}

- Parte teórica e analítica;

- Construção das cônicas com auxílio do software GeoGebra;

- Construção de cônicas por dobraduras - Método de Van Schooten;

- Construção de material concreto.

Tempo estimado para a duração: $8 h$

Tempo real de aplicação:

- $1^{\circ}$ dia: $3 h 40$.

- $2^{\circ}$ dia: $3 h 50$.

Número de alunos participantes: 20.

Local de excecução da oficina: Escola particular do Distrito Federal ${ }^{a}$

${ }^{a}$ Por motivos burocráticos, o nome da escola não pode ser revelado

O primeiro dia, deve ser reservado para se introduzir a base teórica e analítica, baseados em conceitos e definições propostas na primeira parte deste trabalho e sempre considerando as informações relavantes ao nível educacional do público alvo. 
Neste primeiro momento, deve ser iniciado com um breve histórico, uma motivação ao estudo, com a exposição dos aspectos interdisciplinares e que relacione as aplicações reais da teoria, além de todas as definições formais.

O segundo dia, destina-se à aula prática. Inicialmente, com o software Geogebra. Por meio deste método, torna-se possível visualizar e explorar diversas propriedades destas curvas facilitando a compreensão das definições e demonstrações que aparecem no tratamento analítico. Em seguida, será proposto um módulo que trará o método Van Schooten, com as dobraduras podemos perceber os aspectos geométricos e as propriedades refletoras das curvas. Por último, será proposta uma atividade de construção de material concreto, esta terá como objetivo a materialização das curvas.

\subsubsection{METODOLOGIA APLICADA NAS OFICINAS}

A metodologia das oficinas é baseada em explicações minuciosas e rigorosas para que, a partir delas, se consiga concretizar os conceitos que antes eram meramente abstratos.

O uso de métodos construtivistas, de modo que os discentes saiam um pouco da rotina do "quadro e giz" para passarem a utilizar outras fontes de estudos, renovam as suas expectativas sobre o conteúdo que deve ser assimilado.

As aplicações de oficinas teóricas juntamente com a prática, nas quais 
se enquadrem definições, exemplos, desenhos e resoluções de atividades e exercícios aplicados em sala de aula, como formas de explorar outros sentidos e o querer dos alunos, conduzem a um maior desempenho e a uma melhor e mais ampla visão dos e objetivos da Matemática.

Neste panorama, a inserção de mídias digitais e de construção de material concreto são incentivos à redescoberta da Matemática, pois permitem interação entre os alunos levando-os a sentirem prazer em aprender.

Contudo, as atividades de ensino que possuem caráter lúdico requerem cuidados essenciais para que as informações sejam totalmente compreendidas e não sejam vistas como um processo de mera descontração ou perda de tempo.

Diante disso, foram propostas atividades, realizadas em módulos, que buscam o aprimoramento do processo de ensino e, para tanto, seguem os seguintes pressupostos:

I. Articulação entre a teoria e a prática;

II. Realização de oficinas participativas e orientadas;

III. Exploração de recursos visuais;

IV. Estímulo a reflexão, por meio dinâmicas e questionamentos quanto ao conteúdo estudado;

V. Utilização de mídias digitais com intuíto de tormar o ensino dinâmico;

VI. Realização de atividade de construção de material concreto.

Vendo ser indispensável uma nova forma de motivar os alunos da 
Educação Básica a entenderem e usarem o conhecimento matemático de forma a inclui-lo no seu cotidiano, esperamos que os conhecimentos adquiridos no decorrer dessas oficinas sejam de suma importância para o melhor desenvolvimento e raciocínio lógico e cognitivo do aluno, desenvolvendo, assim, a principal função do estudo da Matemática: utilizar a teoria aprendida na resolução de problemas reais. 


\section{Capítulo 18}

\section{CONSTRUÇÃO DAS CÔNICAS POR MEIO DO SOFTWARE GEOGEBRA}

Borba (1999) afirma que, no contexto da Educação Matemática, os ambientes de aprendizagem gerados por aplicativos informáticos podem potencializar o processo de ensino-aprendizagem através da experimentação, com possibilidades de surgimento tanto de novos conceitos como de novas teorias a fim de torná-lo um aliado importante na construção do conhecimento.

A escolha do software GeoGebra deve-se ao fato deste possuir ferramentas fáceis de serem manipuladas, além de permitir uma abordagem tanto sobre os aspectos geométricos como algébricos dos diferentes objetos de construção envolvidos. 
O layout do software é constituído de uma janela inicial que se divide em uma área de trabalho localizado à direita e uma Janela de Álgebra à esquerda, além de um campo de Entrada (Input) que fica abaixo.

Para trabalhar com as cônicas utilizando apenas o mouse no software GeoGebra, deve-se acionar o sétimo botão da barra de ferramentas, conforme indica a figura abaixo:

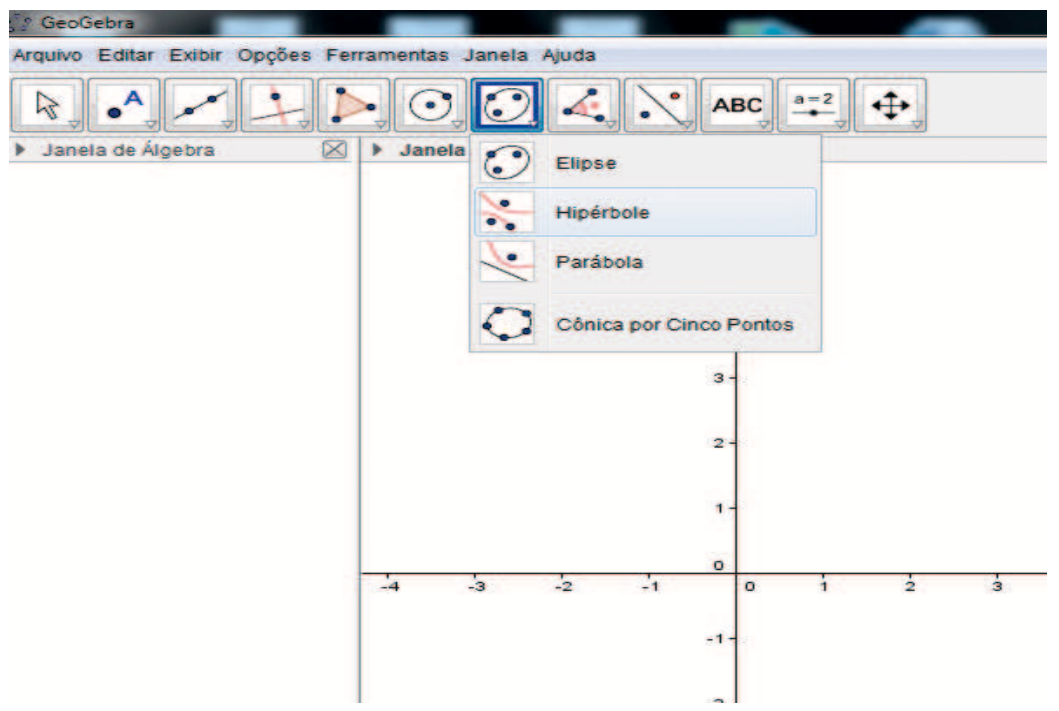

Figura 18.1: Layout do software

Vale ressaltar que o GeoGebra é um software gratuito e pode ser obtido facilmente em sites de busca ou nos endereço http:/ / www.geogebra.org/cms / 


\subsubsection{CONSTRUINDO ELIPSES}

Para construir elipses, no GeoGebra, utilizando o mouse, basta selecionar a ferramenta e clicar em três pontos distintos na Janela de Visualização. Uma vez que três pontos não colineares definem uma elipse.

Os dois primeiros pontos serão os focos e o terceiro será um ponto que ficará sobre a curva da elipse.

Podemos, também, construir elipses digitando comandos na Entrada (Input). Os comandos serão da forma:

- Elipse[(ponto), (ponto), (ponto) ]

- Elipse[ (foco), (foco), (Comprimento do semi eixo maior) ];

- Elipse[ (foco), (foco), (segmento) ] .

Ou, também, há a possibilidade de se escrever a sua equação canônica diretamente na entrada e em seguida teclar Enter.

\subsubsection{Atividade proposta:}

Representar geometricamente as cônicas dadas pelas equações:

a) $\frac{x^{2}}{9}+\frac{y^{2}}{4}=1$ 


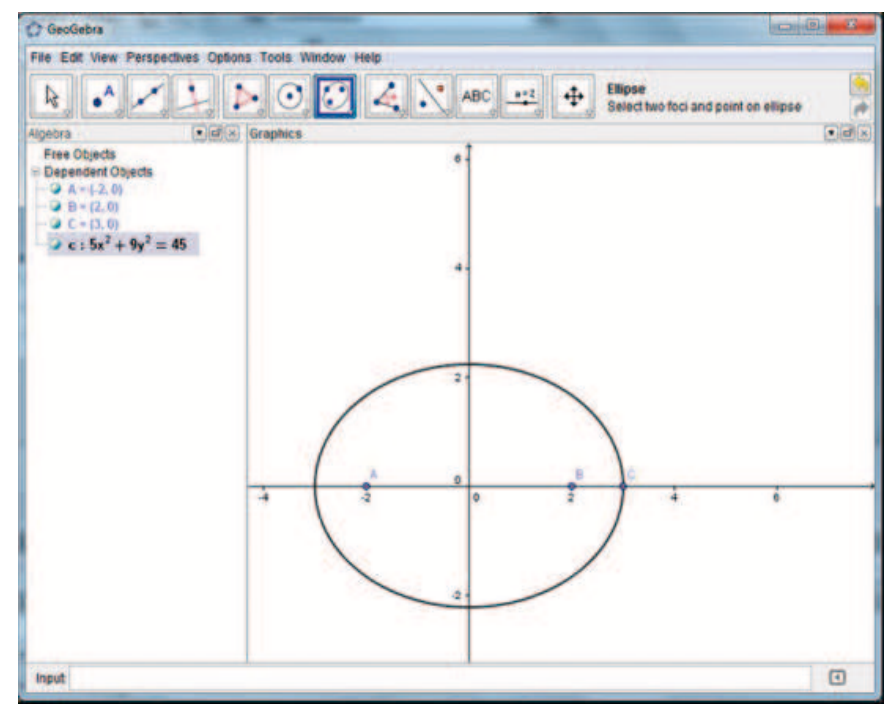

Figura 18.2: Elipse construída no GeoGebra

b) $\frac{(x+1)^{2}}{9}+\frac{(y-2)^{2}}{4}=1$

\section{Questionário a ser respondido:}

a) Você considera a utilização de softawares um instrumento facilitador da compreensão de conceitos matemáticos?

b) As construções das elipses foram claras para que pudesse ser entendida a definição da curva?

c) Houve entendimento do processo de translação dos focos? 


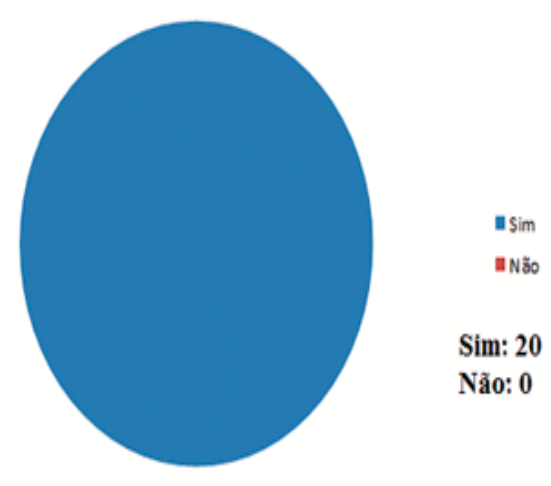

Figura 18.3: Gráfico mostrando a opinião dos alunos

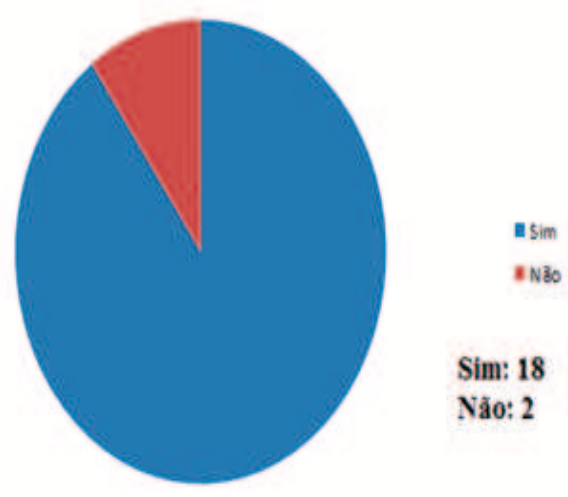

Figura 18.4: Gráfico mostrando a opinião dos alunos

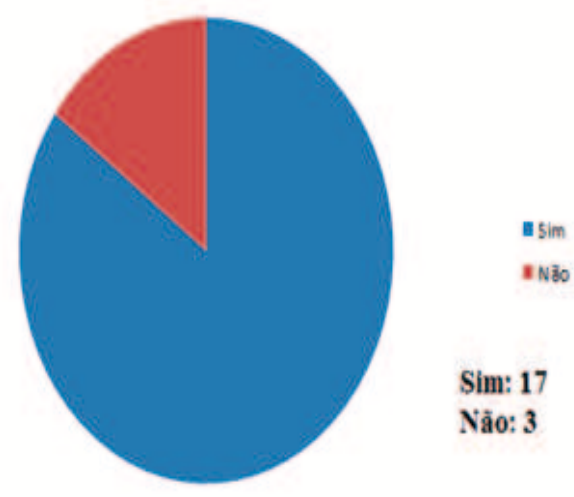

Figura 18.5: Gráfico mostrando a opinião dos alunos 


\subsubsection{CONSTRUINDO HIPÉRBOLES}

O procedimento para obter hipérboles, somente com a utilização do mouse, é semelhante ao usado para obter elipses. Com a ferramenta Hipérbole ativa, clicamos em três pontos distintos na Janela de Visualização.

Esses pontos podem ser construídos enquanto utiliza a ferramenta: os dois primeiros pontos serão os focos e o terceiro será um ponto pelo qual a hipérbole irá passar.

Para construir hipérboles por meio de comandos na Entrada, utilizamos uma das seguintes sintaxes com os devidos parâmetros.

- hiperbole[(ponto), (ponto), (ponto) ];

- hiperbole[ (foco), (foco) , (Comprimento do semi eixo maior) ];

- hiperbole[ (foco), (foco) , (segmento) ].

Ou, também, há a possibilidade de se escrever e sua equação canônica diretamente na entrada e em seguida teclar Enter. 


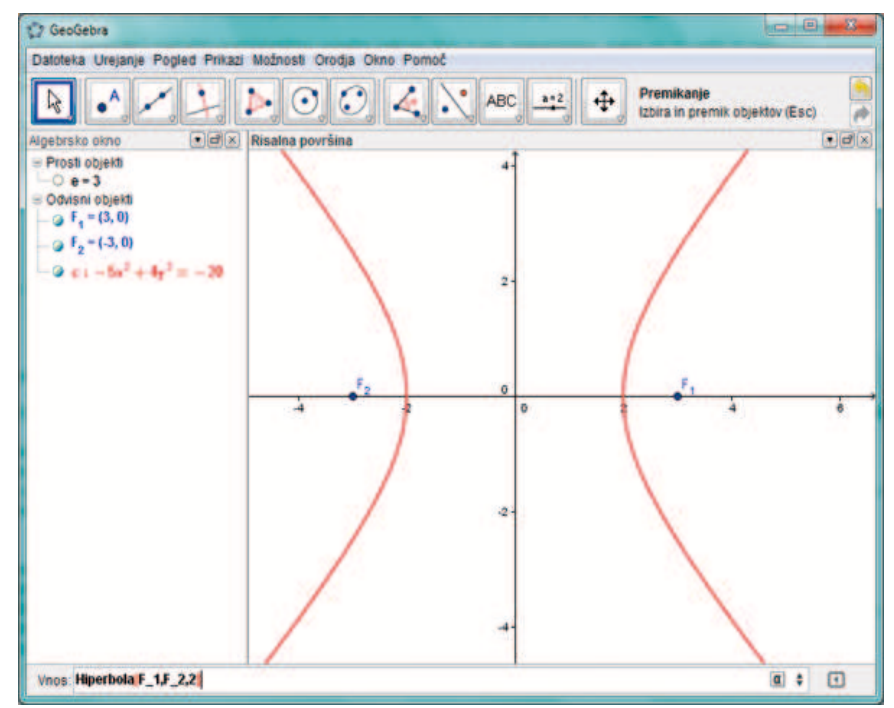

Figura 18.6: Hipérbole construída no GeoGebra

\subsubsection{Atividade proposta:}

Representar geometricamente as cônicas dadas pelas equações:

a) $\frac{x^{2}}{9}-\frac{y^{2}}{4}=1$

b) $\frac{(x+1)^{2}}{9}-\frac{(y-2)^{2}}{4}=1$

\section{Questionário a ser respondido:}

a) As construções das hipérboles foram claras para que pudessem ser entendida a definição da curva? 


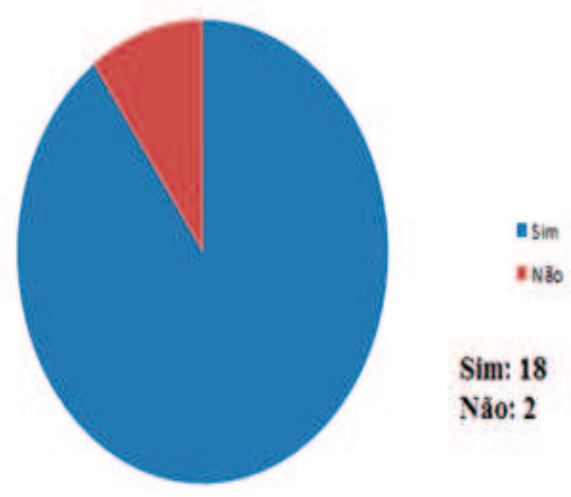

Figura 18.7: Gráfico mostrando a opinião dos alunos

b) Houve entendimento do processo de translação do centro da hipérbole?

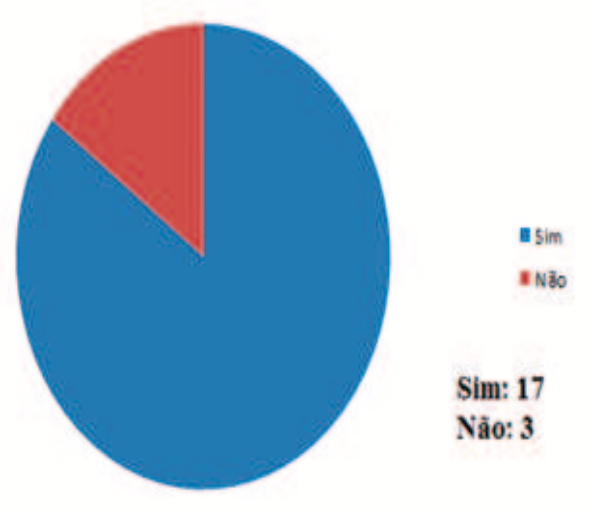

Figura 18.8: Gráfico mostrando a opinião dos alunos

\subsubsection{CONSTRUINDO PARÁBOLAS}

Para se construir parábolas com auxílio do software, devemos proceder da seguinte maneira: 
I. Abrir a tela do GeoGebra. Em seguida, realizar os procedimentos para a construção das parábolas, mostrando a relação que há entre os coeficientes $a, b$ e $c$ da função $f(x)=a x^{2}+b x+c$ e sua representação no plano cartesiano.

II. Digitar na Barra de Entrada a função $f(x)=a * x^{2}+b * x+c$ e clicar em Enter.

III. Para observar a relação do coeficiente $a$ com a curva, deve-se selecionar a ferramenta mover, em seguida, clicar sobre a bolinha dos valores de $a$ que aparece na tela principal sobre uma reta, e movê-la. Haverá uma alteração de valores, que poderá ser observada graficamente.

Para observar a relação que há entre o coeficiente $b$ e a curva, deve-se clicar sobre a bolinha dos valores de $b$ e movê-la.

Para observar a interferência do termo independente $c$, na função, deve se clicar sobre a bolinha dos valores de $c$ e movê-la.

\subsubsection{Atividade proposta:}

Representar geometricamente as cônicas dadas pelas equações:

a) $y^{2}-5 x=0$

b) $(y-2)^{2}-5(x-1)=0$ 


\section{Questionário a ser respondido:}

a) As construções das parábolas foram claras para que pudessem ser entendida a definição da curva?

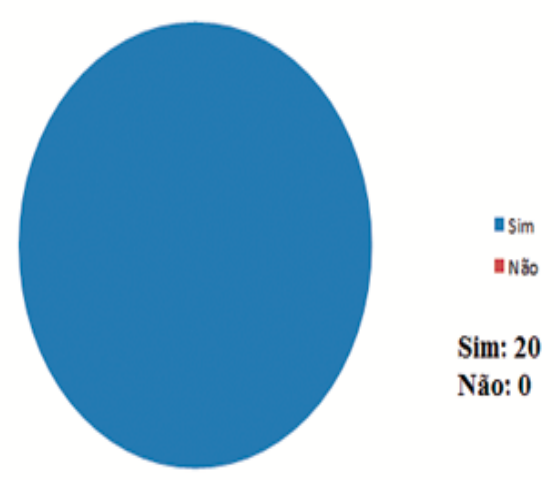

Figura 18.9: Gráfico mostrando a opinião dos alunos

b) Houve entendimento do significado de foco e diretriz da parábola?

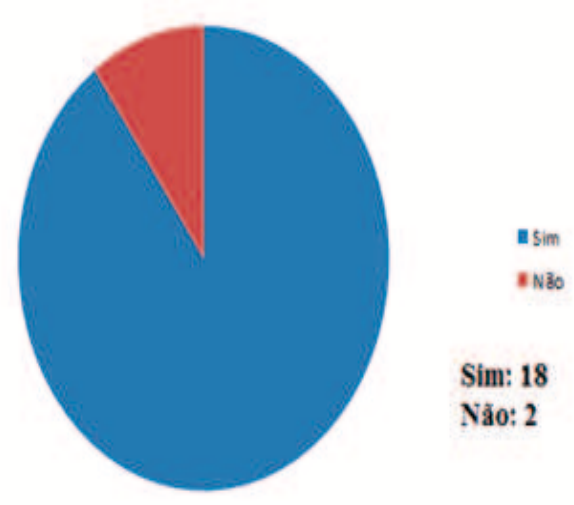

Figura 18.10: Gráfico mostrando a opinião dos alunos 


\subsubsection{CONSIDERAÇÕES FINAIS SOBRE A APLICAÇÃO DESTE MÓDULO DA OFICINA}

Como pôde ser visto, por meio das perguntas avaliativas, a aplicação deste módulo da oficina, de modo geral, teve grande valia para os alunos, uma vez que com a utlização do software em questão conseguimos uma visualização imediata das curvas estudadas e do processo de translação dos focos. Ou seja, uma das grandes vantagens em se trabalhar com o GeoGebra é o pensamento visual facilitando a compreensão dos conceitos que, outrora, seriam de difícil percepção sem esse recurso, tornando-se, assim, um grande aliado do professor. 


\section{Capítulo 19}

\section{CONSTRUÇÃO DAS CÔNICAS POR DOBRADURAS: MÉTODO DE VAN SCHOOTEN}

Em 1657, Van Schooten publicou a obra intitulada Exercitationum mathematicarum libri quinque (Os cinco livros de exercícios matemáticos), em que o mais famoso dentre os cinco manuscritos é dedicado à descrição de diferentes instrumentos para traçar cônicas, além de métodos para se conseguir cônicas por dobraduras de papel.

Baseado nesse modelo, reproduziremos algumas das atividades propostas: 


\subsubsection{CONSTRUÇÃO DA ELIPSE POR DOBRADURAS}

\section{Material:}

Papel manteiga, tesoura e compasso.

\section{Procedimentos:}

Marque um ponto $C$ no centro da folha de papel.

Com o auxílio do compasso, desenhe uma circunferência. (Garanta que esta circunferência tenha um raio de pelo menos $16 \mathrm{~cm}$ para se ter uma boa visualização ao final).

Em seguida, recorte a circunferência que foi desenhada, marcando um ponto $F$ qualquer na parte interna da circunferência.

Escolha um ponto $D$ sobre a circunferência e dobre o círculo de tal maneira que o ponto $D$ coincida com o pontos $F$, como mostra a figura ao lado. Tenha certeza de que a dobra seja bem marcada no papel e, então, desdobre o papel.

Repita esse procedimento várias vezes conforme a figura. 


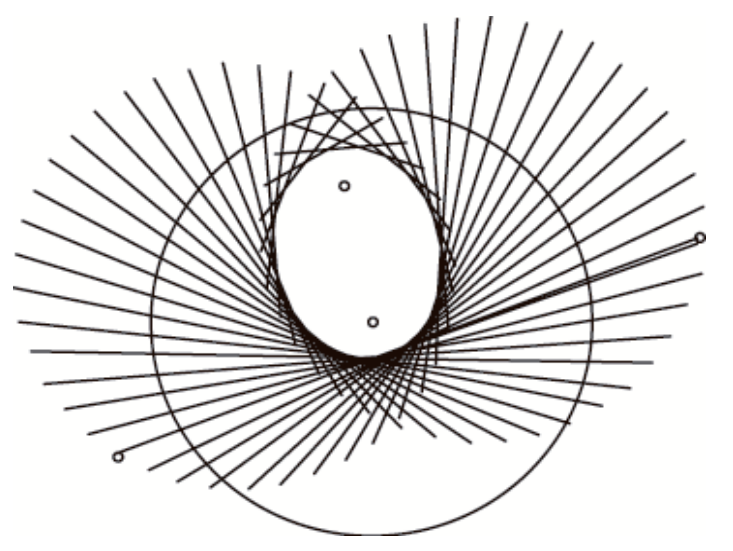

Figura 19.1: Traços da elipse em dobraduras

Após a realização desse algoritmo, fica fácil concluir que a dobra assim obtida é a mediatriz do segmento de reta determinado pelos pontos $F$ e $D$, como a figura ao lado ilustra.

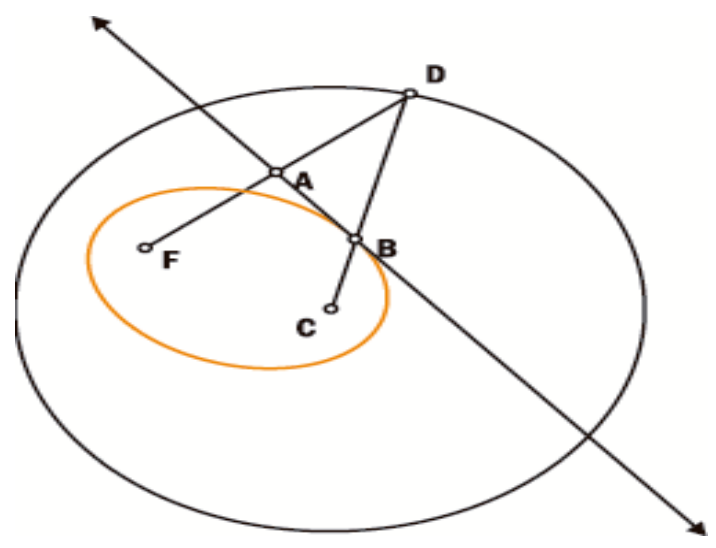

Figura 19.2: Mediatriz da elipse

Como a reta $r$ é a mediatriz do segmento de reta $\overline{F D}$, os triângulos $\triangle F B A$ e $\triangle D A B$ são congruentes.

Pois, de fato, estes triângulos são retângulos em $A$ e têm o lado comum 
$\overline{B A}$ e, além disso, $\overline{F A}=\overline{A D}$.

Contudo, para realmente provarmos que a curva construída é uma elipse, precisamos mostrar que a soma de $\overline{C B}+\overline{B F}=K$, uma constante real.

De fato, como os triângulos $\triangle F B A$ e $\triangle D A B$ são congruentes, temos que $\overline{B F}=\overline{B D}$.

Assim, $\overline{C B}+\overline{B F}=\overline{C B}+\overline{B D}=\overline{C D}$ o que prova que $B$ está sobre uma elipse de focos em $C$ e $F$, pois $\overline{C D}$ é o raio da circunferência que é constante, qualquer que seja o ponto $D$ da circunferência, o que demonstra que a curva obtida, realmente, é uma elipse.

\subsubsection{CONSTRUÇÃO DA HIPÉRBOLE POR DOBRADU- RAS}

\section{Material:}

Papel manteiga, lápis, tesoura e compasso.

\section{Procedimentos:}

Construa uma circunferência no pedaço de papel manteiga. 
Sem seguida, marque um ponto $F$ no seu exterior deste círculo.

Dobre o papel diversas vezes de tal modo que o ponto $F$ sempre coincida com pontos sobre a borda do círculo.

Após dobrar o papel um grande número de vezes, as dobras devem ter definido no papel uma curva com o aspecto mostrado na figura abaixo.

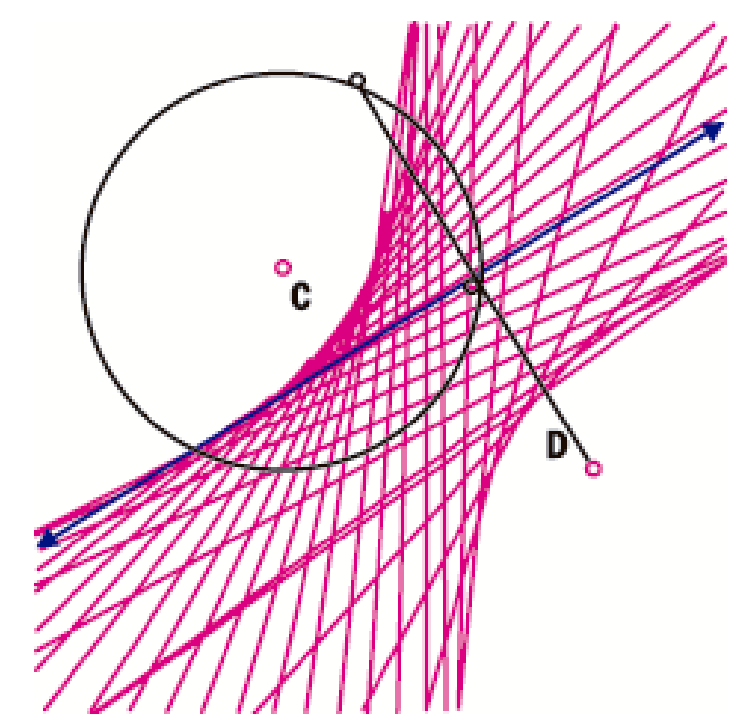

Figura 19.3: Traços da hipérbole em dobradura

A figura apresenta um aspecto parecido com o de uma hipérbole.

Contudo, deveremos provar que realmente esta forma caracteriza a curva em questão.

De fato, cada marca foi obtida dobrando-se o papel de forma a fazer o ponto $D$ coincidir com o ponto $F$. 
Exatamente como no caso da elipse, é fácil concluir que a dobra assim obtida é a mediatriz do segmento de reta determinado pelos pontos $F$ e $D$, conforme a figura abaixo:

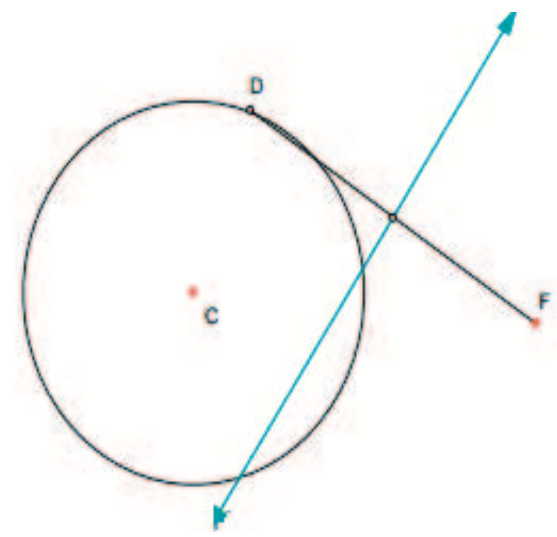

Figura 19.4: Mediatriz da hipérbole

É preciso demonstrar que quando $D$ percorre a circunferência, o ponto $B$ de tangência, determinado pela interseção da dobra com o raio $C D$, traça realmente uma hipérbole com focos nos pontos $C$ e $F$.

A figura abaixo nos ajudará nesta tarefa. Usaremos, também, a definição geométrica de hipérbole.

Como a reta $\overline{B A}$ é a mediatriz do segmento de reta $\overline{F D}$, os triângulos $\triangle F B A$ e $\triangle D A B$ são congruentes.

Para provar que a curva traçada é de fato é uma hipérbole, precisamos mostrar que a diferença $\overline{B F B C}=K$, uma constante real. 


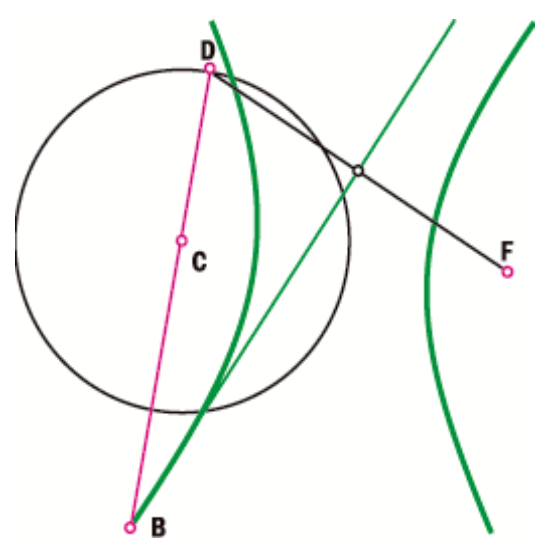

Figura 19.5: Figura de apoio para confirmação que a curva obtida é uma hipérbole

De fato, como $\overline{B F}=\overline{B D}$, pois os triângulos $\triangle F B A$ e $\triangle D A B$ são congruentes.

Assim, $\overline{B F}-\overline{B C}=\overline{B D}-\overline{B C}=\overline{C D}$ o que prova que $B$ está sobre uma hipérbole de focos em $C$ e $F$, pois $\overline{C D}$ é o raio da circunferência que é constante, qualquer que seja o ponto $D$ da circunferência.

Além disso, para outro ponto qualquer $T$, sobre a dobra $\overline{R S}$ temos que:

$$
\overline{T F}-\overline{T C}=\overline{T D}-\overline{T C}<\overline{C D}
$$

Pois o lado $\overline{C D}$ do triângulo $\triangle C T D$ é maior do que a diferença dos outros dois. Assim, $T$ não está na hipérbole. 


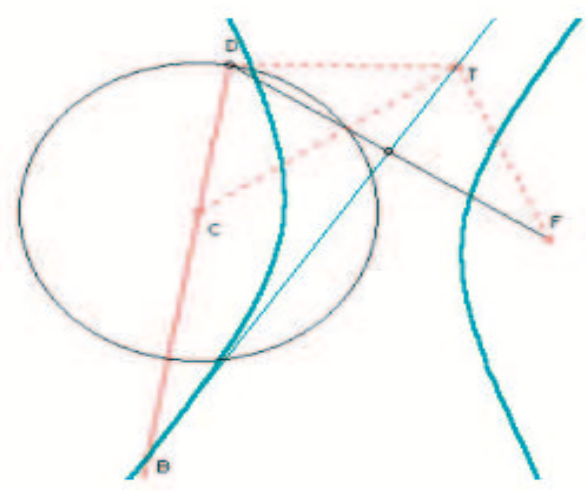

Figura 19.6: Comprovação geométrica que a figura construída é uma hipérbole

\subsubsection{CONSTRUINDO PARÁBOLA POR DOBRADURAS}

\section{Material:}

Papel manteiga, lápis e régua.

\section{Procedimentos:}

Passo 1: Desenhe uma reta, horizontalmente, numa folha de papel e marque, fora dessa reta, um ponto fixo $F$.

Passo 2: Selecione um ponto $D$ sobre a reta, e dobre o papel de forma a fazer coincidir os pontos $D$ e $F$. Trace sobre o papel a reta que coincide com a dobra. A figura abaixo, ilustra a construção de uma dobra.

Passo 3: Repita essa operação para diferentes escolhas do ponto $D$. 


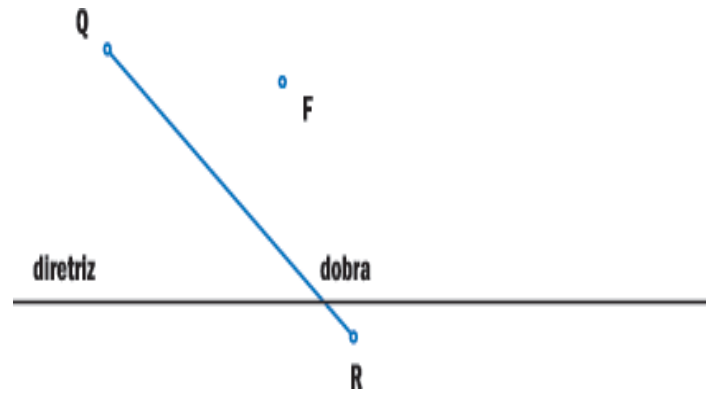

Figura 19.7: Dobradura parábola

Quando você a tiver realizado esta operação um número suficiente de vezes, poderá observar que as dobras parecem tangenciar uma curva. Esta curva parece uma parábola.

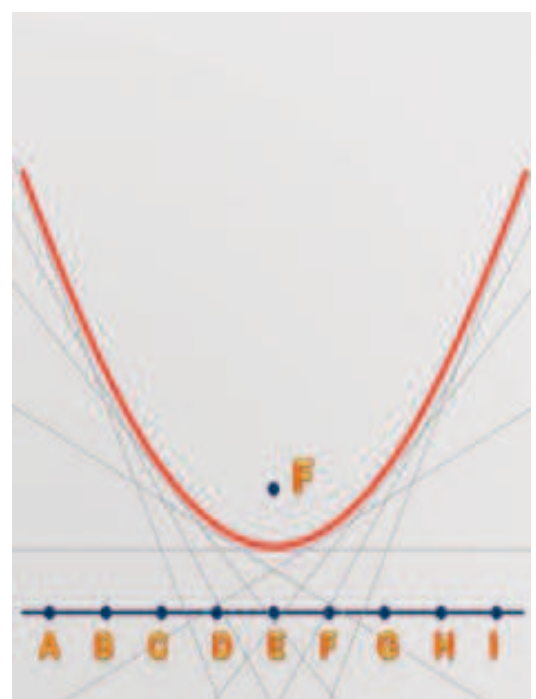

Figura 19.8: Figura de apoio na construção de parábolas por dobradura 
Nosso experimento dobrando papel ilustra uma outra propriedade importante das parábolas. A reta formada por cada uma das dobras é tangente à parábola. Como a reta $\overline{R Q}$ foi obtida superpondo-se o ponto $D$ sobre o ponto $F$, os ângulos $\widehat{F P R}$ e $\widehat{D P R}$ são congruentes. Os ângulos $\widehat{D P R} \mathrm{e}$ $\widehat{E P Q}$ são opostos pelo vértice e, portanto, também são congruentes.

Dessa maneira, concluímos que os ângulos $\widehat{E P R}$ e $\widehat{F P Q}$ têm a mesma medida.

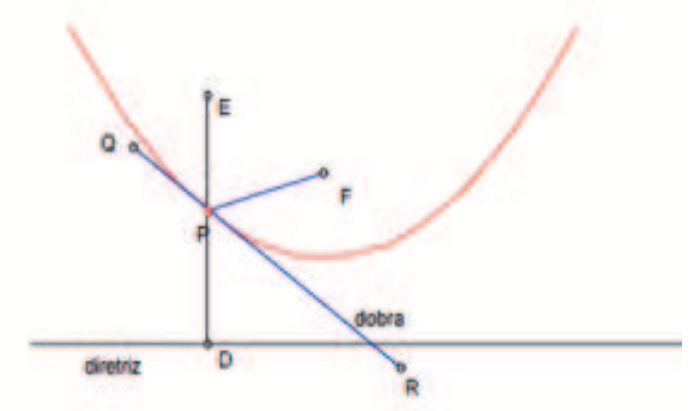

Figura 19.9: Figura de apoio reta tangente à parabola 


\section{Questionário a ser respondido:}

a) Você considera o método de dobraduras um bom instrumento complementar para melhoria da compreensão do que foi estudado algebricamente?

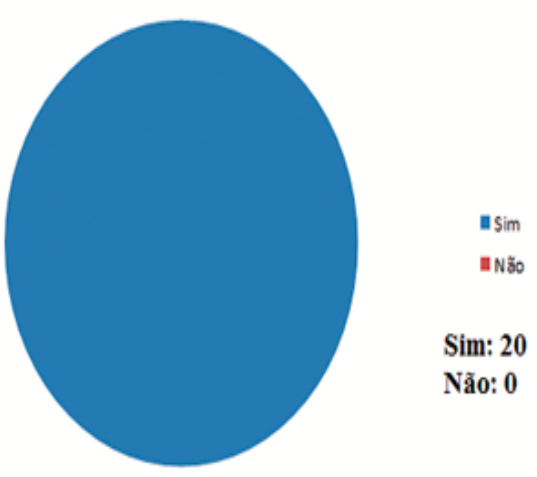

Figura 19.10: Gráfico mostrando a opinião dos alunos

b) A prática deste módulo da oficina trouxe algum acréscimo de entendimento sobre o conteúdo?

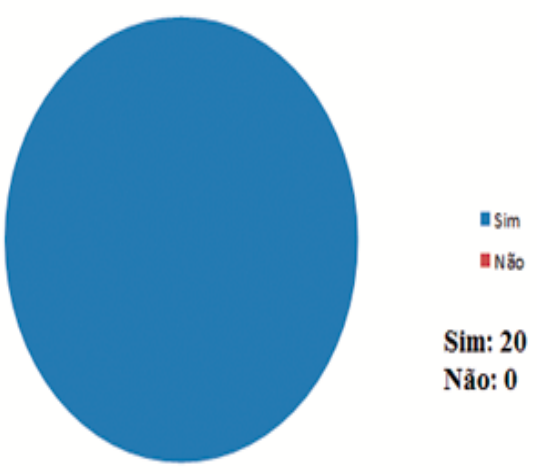

Figura 19.11: Gráfico mostrando a opinião dos alunos 
c) Houve o entendimento das propriedades focais das curvas cônicas?

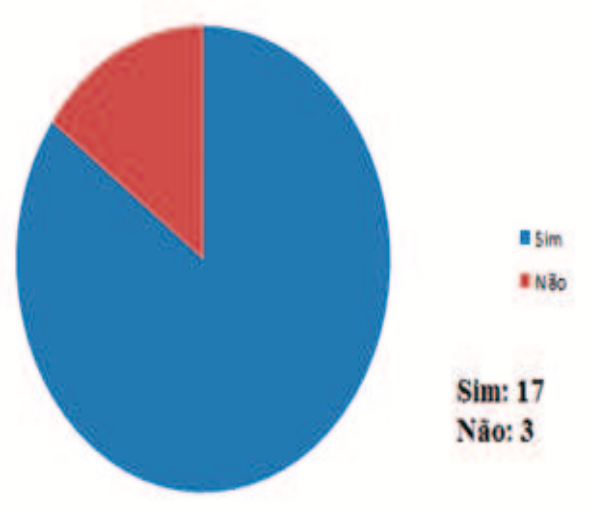

Figura 19.12: Gráfico mostrando a opinião dos alunos

\subsubsection{CONSIDERAÇÕES FINAIS SOBRE A APLICAÇÃO DESTE MÓDULO DA OFICINA}

Segundo Piaget, todo conhecimento é ligado à ação de conhecer um objeto ou evento e assimilá-lo a um esquema de utilidade prática. Isto é verdade do mais elementar nível sensório motor ao mais elevado nível de operações lógico-matemáticas.

O processo de obtenção das cônicas, utilizando o método das dobraduras proposto por Van Schooten, consiste, basicamente, em obter a caracterização dessas curvas por meio das suas propriedades focais e, sobretudo, pelos pressupostos de tangência.

O ensino de geometria deve ser baseado no processo de realização do fenômeno percebido anteriormente, nas formas e na extensão gradual dos possíveis pontos de vista do mundo que nos circula. Deve-se valorizar a 
experimentação e a habilidade de se visualizar o ponto, a linha reta, o plano e as relações entre eles. Dobraduras de papel (origami) provaram ser um ambiente excepcional para o trabalho com alunos neste respeito. 


\section{Capítulo 20}

\section{CONSTRUÇÃO DE MATERIAL CONCRETO}

O trabalho em sala de aula, com a utilização do material concreto, influência na aprendizagem dos alunos desde a educação infantil até final da educação Básica, favorecendo o desenvolvimento do raciocínio lógico, rapidez no pensamento dedutivo, socialização, organização do pensamento e concentração que é necessária para compreensão e resolução de problemas matemáticos e do cotidiano.

No entanto, é preciso que esse trabalho seja executado de forma dirigida para que o educando possa, realmente, alcançar o conhecimento desejado.

Dessa forma, cabe ao educador perceber a necessidade de se utilizar a metodologia de construção de materiais concretos para que a aula possa ser mais dinâmica, além de, sempre, conciliar teoria e prática para instigar 
os alunos a participarem da aula, exporem suas opiniões e interagirem nos grupos.

\subsubsection{CONSTRUINDO UMA ELIPSE COM LÁPIS, PA- PEL, BARBANTE E PERCEVEJOS}

\section{Material:}

Lápis, meia cartolina, percevejos(tachinhas de metal), isopor, cola e barbante.

\section{Procedimentos:}

No primeiro momento, será retomada a definição formal de elipse como um lugar geométrico, além dos seus principais elementos característicos.

Sendo assim:

Uma elipse $\epsilon$ de focos $F_{1}$ e $F_{2}$ é o conjunto de todos os pontos $P$ do plano cuja soma nas distâncias $F_{1}$ e $F_{2}$ é igual a uma constante $2 a>0$, onde 2 a é maior do que a distância entre os focos $2 c>0$.

Ou seja, sendo $0<c<a$ e $d\left(F_{1}, F_{2}\right)=2 a$,

$$
\epsilon=\left\{P \mid d\left(P, F_{1}\right)+d\left(P, F_{2}\right)=2 a\right\}
$$

Para a construção da elipse, devemos prosseguir da seguinte maneira: 
Passo 1 - Cole a cartolina na placa de isopor;

Passo 2 - Defina quem são os focos da elipse;

Passo 3 Fixe, com as tachinhas de metal, o barbante nesses dois pontos deixando uma folga no barbante (pois, essa folga que nos deixará traçar a elipse);

Passo 4 - Encoste o lápis no barbante e faça-o deslizar pelo barbante, mantendo o barbante esticado.

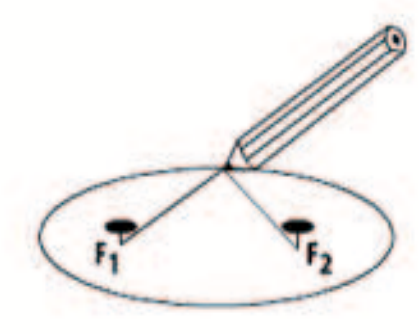

Figura 20.1: Método de construção da elipse

\section{SIMETRIAS NA ELIPSE:}

Com o uso apenas da definição geométrica, é fácil verificar que a elipse é simétrica em relação à reta que passa pelos focos.

Sendo assim, devemos demonstrar que se $P$ é um ponto qualquer pertencente à elipse, sua imagem espelhada $P_{1}$ em relação à reta que passa por $F_{1}$ e $F_{2}$ também será um ponto pertencente à elipse. 


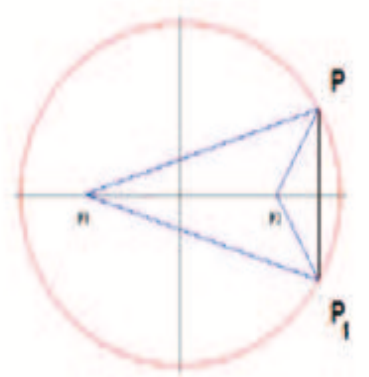

Figura 20.2: Simetria na elipse

Nesta oficina, podemos verificar experimentalmente, ao dobrarmos a elipse sobre a reta suporte que passa pelos focos.

Verificando, assim, que existe uma imagem espelhada de $P$ pertencente à elipse.

\subsubsection{CONSTRUINDO UMA HIPÉRBOLE COM PAPEL E BARBANTE:}

Material: Papel manteiga, tesoura, lápis e régua.

\section{Procedimentos:}

No primeiro momento, será retomada a definição formal de hipérbole como um lugar geométrico, além dos seus principais elementos característicos. 
Definição: Uma hipérbole $H$ de focos $F_{1}$ e $F_{2}$ é o conjunto de todos os pontos do plano para os quais o módulo da diferença de suas distâncias $F_{1}$ e $F_{2}$ é igual a uma constante $2 a>0$, onde 2 a é menor do que a distância entre os focos $2 c>0$.

$$
H=\left\{P /\left|d\left(P, F_{1}\right)-d\left(P, F_{2}\right)\right|=2 a\right\}
$$

Onde: $0<a<c$ e $\left.d_{(} F_{1}, F_{2}\right)=2 c$

Sendo assim, para a construção da hipérbole devemos prosseguir da seguinte maneira:

Passo 1: Marque o ponto $O$ no centro da meia cartolina;

Passo 2: Trace a reta $r$ passando pelo ponto $O$ e paralela à borda maior da meia cartolina;

Passo 3: Marque os pontos $F_{1}$, do lado direito do ponto $O$, e $F_{2}$, do lado esquerdo do ponto $O$, pertencentes à reta $r$ e distantes 5 centímetros do ponto $O$;

Passo 4: Marque os pontos $A_{1}$ do lado direito do ponto $O$, e $A_{2}$ do lado esquerdo do ponto $O$, pertencentes à reta $r$ e distantes 4 centímetros do ponto $O$;

Passo 5: Recorte dois pedaços de barbante de tamanhos $10 \mathrm{~cm}$ e dois pedaços de tamanho $2 \mathrm{~cm}$. 
Passo 6: Coloque uma ponta do pedaço de barbante de tamanho $10 \mathrm{~cm}$ sobre $F_{1}$ e uma ponta do pedaço de tamanho $2 \mathrm{~cm}$ sobre $F_{2}$. Agora, encontre um ponto na metade de cima da cartolina onde a outra ponta de cada um dos barbantes se encontra. Marque o ponto.

Passo 7: Repita o $6^{\circ}$ passo com os outros pedaços de barbante de tamanho $10 \mathrm{~cm}$ e $2 \mathrm{~cm}$ e marque o ponto onde as pontas se encontram na metade de baixo da cartolina.

Passo 8: Passe a cola nos pedaços de barbante de cola e cole-os na posição encontrada para marcar os pontos de acordo com o $6^{\circ}$ passo e com o $7^{\circ}$ passo.

Passo 9: Repita do quinto ao oitavo passo usando pares de pedaços de barbantes, todos com $8 \mathrm{~cm}$ de diferença do pedaço maior para o pedaço menor, por exemplo pedaços de tamanhos $12 \mathrm{~cm} \mathrm{e} 4 \mathrm{~cm}, 14 \mathrm{~cm} \mathrm{e} 6 \mathrm{~cm}, 17 \mathrm{~cm}$ e $9 \mathrm{~cm}, 20 \mathrm{~cm}$ e $12 \mathrm{~cm}, 24 \mathrm{~cm}$ e $16 \mathrm{~cm}$.

Passo 10: Trace uma curva que passe pelos pontos onde as pontas de barbante se encontram e pelo ponto $A_{1}$.

Passo 11: Tente traçar uma curva simétrica à curva traçada no $10^{\circ}$ passo que passa por $A_{2}$.

Resultado: 


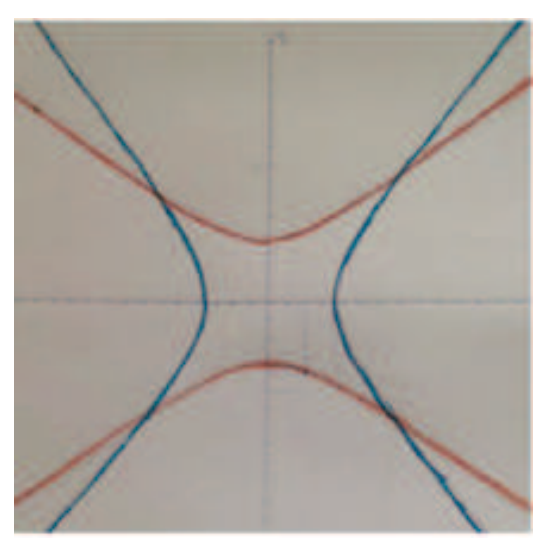

Figura 20.3: Resultado da construção da hipérbole com barbantes

\subsubsection{CONSTRUINDO PARÁBOLA COM LÁPIS, RÉGUA E BARBANTE - MÉTODO DE KEPLER}

\section{Material utilizado:}

Régua, lápis, esquadro, barbante e régua T.

\section{Procedimentos:}

No primeiro momento, será apresentada a definição formal de parábola como um lugar geométrico, além dos seus principais elementos característicos.

Definição: Sejam $l$ uma reta e $F$ um ponto do plano não pertencente a $l$. A parábola $P$ de foco $F$ e diretriz $l$ é o conjunto de todos os pontos do plano cuja distância a $F$ é igual a distância a $l$. Ou seja:

$$
P=\{P / d(P, F)=d(P, l)\}
$$

Passo 1: Trace uma reta no plano e um ponto não pertencente a essa 
reta.

Passo 2: Prenda a extremidade o fio no ponto marcado e com a ponta do pincel mantenha o fio sempre esticado e apoiado na lateral da régua $\mathrm{T}$.

Passo 3: Movimente a régua puxando-a para direita mantendo o fio sempre esticado e junto apoiado na lateral da mesma.

Passo 4: Movimente a régua para a esquerda.

Os pontos da curva obtida pertencem a uma parábola, pois todo ponto $P$ sobre a curva é equidistante do ponto $F$ e da reta $r$, uma vez que o fio tem comprimento igual a distância que vai de $A$ até a extremidade da régua T.

A reta fixada será chamada de diretriz da parábola e o ponto fixado será chamado de foco.

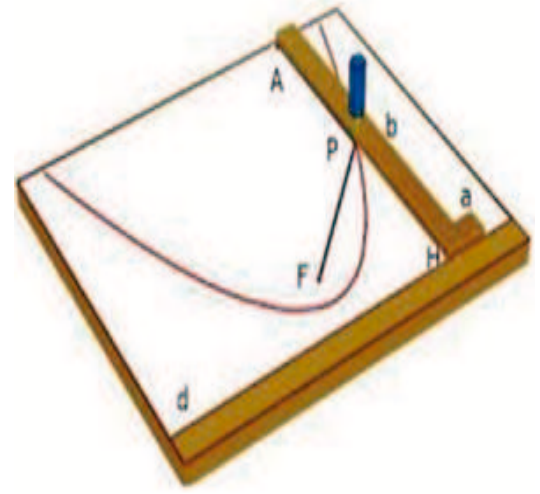

Figura 20.4: Resultado da construção da parábola 


\subsubsection{CONSIDERAÇÕES FINAIS SOBRE A APLICAÇÃO DESTE MÓDULO DA OFICINA}

O avanço das discussões sobre o papel e a natureza da educação e o desenvolvimento da psicologia, ocorridos no seio das transformações sociais e políticas, contribuíram historicamente para que as teorias pedagógicas que justificam o uso na sala de aula de materiais "concretos" ou jogos fossem, ao longo dos anos, sofrendo modificações e tomando feições diversas.

Contudo, no bojo da nova concepção de educação e de homem que surgem, primeiramente, as propostas de Pestalozzi (1746-1827), considerado um pioneiro na ideia de "escola-ativa".

Nesta escola, o manuseio de materiais concretos permite aos alunos experiências físicas que se dão ora em contado direto com os materiais, ora realizando medições, descrevendo ou comparando com outros de mesma natureza.

Com base nesta perspectiva, acreditamos que a construção de materiais concretos vem ao encontro dos anseios dos professores e dos alunos que buscam meios alternativos de trabalhar em sala de aula. Por óbvio, este método deve ser encarado com uma complementação de um ensino formal. 


\section{Capítulo 21}

\section{CONSIDERAÇÕES FINAIS}

"Ensinar é um exercício de imortalidade. De alguma forma continuamos a viver naqueles cujos olhos aprenderam a ver o mundo pela magia da nossa palavra. O professor, assim, não morre jamais". - Rubem Alves.

Assim como em todas as áreas da vida, a motivação é essencial para a concretização de ações. A escola, mais que uma obrigação social, deve ser um lugar gerador de sonhos, onde o indivíduo deve se sentir feliz por estar na condição de eterno aprendiz.

Contudo, não podemos nos esquecer que os alunos não são todos iguais. São pessoas singulares, que reagirão distintamente aos objetivos estabelecidos, aos conteúdos e, principalmente, à maneira como o professor se relaciona com a turma.

O educador deve se conscientizar que o aluno é formado através das 
experiências que são por ele vivenciadas. O desenvolvimento do aluno tem uma forte ligação com o ambiente em que vive, com sua relação cultural, suas limitações físicas, biológicas e intelectuais e, principalmente, a maneira como se relaciona com a família, portanto, para cada indivíduo o conteúdo será assimilado de uma maneira.

O docente deve estar atento às características individuais de seus educandos, de maneira que possa melhor planejar as aulas, a fim de atingir o maior número possível de alunos e alcançar sucesso em seus objetivos.

Desta forma, cabe ao orientador estar munido de vários artifícios para poder transmitir com eficiência o conteúdo desejado.

Docentes capacitados, estimulados e que valorizam a diversidade dos seus alunos levam a uma aprendizagem mais significativa e duradoura, capaz de provocar mudanças extraordinariamente irreversíveis em cada um deles.

Vale lembrar que não se deve privilegiar somente a cultura do acerto. Esta conduta que é, muitas vezes, acentuada em sala de aula, acaba por não reconhecer o erro como elemento importante na construção do conhecimento. Nessa concepção, o erro é tido como um vírus a ser eliminado e, desse modo, é sempre indesejável: o aluno se sente constrangido ao errar.

Quase nunca nos damos a oportunidade de refletir sobre o erro. Isso acarreta diálogos cada vez mais precários entre o professor e o aluno e, por 
extensão, entre a escola e a família.

Sendo assim, o processo de aprendizagem não deve estar focado apenas no produto a ser obtido, mas considerar todas as fases de desenvolvimento.

Um ensino formal introduzido com rapidez e desarticulado do conhecimento informal que o educando já possui, resulta numa aprendizagem memorística, que leva a uma utilização mecânica da Matemática, gerando erros sistemáticos difíceis de serem compreendidos pelo professor e eliminados pelo aluno.

Ou seja, não devemos propiciar que os nossos alunos tenham a cultura de reproduzir mecanicamente sem uma reflexão prévia.

Sendo assim, na tentativa de melhorar o ensino na Educação Básica, esta obra traz um apanhado geral de fundamentações teóricas formuladas por grandes matemáticos, no decorrer dos séculos, sobre o estudo das cônicas.

O objetivo principal desse trabalho é trazer uma nova abordagem para o ensino das curvas cônicas. Mostrando o quão fascinante é esse conteúdo que, infelizmente, caiu em esquecimento em nosso currículo educacional.

Para reafirmar que a escola deve ser um ambiente transformador, é proposta, também, uma oficina que tem a função de estimular os estudan- 
tes a agirem reflexivamente, construindo os seus próprios conceitos significativos, tornando-os, assim, verdadeiros protagonistas no processo ensinoaprendizagem.

Ao efetuar as práticas da oficina, os alunos podem percerber que errar é, sem dúvida, decorrência da busca e, pelo óbvio, só quem não busca não erra. Isso não significa que se deve incentivar a errar mas, sim, deve-se incorporar esse erro como uma possibilidade de se chegar a novos conhecimentos. Criando assim, efetivamente, um ambiente construtivista.

Além disso, após as construções, devem ser respondidos os questionários propostos. Estes têm a pretensão de conduzir o aluno a um raciocínio matemático que se mostrará eficiente para a compreensão e assimilação dos conceitos teóricos e das demonstrações apresentadas previamente. Além de trazer um feedback ao docente das dificuldades apresentadas durante a execução e do grau de entendimento e assimilação do conteúdo, viabilizando, assim, as correções para as aplicações futuras.

Evidenciam, também, a urgência de uma reflexão acerca de novas estratégias pedagógicas que contribuam para a facilitação do processo de ensino aprendizagem da Matemática. Devemos, sempre, adotar práticas que estimulem os alunos ao pensamento independente.

O uso de metodologias alternativas de ensino aliada a boa e velha prática docente de aulas expositivas tornam a disciplina mais interessante e interativa, propiciando aos estudantes o desenvolvimento de seus conhecimentos, habilidades e, por consequência, despertam a motivação para o 
estudo, trazendo uma quebra de paradigma que a Matemática é algo inacessível para a maioria dos alunos.

Com a aplicação da oficina, podemos verificar que o caráter lúdico, orientado, dinâmico e de conteúdo são fundamentais para a consolidação do tema, oferecendo um amplo conhecimento prático e de resultados.

Por fim, deixamos claro que o tema não foi esgotado, pois, em um universo tão rico, ainda há muito o que ser pesquisado, discutido e analisado. Com a leitura dessa dissertação, espera-se despertar o interesse dos profissionais da área a compreenderem melhor a caracterização das curvas cônicas, as suas propriedades, as diferentes visões do conteúdo e motivá-los ao planejamento de aulas que fujam do tradicionalismo massante, além de estimular novas pesquisas na área. 


\section{Referências Bibliográficas}

[1] Aléssio de Caroli, Carlos A. Callioli, and Miguel O. Feitosa. Matrizes, Vetores, Geometria Analítica. Nobel, São Paulo, 1976.

[2] Ávila, Geraldo. Kepler e a órbita elíptica. Revista do Professor de Matemática, $\mathrm{n}^{\circ} 15,1989$.

[3] Borba, M. C. . Tecnologias Informáticas na Educação Matemática e Reorganização do Pensamento. In: M.A.V. Bicudo (org.). Pesquisas em Educação Matemática: Concepções Perspectivas. São Paulo: UNESP, p. 285- 295. 1999.

[4] Bordallo, M. As Cônicas na Matemática Escolar Brasileira: História, Presente e Futuro. Dissertação Rio de Janeiro: UFRJ, dissertação de mestrado, 2011.

[5] Boulos, Paulo: Geometria Analítica (Um Tratamento Vetorial).

[6] Boyer, Carl B: História da Matemática, Ed. Edgard Blücher Ltda, 1974.

[7] Courant, R. e Robbins, H., What is Mathematics, Oxford,1941.

[8] Dante, Luiz Roberto: MATEMÁTICA - CONTEXTO E APLICACÔES - VOLUME ÚNICO - Ensino Médio - Integrado;

[9] FREIRE, P. Pedagogia da autonomia: saberes necessários à prática educativa. São Paulo. Paz e terra. 1997. 
[10] Elon L. Lima. Coordenadas no Espa so. SBM, Rio de Janeiro, 1993.

[11] Garbi, Gilberto G. A Rainha das Ciências: Um passeio histórico pelo maravilhoso mundo da matemática. 1. ed. São Paulo. Livraria da Física, 2006.

[12] Giraldo, V.; PINTO MATOS, F. R.; SILVANI CAETANO, P. A. Recursos Computacionais no Ensino de Matemática. Coleção Profmat Rio de Janeiro: SBM, 2012.

[13] Guimarães, L.C. e Belfort, E Roteiros de laboratório de Geometria.1999.

[14] Hartung, G., Construção das Cônicas por Dobragens, Petropolis, 2010. disponível em: ¡http:/ / portaldoprofessor.mec.gov.br/fichaTecnicaAula.html?aula=27219i

[15] Howard Anton and Chris Rorres. Álgebra Linear com Aplicações. Bookman, São Paulo, $8^{\mathrm{a}}$ edição, 2000.

[16] Iezzi, Gelson e Outros: MATEMÁTICA - VOLUME ÚNICO - Ensino Médio - Integrado. Ed. Atual. 2000.

[17] Kaleff, A. M.; TOLEDO, M. I.; Sá L. Criando, Vendo e Entendendo Sólidos de Revolução. Boletim- Gepem, Rio de Janeiro, no 40, fevereiro 2002, pp.34-55.

[18] Legendre, A. M., (1809). Elementos de Geometria Rio: Imprensa Régia. Tradução da 5a. edição francesa (1801, Paris: Librarie de Firmin Didot Frères.) order. Commun. Contemp. Math. 2009.

[19] Lima, E. L. et al. A matemática do ensino médio. Rio de Janeiro: SBM, 2001.(Coleção do professor de matemática).

[20] LOPES, J. F.“Cônicas e Aplicações. Dissertação de Mestrado, IGCEUnesp, Rio Claro 2011. BOULOS, P.; 
[21] MA23-Geometria Analítica. Coleção Profmat Rio de Janeiro: SBM, 2012.

[22] Machado, Antônio dos Santos: MATEMÁTICA - VOLUME ÚNICO Ensino Médio.

[23] Maria Estrada, Carlos Sá, João Queiró, Maria do Céu Silva, Maria José Costa História da Matemática, Universidade Aberta, 2000.

[24] Murdoch, David C. Geometria Analítica: uma introdução ao cálculo vetorial e matrizes. Rio de Janeiro. 1971. $2^{\mathrm{a}}$ edição.

[25] Neto, F.Q. Tradução Comentada da Obra Novos Elementos das Seções Cônicas (Philippe de La Hire - 1679) e sua Relevância para o Ensino de Matemática. Dissertação Rio de Janeiro: UFRJ, dissertação de mestrado, 2008.

[26] Sato, J. As Cônicas e suas Aplicações: A construção da parábola pelo método da dobradura.

Disponível em: http://www.sato.prof.ufu.br/Conicas/Curso ${ }_{C}$ onicas Aplicacoes.pdf.

[27] Silva, Silvio Tomé. Cônicas: uma abordagem geométrica e algébrica. Maringá, 2013. Dissertação de Mestrado. Mestrado Profissional em Matemática - PROF-MAT, Universidade Estadual de Maringá. Disponível em: http : //bit.profmat?sbm.org.br/xmlui/handle/123456789/335.

[28] Simmons, G.: Cálculo com Geometria Analítica, Volume 2, Ed. McGraw-Hill, (1987).

[29] Souza JR, J. C. e CARDOSO, A. Estudo das Cônicas com Geometria Dinâmica. RPM. Rio de Janeiro: SBM. 68.2009.pp.43 - 48.

[30] Stewart, James: Cálculo, Volume 2, $5^{a}$ edição, Ed. Thomson. Learning, (1983).

[31] Swokowiski, Earl W. Cálculo com Geometria Analítica. 2a . ed. São Paulo:Makron Books,1994.

[32] Wagner, E. Porque as antenas são parabólicas. RPM 33, São Paulo, 1997. p.11-15. 